Modelo de qualidade para componentes de software 
SERVIÇO DE PÓS-GRADUAÇ̃̃O DO ICMC-USP

Data de Depósito: 21.11.2006

Assinatura:

\title{
Modelo de qualidade para componentes de software
}

\author{
Darley Rosa Peres
}

Orientador: Prof ${ }^{a}$. Dr ${ }^{a}$. Rosely Sanches

Dissertação apresentada ao Instituto de Ciências Matemáticas e de Computação - ICMC-USP, como parte dos requisitos para obtenção do título de Mestre em Ciências de Computação e Matemática Computacional. 


\section{Dedicatória}

Aos meus pais e à minha noiva. 


\section{Agradecimentos}

Agradeço aos meus pais, João e Luzia, meu irmão, Dirceu, e familiares, por estarem sempre ao meu lado me apoiando e incentivando em todos os momentos.

À minha noiva Elienay, pelo amor, carinho e compreensão nos momentos de ausência.

À minha orientadora, Rosely, que me auxiliou nesta jornada de conhecimentos, não apenas por compartilhar suas idéias e reflexões, mas também pela sua dedicação, apoio e compreensão durante esses anos de trabalho.

Agradeço também, a todos os amigos que conviveram comigo durante esse tempo todo pelos momentos agradáveis e descontraídos e também pelos momentos de concentração e estudos.

Ao CenPRA, em especial ao pessoal da Divisão de Qualificação de Software (DQS), agradeço pelas oportunidades e pelas trocas de conhecimentos, proporcionando-me um crescimento não apenas profissional mas também pessoal.

Ao CNPq, pelo apoio financeiro.

E principalmente a Deus, não apenas pelas oportunidades e desafios que ele tem colocado diante de mim, mas por iluminar meu caminho e guiar meus passos hoje e sempre. 
Dentre as tecnologias de desenvolvimento de software que promovem o reuso com o objetivo de construir sistemas com prazos e custos menores, sem sacrificar a qualidade dos produtos, está o Desenvolvimento Baseado em Componentes (DBC). O Desenvolvimento Baseado em Componentes consiste na construção de sistemas pela composição de componentes de software de acordo com um processo de desenvolvimento específico.

Para garantir a qualidade desses sistemas, é importante garantir a qualidade de seus componentes. A falta da garantia da qualidade dos componentes de software destinados à reutilização é um dos fatores de inibição do DBC, e existe certa carência de pesquisas sobre a qualidade de componentes de software.

Desta maneira, o principal objetivo deste trabalho foi a definição de um modelo de qualidade específico para componentes de software, fornecendo a base para a especificação de requisitos de qualidade e para a avaliação de qualidade dos mesmos. O Modelo está embasado nas normas ISO/IEC $9126 \mathrm{e}$ ISO/IEC 12119, e também na literatura especializada. Uma ferramenta para apoiar avaliações de componentes (e de produtos de software de forma geral) também foi desenvolvida.

Foram realizadas ainda quatro avaliações de componentes através de estudos de casos para verificar a aplicabilidade e utilidade do modelo de qualidade e da ferramenta desenvolvida. Dois questionários foram respondidos pelos avaliadores responsáveis pelas avaliações coletando assim, suas considerações sobre o modelo de qualidade e sobre a ferramenta. 


\section{Abstract}

Among the software development technologies that promote the reuse aiming to build systems with periods and smaller costs, without sacrificing the quality of products, is the Component-Based Development (CBD). The Component-Based Development consists on the construction of systems by the composition of software components according to a specific development process. To guarantee the quality of those systems, it is important to guarantee the quality of their components. The lack of warranty of the quality of the software components destined to reuse is one of the inhibition factors of CBD, and there is certain lack of researches about quality of software components.

This way, the main objective of this work was the formalization of a specific quality model for software components, supplying the base for the specification of quality requirements and for the quality evaluation of the same ones. The model is based on the norms ISO/IEC 9126 and ISO/IEC 12119, and also in the specialized literature. A tool to support components evaluations (and software products in a general way) was also developed.

It was realized four components evaluations through case studies to verify the applicability and usefulness of the quality model and the developed tool. Two questionnaires were answered by the appraisers responsible for the evaluations collecting thereby, their considerations on the quality model and the tool. 


\section{Sumário}

Lista de Figuras iv

Lista de Tabelas vi

1 Introdução 1

1.1 Motivação. . . . . . . . . . . . . . . . . . . 2

1.2 Objetivo $\ldots \ldots \ldots \ldots \ldots \ldots \ldots \ldots \ldots \ldots \ldots \ldots \ldots \ldots \ldots \ldots \ldots \ldots$

1.3 Organização do Trabalho. . . . . . . . . . . . . . . . 4

2 Componentes de Software $\quad 7$

2.1 Considerações Iniciais. . . . . . . . . . . . . . . 7

2.2 Introdução . . . . . . . . . . . . . . 7

2.3 Componentes de Software. . . . . . . . . . . . . . . . . . 8

2.4 Desenvolvimento Baseado em Componentes - DBC . . . . . . . . . 15

2.5 Considerações Finais. . . . . . . . . . . . . . . . . . . . . 19

3 Qualidade de Produtos de Software $\quad 21$

3.1 Considerações Iniciais. . . . . . . . . . . . . . . . . . . . . . . . . 21

3.2 Introdução . . . . . . . . . . . . . . . . . 21

3.3 Qualidade de Produtos de Software . . . . . . . . . . . . . . . . . 22

3.3.1 Norma ISO/IEC 9126 - Engenharia de Software - Qualidade de Produto: Evolução Histórica. . . . . . . . . . . . . . . 24

3.3.2 Norma ISO/IEC 9126: Engenharia de Software - Qualidade do Produto (versão atual) . . . . . . . . . . . . . . . . . . 26

3.3.3 Norma ISO/IEC 12119: Information technology - Software packages - Quality requirements and testing. . . . . . . . 32

3.4 Considerações Finais. . . . . . . . . . . . . . . . . . 38

4 Qualidade de Componentes de Software 41

4.1 Considerações Iniciais. . . . . . . . . . . . . . . . . . . . . . . 41

4.2 Introdução . . . . . . . . . . . . . . . . . 41

4.3 Qualidade de Componentes. . . . . . . . . . . . . . . . . . . . . 42 
4.4 Considerações Finais. $\ldots \ldots \ldots \ldots \ldots \ldots \ldots \ldots \ldots \ldots \ldots \ldots$

5 Modelo de Qualidade para Componentes de Software 51

5.1 Considerações Iniciais. . . . . . . . . . . . . . . . . . 51

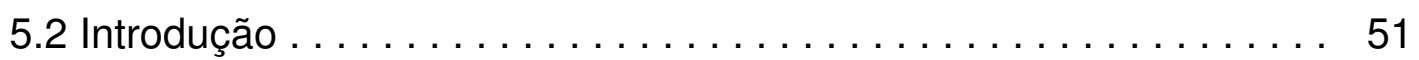

5.3 Modelo de Qualidade para Componentes de Software. . . . . . . . 52

5.3.1 Características e Subcaracterísticas de Qualidade do Modelo. . 57

5.3.2 Atributos e Métricas de Qualidade do Modelo............ 64

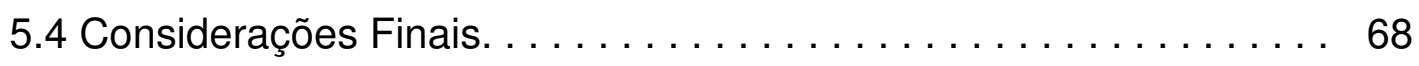

6 Ferramenta de Apoio a Avaliação - BMA $\quad 71$

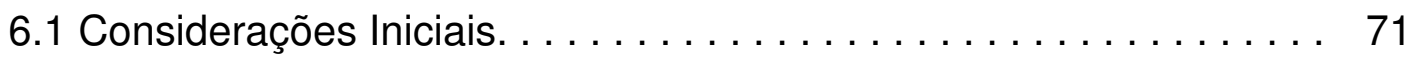

6.2 Visão Geral das Funcionalidades da Ferramenta BMA. . . . . . . . 71

6.3 Considerações Finais. . . . . . . . . . . . . . . . 81

7 Verificação da Aplicabilidade e Utilidade do Modelo de Qualidade e da Ferramenta BMA 83

7.1 Considerações Iniciais. . . . . . . . . . . . . . . . . 83

7.2 Visão Geral do Processo de Avaliação apresentado na Norma ISO/IEC $14598-1 \ldots \ldots \ldots \ldots \ldots \ldots \ldots \ldots \ldots \ldots . . \ldots 4$

7.3 Processo de Avaliação para Componentes de Software. . . . . . . 86

7.4 Estudos de Caso . . . . . . . . . . . . . . . . . . . . . . 90

7.4.1 Estudo de Caso 1 - Componente JBarcodeBean. . ........ 90

7.4.2 Estudo de Caso 2 - Componente Turbo Power Async Professional ....................... 93

7.4.3 Estudo de Caso 3 - Componente FolderMgr ............ 95

7.4.4 Estudo de Caso 4 - Comparação entre 2 componentes de criptografia. ....................... 97

7.5 Conclusão sobre as considerações dos avaliadores. . . . . . . . . 99

7.6 Considerações Finais. . . . . . . . . . . . . . . . . . . 99

8 Conclusões e Trabalhos Futuros 101

8.1 Lições Aprendidas . . . . . . . . . . . . . . . . . . . . . . . 103

8.2 Contribuições. .............................. 104

8.3 Trabalhos Futuros . . . . . . . . . . . . . . . . . . 105 
Referências Bibliográficas

Anexo A

115

Anexo B 


\section{Lista de Figuras}

Figura 2.1 - Desenvolvimento Baseado em Componentes DBC (Adaptado de (Pressman, 2002)) . . . . . . . . . . . . . . . . 17

Figura 3.1 - Três níveis de qualidade (Adaptado de (ISO, 2001)). . . . . . 28

Figura 3.2 - Modelo de qualidade para qualidade externa e interna.

(Adaptado de (ISO, 2001)) . . . . . . . . . . . . . . . . . 29

Figura 3.3 - Modelo de qualidade para qualidade em uso (Adaptado de (ISO, 2001)).......................... 31

Figura 5.1 - Estrutura definida pela Norma ISO/IEC 9126-1. (Adaptado de (ISO, 2001))........................ 53

Figura 5.2 - Modelo de Qualidade Externa para Componentes de Software 56

Figura 5.3 - Modelo de Qualidade em Uso para Componentes de Software (Adaptado de (ISO, 2001)) . . . . . . . . . . . . . . . . 56

Figura 6.1 - Principais Funcionalidades da Ferramenta BMA. . . . . . 72

Figura 6.2 - Interface GUI - Cadastrar Modelo . . . . . . . . . . . . . 74

Figura 6.3 - Interface GUI - Cadastrar Característica . . . . . . . . . . 74

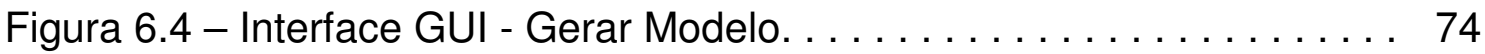

Figura 6.5 - Relatório do Modelo de Qualidade gerado pela Ferramenta BMA............................. 75



Figura 6.7 - Interface GUI - Cadastrar Perguntas . . . . . . . . . . . 76

Figura 6.8 - Página de solicitação de uma avaliação $\ldots \ldots \ldots \ldots \ldots \ldots 77$

Figura 6.9 - Páginas de manutenção de Laboratórios e Avaliadores . . . . . 78

Figura 6.10 - Página de autorização de avaliadores para uma avaliação. . . 79

Figura 6.11 - Execução de uma avaliação por meio da Ferramenta BMA . . 80

Figura 6.12 - Execução de uma avaliação por meio da Ferramenta BMA

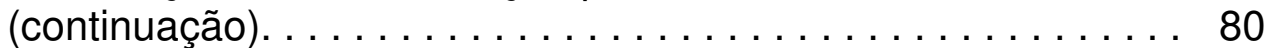


Figura 7.1 - Processo de Avaliação segundo ISO 14598-1 (Adaptado de (ISO, 2001a))......................... 84

Figura 7.2 - Níveis de pontuação para a avaliação. . . . . . . . . . 88

Figura 7.3 - Resultado final da avaliação do componente JBarcodeBean . . 92

Figura 7.4 - Resultado final da avaliação do componente TurboPower . . . 94

Figura 7.5 - Resultado final da avaliação do componente FolderMgr. . . . . 96

Figura 7.6 - Resultado final da avaliação dos componentes JSecurity e vH Crypto .............................. 98 


\section{Lista de Tabelas}

Tabela 2.1 - Características de componentes. . . . . . . . . . . 12

Tabela 3.1 - Características de Qualidade de Produto de Software

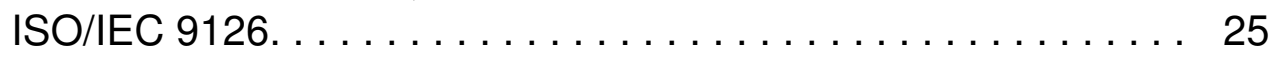

Tabela 3.2 - Características e Subcaracterísicas Externas e Internas da norma ISO/IEC $9126-1 \ldots \ldots \ldots \ldots \ldots \ldots \ldots \ldots . \ldots \ldots$

Tabela 3.3 - Características de Qualidade em Uso da norma ISO/IEC

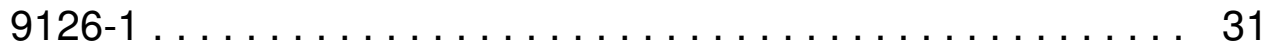

Tabela 3.4 - Requisitos de Qualidade para a Descrição do Produto . . . . . . 34

Tabela 3.5 - Requisitos de Qualidade para a Documentação do Usuário . . 35

Tabela 3.6 - Requisitos de Qualidade para Programas e Dados. . . . . . . . 36

Tabela 3.7 - Instruções para teste. . . . . . . . . . . . . . . 36

Tabela 4.1 - Características, subcaracterísticas e atributos para componentes COTS (Adaptado de (Bertoa, 2002)) . . . . . . . . 44

Tabela 4.2 - Modelo de Qualidade de Componentes. Adaptado de (Alvaro, 2006))......................... 48

Tabela 5.1 - Atributos para a característica "Funcionalidade / Adequação" (Adaptado de (ISO, 2003)) . . . . . . . . . . . . . . . . . 65

Tabela 5.2 - Atributo e métricas para a característica "Conteúdo" do artefato Descrição do Componente. (Adaptado de (Rêgo, 1996)). . . . . . . . . . . . . . . . . . . . . . . 66

Tabela 5.3 - Atributo e métricas para a característica "Completitude / Identificação e Indicação" do artefato Documentação do Componente. (Adaptado da (ISO, 1994), (Rêgo, 1996)). . . . . 67

Tabela 5.4 - Atributo e métrica para a característica "Eficácia" de qualidade em uso. (Adaptado de (ISO 9126-4)) . . . . . . . 68

Tabela 7.1 - Questionário de avaliação. . . . . . . . . . . . . 87 


\section{Capítulo 1}

\section{Introdução}

O aumento da competitividade $\mathrm{e}$ as grandes exigências atuais do mercado de software estão fazendo com que as empresas passem a se preocupar cada vez mais com as metodologias de desenvolvimento visando reduzir riscos referentes a estimativas, custo e prazo de entrega. Além disso, há uma preocupação maior pela qualidade e satisfação dos clientes com o produto final e atendimento dos requisitos dos stakeholders.

Essas preocupações têm levado as organizações a buscarem novas perspectivas para o desenvolvimento de software com o foco na melhoria das práticas de desenvolvimento aumentando a produtividade e a qualidade, bem como a redução de custos e esforços (Li et al., 2006).

Nesse sentido, o reuso é um importante aspecto a ser considerado, pois potencialmente apresenta um impacto positivo na qualidade, produtividade e custo do software (Brito et al., 2006). Segundo Sametinger (1997), reconhecer o fato de que muitos sistemas apresentam componentes similares ou até mesmo idênticos, os quais são desenvolvidos repetidamente, conduz à tentativa de reutilizar componentes já existentes. Dessa forma, o Desenvolvimento Baseado em Componentes (DBC) surgiu como uma perspectiva de desenvolvimento de software caracterizada pela composição de partes já existentes. Conforme Szypersky (Szypersky et al., 2002), construir novas soluções pela combinação de componentes desenvolvidos ou adquiridos de terceiros, possibilita $o$ aumento da qualidade e dá suporte ao rápido desenvolvimento, levando à diminuição do custo de desenvolvimento e também de tempo de entrega do produto ao mercado.

O termo componente tem sido amplamente utilizado, contendo inúmeras definições, cada uma delas apresentando as propriedades mais relevantes 
para o contexto no qual está inserido. No contexto deste trabalho, é utilizada a definição de Villela (Villela, 2000) para componentes de software:

"Componentes de software são artefatos autocontidos, claramente identificáveis, que descrevem ou realizam uma função específica e têm interfaces claras em conformidade com um dado modelo de arquitetura de software, documentação apropriada e um grau de reutilização definido".

Esse conceito foi escolhido por reunir diversas propriedades importantes de componentes, como: a) unidade fornecedora de serviços; b) autocontido (disponibiliza seus serviços de forma completa); c) conformidade de suas interfaces com um modelo de arquitetura. A definição destaca ainda, a maturidade através do grau de reutilização, e, por fim, a necessidade de uma documentação adequada. É importante ressaltar também que, no contexto deste trabalho, o foco são os componentes do tipo caixa-preta, ou seja, componentes prontos que estão disponíveis para serem reutilizados. 0 conceito apresentado será utilizado como ponto de partida para a discussão das características, subcaracterísticas, atributos e métricas que irão compor o modelo de qualidade proposto.

\subsection{Motivação}

Diversos trabalhos de pesquisa apresentam métodos, técnicas, processos, e, principalmente, ferramentas e ambientes para apoiarem o DBC. Tais trabalhos, entretanto não focam especificamente um requisito importante para o sucesso do DBC: a qualidade dos componentes de software (Alvaro et. al., 2006).

Em uma pesquisa, desenvolvida pelo Software Engineering Institute (SEI), foram examinados componentes de software sob a perspectiva técnica e de negócios (Bass et. al., 2000). A partir dessa pesquisa foi identificado um conjunto de inibidores para adoção de componentes de software e entre esses inibidores estava a "carência de componentes certificados". 
Assim, a principal motivação deste trabalho é fornecer uma forma de reduzir a carência de componentes com qualidade e contribuir na linha de pesquisa em qualidade e certificação de componentes de software (Morris et al., 2001), (Goulao, 2002), (Schmidt, 2003), (Wallnau, 2003), (Alvaro et. al., 2005), (Alvaro et. al., 2006).

Essa linha de pesquisa relacionada à questão da qualidade dos componentes vem sendo explorada pela comunidade de DBC, pois sabe-se que a qualidade dos componentes utilizados no desenvolvimento interfere na qualidade do sistema desenvolvido e, em um ambiente real, um desenvolvedor que recupera um componente falho ou com baixa qualidade certamente se tornará desencorajado para realizar uma nova consulta. Com isso, torna-se extremamente importante assegurar a qualidade dos componentes de software que serão armazenados no repositório e recuperados futuramente para reutilização (Alvaro et. al., 2005).

\subsection{Objetivo}

Este trabalho tem por objetivo apresentar o modelo de qualidade específico para componentes de software desenvolvido, que fornece a base para apoiar avaliações de componentes com o intuito de certificar a qualidade dos mesmos, podendo essa certificação da qualidade, servir tanto como critério de admissibilidade dos componentes nos repositórios, como critério para seleção/aquisição de componentes.

Para que possa suprir as necessidades da comunidade de DBC, tanto do ponto de vista dos avaliadores, quanto dos desenvolvedores de componentes e/ou adquirente/usuário de componentes de software, o modelo de qualidade desenvolvido está de acordo com normas internacionais de qualidade, como por exemplo, as normas ISO/IEC 9126-1 (2001) e ISO/IEC 12119 (1994).

Em complemento ao modelo de qualidade para componentes, é apresentada também uma ferramenta para apoiar avaliações que são baseadas em modelos de qualidade. A ferramenta auxilia avaliações não apenas de componentes, mas também de produtos de software em geral. 
Objetiva-se com isso, reduzir o esforço necessário para a aplicação dessas avaliações, bem como os custos e tempo envolvidos. Além disso, a ferramenta pode facilitar o aprendizado quanto à utilização do modelo, visto que ela pode servir também como guia durante a avaliação, diminuindo as chances de erros.

Dessa forma, espera-se contribuir com a comunidade de DBC, pois o modelo de qualidade proposto permite que a qualidade dos componentes de software seja especificada e avaliada em diferentes perspectivas pelos envolvidos com busca, seleção/aquisição, uso e avaliação de componentes.

\subsection{Organização do Trabalho}

Este trabalho está organizado em tópicos relacionados à revisão bibliográfica e aos produtos deste trabalho de mestrado, organizado ao todo em oito capítulos e três anexos.

Apresentou-se neste capítulo uma breve contextualização e motivação para o trabalho realizado.

No capítulo 2 são apresentados definições e conceitos de componentes de software e também algumas características do processo de desenvolvimento, dando maior enfoque à definição de componentes utilizada no contexto deste trabalho.

Qualidade de produto de software e as normas ISO/IEC 9126-1 e ISO/IEC 12119 são discutidas no capítulo 3.

No capítulo 4, são relatados aspectos relacionados à qualidade de componentes de software através da apresentação de trabalhos correlatos.

No capítulo 5, é apresentado o modelo de qualidade para componentes de software com sua estrutura de características, subcaracterísticas, atributos e métricas de qualidade. $O$ modelo está embasado nas normas de qualidade apresentadas no capítulo 3 e em trabalhos específicos sobre componentes e qualidade de componentes apresentados nos capítulos 2 e 4 .

A ferramenta que auxilia na execução de avaliações não apenas de componentes, mas de produtos de software de forma geral, é apresentada no capítulo 6. 
No capítulo 7, relata-se o estudo de caso realizado e, no capítulo 8, as conclusões e trabalhos futuros.

Por fim, no Anexo A, é apresentado o modelo de qualidade para componentes de software com todas as suas características, subcaracterísticas, atributos e métricas de qualidade. No Anexo $B$, são apresentados os questionários para a verificação da aplicabilidade e utilidade do modelo e da ferramenta. 


\section{Capítulo 2}

\section{Componentes de Software}

\subsection{Considerações Iniciais}

A busca por um entendimento comum sobre os conceitos do Desenvolvimento Baseado em Componentes (DBC) tem sido um desafio para a indústria de software e para os grupos de pesquisas. Apesar dos esforços, pouco sucesso foi obtido quanto a uma padronização ou consenso sobre o conceito básico de componente. Sob o foco deste trabalho, são apresentadas neste capítulo definições e conceitos de componentes de software e também algumas características do processo de Desenvolvimento Baseado em Componentes (DBC).

\subsection{Introdução}

A preocupação e os esforços empregados para melhorar as práticas de desenvolvimento de software buscando o aumento da produtividade e da qualidade, bem como a redução de custos e esforços, evidenciam novas perspectivas para o desenvolvimento de software.

Um importante aspecto a ser considerado no desenvolvimento de software com impacto positivo na qualidade, produtividade e custo é o reuso de software (Gill, 2006). De acordo com Almeida (2005), reuso de software é o processo de criar sistemas a partir de software existentes, ao invés de construir desde o início.

Reconhecer o fato de que muitos sistemas apresentam componentes similares ou até mesmo idênticos, os quais são repetidamente desenvolvidos desde o início, conduz à tentativa de reutilizar componentes já existentes. Componentes e reuso completam-se perfeitamente, a utilização de componentes para construir sistemas de software quase que automaticamente 
conduz ao reuso, embora a utilização de componentes por si só não seja suficiente para garantir o reuso de software (Sametinger, 1997).

O Desenvolvimento Baseado em Componentes (DBC) surgiu como uma perspectiva de desenvolvimento de software caracterizada pela composição de partes já existentes e, segundo Lau (2006), o DBC é um importante tópico emergente na engenharia de software, com potencial para oferecer benefícios como, aumento do reuso e diminuição dos custos de fabricação. Atualmente há interesse na noção de desenvolvimento de software por meio da integração planejada de componentes já existentes (Gill, 2006). Conforme Szypersky (Szypersky et al., 2002), construir novas soluções pela combinação de componentes desenvolvidos e/ou comprados aumenta a qualidade e dá suporte ao rápido desenvolvimento, levando à diminuição do tempo de entrega do produto ao mercado.

Os sistemas definidos através da composição de componentes permitem que sejam adicionadas, removidas e substituídas partes do sistema sem a necessidade de sua completa substituição. Com isso, DBC auxilia na manutenção dos sistemas de software, por permitir que os sistemas sejam atualizados através da integração de novos componentes e/ou atualização dos componentes já existentes.

A recente atenção $e$ interesse que recaem sobre $D B C$ têm proporcionado a difusão de seus benefícios e características. Entretanto, uma grande dificuldade está em conceituar um componente.

\subsection{Componentes de Software}

O conceito exato de componente em DBC ainda não é um tópico fechado. Cada grupo de pesquisa caracteriza, da maneira mais adequada ao seu contexto, o que seria um componente, assim, é possível encontrar na literatura, diversas definições de componentes.

Em Sametinger (1997) é apresentado que componentes podem ser vistos como alguma parte do sistema de software que é identificável e 
reutilizável, ou como o estado seguinte de abstração depois de funções, módulos e classes.

D’Souza (1999) apresenta duas definições, uma para componentes de forma geral e outra para componentes na forma de código:

"Um componente (em geral) é um pacote coerente de artefatos de software que pode ser independentemente desenvolvido e distribuído como uma unidade, e que pode ser composto, sem alterações, com outros componentes para construir algo maior".

“Um componente (em código) é um pacote coerente de implementação que pode ser desenvolvido e distribuído independentemente, provê interfaces explícitas e bem especificadas, define interfaces que ele precisa de outros componentes, e pode ser combinado com outros componentes pela configuração de suas propriedades, sem a necessidade de modificação".

Na primeira definição, D’Souza (1999) destaca que um componente é um pacote que pode conter vários artefatos, por exemplo: código executável, código fonte, projetos, especificações, teste, e documentação. Ele também menciona o desenvolvimento e a distribuição independentes, além da capacidade de ser utilizado para a construção de algo maior, isto é, participar de composições.

$\mathrm{Na}$ segunda definição, o autor enfatiza aspectos relacionados à utilização do componente, à dependência contextual, isto é, que outros componentes são necessários (interfaces que o componente necessita). Aspectos relacionados à composição são mais detalhados nessa segunda definição, citando a necessidade das interfaces que o componente provê e a configuração de propriedades internas.

Em Brown (1998), componente é caracterizado como "conjunto independente de serviços reutilizáveis", que podem ser considerados independentemente. 
O primeiro elemento da definição de Brown é o conceito de "serviços reutilizáveis", isso implica que o componente provê habilidades que muitos outros componentes podem acessar.

O segundo elemento da definição de Brown é "independente" e indica a ausência de vínculo do componente com o contexto em que ele pode ser usado. A expectativa de que os componentes cooperem entre si para completar uma solução não deve estar vinculada à existência de dependências entre eles, pois os componentes não devem ser desenvolvidos com dependências fixas entre si.

A definição de Brown, por si só, não explicita diferentes características de componente. Entretanto, essas características são identificadas e apresentadas quando do detalhamento dos dois elementos da definição.

Segundo Szyperski (Szyperski et al., 2002), um "componente de software é uma unidade de composição com interfaces contratualmente especificadas e explícitas dependências de contexto. Componente de software pode ser usado independente e combinado com outras partes".

Essa definição de Szyperski busca compreender as propriedades dos componentes de serem unidades com atuação independente e de poderem ser combinados a outras partes. Entretanto, cada uma destas propriedades apresenta inúmeras implicações.

A propriedade de ser uma unidade de atuação independente exige que o componente seja separado do ambiente e dos demais componentes. Também não deve existir a perspectiva de se ter acesso a detalhes de construção do componente. Logo, o componente precisa encapsular sua implementação e interagir com o ambiente através de interfaces bem definidas, ou seja, é necessário que o componente apresente uma especificação indicando o que é exigido para seu reuso e o que ele provê (interfaces contratualmente especificadas).

Ainda buscando melhor elucidar a conceituação de Szyperski, tem-se que a necessidade dos componentes de especificarem suas dependências de 
contexto diz respeito à necessidade deles de indicarem o que o ambiente em que serão acionados deve prover para que eles funcionem.

A definição apresentada por Szyperski expressa explicitamente importantes propriedades que caracterizam os componentes, o que não se verifica na definição de Brown (1998), por essas características estarem implícitas aos elementos que a compõem.

Em Werner (2000), são listados alguns aspectos que um componente de software deve possuir. Dentre estes aspectos, constatou-se que um componente deve:

- Descrever ou realizar uma função específica (Sametinger, 1997) (D'Souza, 1999);

- Estar em conformidade e prover um conjunto de interfaces bem definidas (Sametinger, 1997) (Szyperski et al., 2002);

- Ter disponível uma documentação adequada (Sametinger 1997);

- Estar inserido no contexto de um modelo que oriente a composição deste componente com outros (arquitetura de software); e

- Ser autocontido em termos da funcionalidade que provê.

Outro ponto importante é que, no início, a visão de um componente como um elemento, somente como código, era bastante comum e, atualmente, essa visão está mudando e os engenheiros de software começam a visualizar componentes em todos os níveis de abstração (D'Souza, 1999), (Heineman, 2001), (Ommering, 2002), (Almeida, 2005).

Villela (2000) apresenta uma definição, a fim de estabelecer o que vem a ser um componente de software.

"Componentes reutilizáveis são artefatos autocontidos, claramente identificáveis, que descrevem ou realizam uma função especifica e possui interfaces claras em conformidade com um dado modelo de arquitetura de software, documentação apropriada e um grau de reutilização definido." 
A definição de Villela apresenta vários aspectos de componentes de uma forma mais geral, é possível observar isso, no quadro comparativo das características de componente a partir das definições dos quatro autores (Villela, 2000), (D'Souza, 1999), (Brown, 1998), (Szyperski et al., 2002), apresentado na Tabela 2.1.

Tabela 2.1 - Características de componentes.

\begin{tabular}{|l|c|c|c|c|}
\hline & (Villela, 2000) & (D'Souza 1999) & (Brown, 1998) & $\begin{array}{c}\text { (Szyperski et al., } \\
\text { 2002) }\end{array}$ \\
\hline Identificação & $\begin{array}{c}\text { Artefato } \\
\text { identificável }\end{array}$ & $\begin{array}{c}\text { Pacote } \\
\text { independente }\end{array}$ & $\begin{array}{c}\text { Conjunto } \\
\text { independente }\end{array}$ & $\begin{array}{c}\text { Unidade de } \\
\text { composição }\end{array}$ \\
\hline Funcionalidade & $\begin{array}{c}\text { Funções } \\
\text { específicas }\end{array}$ & Serviços providos & $\begin{array}{c}\text { Serviços } \\
\text { reutilizáveis }\end{array}$ & Serviços providos \\
\hline Independência & Autocontido & Independente & Independente & Autocontido \\
\hline Interação & Interface & Interface & Serviços & Interface \\
\hline $\begin{array}{l}\text { Conformidade } \\
\text { com modelo de } \\
\text { componente }\end{array}$ & $\begin{array}{c}\text { Declara a } \\
\text { necessidade de } \\
\text { conformidade }\end{array}$ & $X$ & $X$ & $X$ \\
\hline $\begin{array}{l}\text { Documentação } \\
\text { com a qual se } \\
\text { preocupa }\end{array}$ & $\begin{array}{c}\text { Apropriada para } \\
\text { reuso }\end{array}$ & $X$ & $\begin{array}{c}\text { Especificação } \\
\text { dos serviços }\end{array}$ & $\begin{array}{c}\text { Especificação das } \\
\text { interfaces }\end{array}$ \\
\hline $\begin{array}{l}\text { Preocupação } \\
\text { com reuso }\end{array}$ & $\begin{array}{c}\text { Condição de } \\
\text { reuso }\end{array}$ & $X$ & $X$ & $X$ \\
\hline
\end{tabular}

A definição de Villela (2000) será utilizada como base no decorrer deste projeto. Por isso, os termos por ela indicados são mais detalhados a seguir:

Pela definição de Villela, os componentes são tratados como artefatos por poderem assumir diferentes formas como, por exemplo, código, documentação, especificação de funcionalidades, entre outros. Isso está claro quando a definição diz que os componentes "descrevem ou realizam uma função específica", mas, para este trabalho, o componente é visto apenas como uma unidade executável (caixa-preta), que realiza uma função específica, de forma autocontida, com interfaces claras, documentação apropriada e grau de reutilização.

Ser autocontido significa que a função que o componente desempenha deve ser realizada por ele, de forma completa, sem a necessidade de incluir/depender de outros componentes para isso. Caso exista alguma 
dependência, então todo o conjunto deve ser visto como um componente de software. Por exemplo, uma função pode ser considerada autocontida se ela pode ser utilizada sem a necessidade de qualquer outra função. Vendo a função como um componente, e, caso ela necessite de outra função para alcançar seus objetivos, então todo o conjunto de funções deve ser visto como um componente de software.

Um componente deve, também, ser claramente identificável, de forma que possa ser facilmente encontrado, seja qual for sua localização, ou seja, deve estar contido em um único módulo ou pacote, ao invés de espalhados e misturados no meio de códigos ou de artefatos de software. Em um sistema distribuído, é importante também que o componente seja identificado de maneira única sem ambigüidades, pois, atualmente, distribuição e interoperabilidade são características desejadas pelas aplicações.

Os componentes têm uma funcionalidade clara e específica que realizam. Sametinger (1997) diz que a funcionalidade de um dado componente deve ser bem caracterizada, de forma que possa ser facilmente identificável em relação a sua utilidade em um dado contexto. Por exemplo, um componente de validação de CPF para um sistema de controle financeiro.

Um determinado componente não é completamente independente dos outros componentes e do ambiente. O que determina como se dá essa dependência do componente, em relação aos demais e ao ambiente que o cerca, são suas interfaces. As interfaces de um componente determinam como esse componente pode ser reutilizado e interconectado com outros componentes, ocultando os detalhes que não são necessários para o reuso. As interfaces definem uma operação ou um conjunto de operações que está disponível para um componente. Szyperski define uma interface como um conjunto de assinaturas de operações que podem ser invocadas por um cliente. Segundo Councill (2001), a interface descreve o comportamento de um componente, que é obtido por considerar somente as interações de suas interfaces e por ocultar todas as demais interações.

Ainda conforme Councill, existem dois tipos de interfaces: providas e requisitadas. Um componente suporta uma interface provida se contém a implementação de todas as operações definidas pela interface. Por outro lado, 
um componente necessita de uma interface requisitada se solicita uma interação definida na interface e espera que algum outro elemento de software suporte essa interface.

A definição de Villela (2000), enfatiza a conformidade das interfaces com um modelo de arquitetura, impondo, assim, um conjunto de padrões e convenções, que o componente deve seguir, para permitir a sua composição com outros componentes. Villela afirma que a arquitetura de software está mais ligada à composição dos componentes e à infra-estrutura de conexão, assim, os conceitos modelos de arquitetura e frameworks de componentes são conceitos que estão relacionados à arquitetura de software em DBC. Bachman et al. (2000) definem modelo de arquitetura de componentes como uma especificação de padrões e convenções, impostas sobre os desenvolvedores, para a criação de componentes. Acrescentam que essa conformidade é o que diferencia componentes de outros pacotes de software. Os principais modelos de componentes disponíveis atualmente são: CCM (CORBA Component Model) do OMG (Object Management Group); DCOM (Distributed Component Object Model) e COM/COM+ (Component Object Model) da Microsoft; e JavaBeans e Enterprise JavaBeans (EJB) da Sun Microsystems. O conceito framework de componentes é definido como uma implementação dos serviços que dão suporte ou reforçam o modelo de componentes. A função do framework é gerenciar os recursos compartilhados pelos componentes e prover um mecanismo que possibilite a comunicação (interação) entre eles.

A documentação é também indispensável para a reutilização. Essa deve ser suficiente para que se possa recuperar um componente, avaliar sua adequação para o contexto da reutilização, fazer adaptações (se for o caso) e integrar o componente ao seu novo ambiente. Ou seja, a documentação que acompanha o componente deve ser completa, facilitando o entendimento, avaliação e utilização do componente.

Por fim, outro conceito importante é o que os pesquisadores chamam de grau de reutilização do componente. Componentes devem ser mantidos de modo a preservar a reutilização sistemática e o grau de reutilização compreende diferentes informações como, por exemplo, quem é o proprietário, quem deve ser contatado em caso de problemas, qual é a situação de 
qualidade e quantas vezes e onde o componente foi reutilizado (Sametinger, 1997).

\subsection{Desenvolvimento Baseado em Componentes - DBC}

O Desenvolvimento Baseado em Componentes (DBC) surgiu como uma perspectiva para o desenvolvimento de software, com o objetivo de "quebrar" blocos monolíticos em componentes interoperáveis, reduzindo, dessa forma, a complexidade do desenvolvimento, assim como os custos, através da utilização de componentes que, em princípio, seriam adequados para serem utilizados em outras aplicações (Sametinger, 1997).

De acordo com estudos realizados por diversas organizações, tais como - Gartner Group, a Gica, a Ovum e a PriceWaterhouseCoopers (Bass et al., 2000), (Bachman et al., 2000), (Williams, 2000), o desenvolvimento baseado em componentes é uma atividade com um peso crescente na indústria de software. A principal força justificativa desse crescimento é econômica. O DBC é encarado como uma abordagem que permite simultaneamente reduzir custos no desenvolvimento, encurtar o período necessário ao desenvolvimento do software e aumentar a sua qualidade (Szyperski et. al., 2002). As reduções de custos e de período de desenvolvimento são resultantes da reutilização de componentes já existentes. A qualidade é aumentada uma vez que os componentes já foram previamente testados e avaliados, principalmente se esses componentes já foram reutilizados por diversos sistemas, aumentando assim, o seu nível de maturidade.

O Desenvolvimento Baseado em Componentes é considerado uma técnica importante no desenvolvimento de software. Um conjunto de fatores que despertou o interesse nessa área, provendo a motivação necessária para acreditar que o DBC possa ser efetivo e realizado em larga escala, de acordo com Sametinger (1997) e D'Souza (1999), foram:

- O surgimento da Internet, que aumentou a preocupação em relação à computação distribuída; 
- A mudança da estrutura de sistemas baseados em mainframes para sistemas baseados na arquitetura cliente/servidor, levando os desenvolvedores a considerarem as aplicações não mais como sistemas monolíticos, mas sim como um conjunto de sub-sistemas interoperáveis; e

- O surgimento de Padrões para construção de componentes e aplicações, como os definidos pelo Object Management Group (OMG) e Component Object Model (COM).

Como foi mencionado, o desenvolvimento baseado em componentes é uma atividade que utiliza componentes no desenvolvimento de sistemas. Dessa forma, é importante que já existam componentes de software prontos e que estejam disponíveis para serem selecionados e reutilizados na composição dos sistemas. O processo começa quando uma equipe de software estabelece os requisitos para um sistema a ser construído usando técnicas de coleta de requisitos convencionais.

Com os requisitos já estabelecidos e usando os métodos de análise e projeto arquitetural (Pressman, 2002), a equipe de software refina um estilo arquitetural adequado para o modelo de análise criado para a aplicação a ser construída.

Uma vez estabelecida a arquitetura, ela deve ser preenchida por componentes que estão disponíveis em bibliotecas de reuso ou componentes procedentes de diferentes origens, incluindo componentes já desenvolvidos para outros projetos e componentes desenvolvidos e comercializados por diferentes empresas. Por fim, caso não existam componentes suficientes para preencher a arquitetura do sistema, é necessário que novos componentes sejam trabalhados por engenharia para satisfazer as necessidades do cliente. Assim, o fluxo de tarefas para o desenvolvimento baseado em componentes tem dois caminhos paralelos. Quando os componentes reutilizáveis estão disponíveis para possível integração na arquitetura, eles precisam ser qualificados e adaptados. Quando novos componentes são necessários, precisam ser construídos. Os componentes resultantes são então compostos (integrados) no gabarito da arquitetura e testados rigorosamente (Pressman, 2002). 
Na Figura 2.1, é ilustrado o processo de desenvolvimento baseado em componentes.

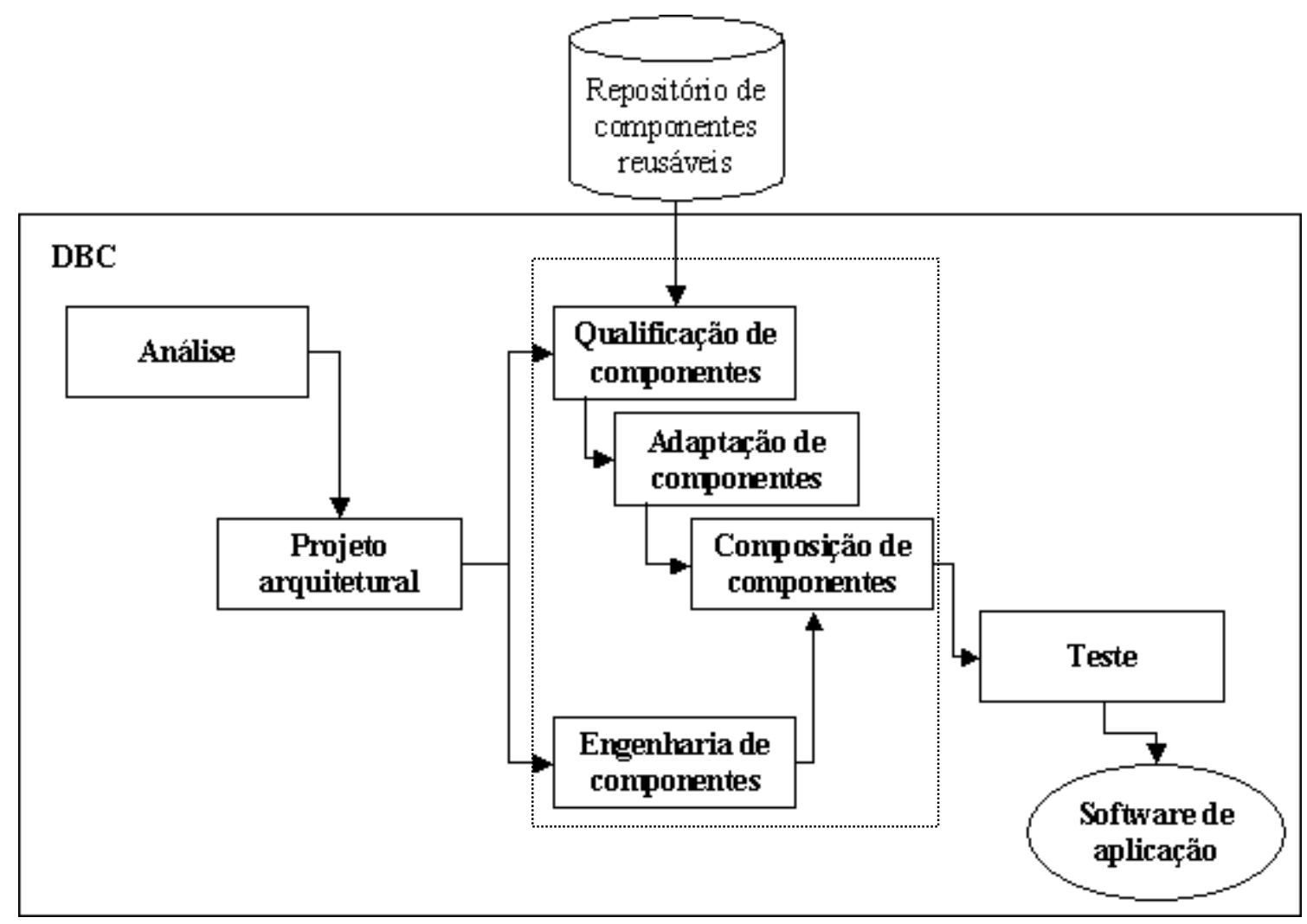

Figura 2.1 - Desenvolvimento Baseado em Componentes DBC (Adaptado de (Pressman, 2002)).

O repositório de componentes de software, também tratado como biblioteca de componentes, é necessário para a engenharia de software baseada em componentes, ele pode ser composto por componentes que são desenvolvidos internamente, por componentes extraídos de aplicações existentes e ou por componentes adquiridos de terceiros.

No entanto, a existência de componentes de software não garante que eles possam ser integrados fácil ou efetivamente na arquitetura escolhida para uma nova aplicação na fase de Projeto arquitetural. É por essa razão que uma seqüência de atividades de desenvolvimento baseado em componentes é aplicada quando um componente é proposto para uso (Pressman, 2002).

Como pode ser observado na Figura 2.1, as fases de "Qualificação de componentes", "Adaptação de componentes", "Composição de componentes", 
e "Engenharia de componentes" são específicas do processo de Desenvolvimento Baseado em Componentes. Já as fases de "Análise", "Projeto arquitetural", e "Teste" utilizam métodos de engenharia de software tradicionais.

Quando um componente está disponível para uso em um repositório, ele segue para as fases de Qualificação e Adaptação de componentes:

- Qualificação de componentes: garante que um componente candidato vai realizar a função necessária, vai "se encaixar" adequadamente no estilo arquitetônico especificado para o sistema, e vai exibir as características de qualidade (por exemplo, desempenho, confiabilidade e usabilidade) necessárias para a aplicação;

- Adaptação de componentes: tenta eliminar conflitos que possam surgir entre o componente que está sendo utilizado e a arquitetura da aplicação, para que haja uma fácil integração. Uma técnica de adaptação freqüentemente usada é o empacotamento de componentes que pode ser de três tipos: caixa-branca, caixa-cinza e caixa-preta. Empacotamento caixa-branca é aplicado quando são examinados detalhes de processamento internos e são feitas modificações no código. Empacotamento caixa-cinza é aplicado quando não se pode mexer no código interno, mas existe uma linguagem de extensão para remover ou mascarar os conflitos. Empacotamento caixa-preta exige a introdução de pré e pósprocessamento na interface do componente para remover ou mascarar os conflitos.

Caso alguns componentes necessários, não estejam disponíveis para uso depois da fase de Projeto arquitetural, o próximo passo a ser seguido é a Engenharia de Componentes cujo objetivo é desenvolver esses novos componentes de software e integrá-los com os componentes já existentes e que serão utilizados. As práticas para a criação dos novos componentes que podem ser reusados nessa fase de engenharia de componentes são os mesmos conceitos empregados em projetos tradicionais, como abstração, ocultamento, independência funcional, refinamento e programação estruturada, junto com métodos de orientação a objetos, testes, Garantia de Qualidade de Software (SQA) e métodos de verificação de correção. Todas estas práticas 
contribuem para a criação de componentes de software reutilizáveis (Pressman, 2002).

Depois de passar pela fase de qualificação e adaptação de componentes, ou pela engenharia de componentes a fase de Composição de componentes é realizada. Essa fase tem como tarefa combinar os componentes qualificados, adaptados e construídos para compor a arquitetura estabelecida para uma aplicação. Para conseguir isso, uma infra-estrutura deve ser estabelecida para aglutinar os componentes em um sistema em operação. A infra-estrutura (usualmente uma biblioteca de componentes especializados) fornece um modelo para a coordenação de componentes e serviços específicos, que permitem aos componentes se coordenarem entre si e realizarem tarefas comuns.

\subsection{Considerações Finais}

Neste capítulo foram abordados os principais conceitos relacionados a componentes. Algumas definições de componentes foram identificadas e discutidas.

Observou-se que o conceito exato de componente ainda não é um tópico fechado e, de acordo com a adequação ao contexto utilizado, inúmeras definições de componentes de software são encontradas na literatura. Por isso, neste capítulo, foi apresentada e discutida a definição sobre componentes de software de Villela que foi adotado como base neste trabalho por apresentar de forma geral, vários aspectos sobre componentes como: artefato autocontido, claramente identificável, funcionalidade única, interfaces claras, documentação apropriada, entre outras.

Estes aspectos de componentes da definição adotada, auxiliaram na identificação e adequação das características, subcaracterísticas, atributos e métricas de qualidade do modelo, o qual também, está embasado nas normas internacionais de produto e pacotes de software ISO/IEC 9126-1 e ISO/IEC 12119, respectivamente.

Essas duas normas serão apresentadas no próximo capítulo, onde serão discutidos assuntos sobre qualidade de produtos de software. 


\section{Capítulo 3}

\section{Qualidade de Produtos de Software}

\subsection{Considerações Iniciais}

Especificação e avaliação da qualidade de produtos de software são fatores chave para garantir a qualidade adequada. Isso pode ser alcançado pela definição apropriada de características de qualidade, levando em consideração o uso pretendido do produto de software.

Neste capítulo são apresentados aspectos e características que influenciam e que estão relacionados à qualidade de produtos de software em geral. São apresentadas também as normas internacionais ISO/IEC 9126-1 e ISO/IEC 12119 que são utilizadas neste trabalho como base para o modelo de qualidade proposto.

\subsection{Introdução}

Qualidade hoje em dia, não é apenas um diferencial de mercado para a empresa conseguir vender e lucrar mais, é um pré-requisito que a empresa deve conquistar para conseguir colocar o seu produto no mercado global. Empresas produtoras e prestadoras de serviços estão preocupadas em alcançar patamares cada vez maiores de qualidade e de produtividade internacional, para enfrentarem a competitividade que também é cada vez maior.

Mas afinal, o que vem a ser o termo qualidade?

Existem diversas definições para qualidade. Algumas pessoas tentaram uma definição simples e chegaram a frases como: "Qualidade é estar em conformidade com os requisitos dos clientes", "Qualidade é antecipar e 
satisfazer os desejos dos clientes", "Qualidade é escrever tudo o que se deve fazer e fazer tudo o que foi escrito".

De acordo com a norma ISO' 8402 (ISO, 1994a), qualidade "é a totalidade de características de uma entidade que lhe confere a capacidade de satisfazer às necessidades explícitas e implícitas”.

Nota-se que essa definição formal exige alguns complementos, principalmente para definir o que são as entidades, as necessidades explícitas e as necessidades implícitas. A entidade é o produto do qual se está falando, que pode ser um bem ou um serviço. As necessidades explícitas são as próprias condições e objetivos propostos pelo produtor. As necessidades implícitas incluem particularidades dos usuários, implicações éticas, questões de segurança e outras visões subjetivas. Por exemplo, a qualidade de um prato de comida (a entidade, o produto) está relacionada com a satisfação de necessidades (requisitos) tais como: sabor, aparência, temperatura, rapidez no serviço, preço, higiene, valor nutricional, etc. Para avaliar a qualidade de um produto, deve-se fazer uma lista destas necessidades e analisar cada uma delas.

\subsection{Qualidade de Produtos de Software}

Através da história da Engenharia de Software, a melhoria na qualidade de produtos de software sempre foi um objetivo considerado. Atualmente, com o aumento no tamanho e da complexidade, os produtos de software estão se tornando artefatos estratégicos e críticos. Assim, uma atenção especial tem sido voltada ao desenvolvimento e à manutenção de produtos de software com qualidade dentro de restrições de tempo e de recursos estabelecidos nos projetos (Rocha et al., 2001).

Atualmente, muitas instituições se preocupam em criar normas para permitir a correta avaliação de qualidade tanto de produtos de software quanto de processos de desenvolvimento de software. A ISO possui duas normas

\footnotetext{
${ }^{1}$ (International Organization for Standardization)
} 
internacionais para produtos de software, a ISO/IEC ${ }^{2} 9126$ (2001) cujo objetivo é apresentar uma estrutura de qualidade para apoiar a avaliação de produtos de software e a ISO/IEC 12119 (1994) que tem por objetivo estabelecer os requisitos para pacotes de software.

Seguindo a definição de qualidade, a norma ISO 9126-1 (2001) define qualidade de software como: "a totalidade das características de um produto de software, que the confere a capacidade de satisfazer às necessidades explícitas e implícitas". Necessidades explícitas, como foi descrito na definição de qualidade, são aquelas expressas na especificação de requisitos propostos pelo produtor de software após o levantamento da necessidade do cliente. Esses requisitos definem as condições em que o produto deve ser utilizado, seus objetivos, funções e o desempenho esperado. $O$ enfoque da qualidade centrado no atendimento a esses requisitos é denominado "conformidade com os requisitos".

Necessidades implícitas são aquelas que não estão expressas nos documentos do produtor, mas são necessárias para o usuário e são identificadas de acordo com a maturidade do produtor. $O$ enfoque da qualidade centrado nessa classe de necessidades está relacionado à "adequação para uso".

Melhorar a qualidade dos produtos de software visa estabelecer métodos e tecnologias para construir produtos de software de qualidade dentro dos limites de tempo e de recursos disponíveis, pois a qualidade de um produto de software é resultante das atividades realizadas no processo de desenvolvimento do mesmo.

Para avaliar a qualidade de um produto de software, produzido por meio de processos de desenvolvimento bem definidos ou não, é necessário verificar através de técnicas e atividades operacionais, o quanto os requisitos são atendidos. Tais requisitos, de uma maneira geral, é a expressão das necessidades, explicitados em termos quantitativos ou qualitativos, e têm por objetivo definir as características de um software, a fim de permitir o exame de seu atendimento (Tsukumo et al., 1997).

\footnotetext{
${ }^{2}$ (International Electrotechnical Commission)
} 
A seguir, serão abordadas as normas de qualidade de produto de software e de pacotes de software são melhores abordadas.

\subsubsection{Norma ISO/IEC 9126 - Engenharia de Software - Qualidade de Produto: Evolução Histórica}

A norma ISO/IEC 9126 é um padrão internacional desenvolvida pelo Subcomitê de Software (SC7) do Comitê Técnico Conjunto (JTC1) da ISO e IEC. A norma surgiu da necessidade de uma estrutura de qualidade de software que apresentasse um esquema de descrição padronizado, bem definido e amplamente aceito, para julgar a qualidade dos produtos de software.

Desde 1976, muitos trabalhos foram realizados por diversas pessoas e organizações para definir modelos de qualidade de software, e alguns modelos foram adotados e ampliados ao longo dos anos, como os modelos de McCall (McCall, 1977), Boehm (Boehm et al., 1978), e da força Aérea dos Estados Unidos. Entretanto, ao mesmo tempo em que os estudos eram bem-sucedidos, eles também causavam confusão por causa dos muitos aspectos de qualidade oferecidos. Em conseqüência, surgiu a necessidade de um modelo padronizado. Por essa razão, o comitê técnico da ISO/IEC começou a trabalhar para desenvolver o consenso requerido e encorajar a padronização em âmbito mundial.

As primeiras tentativas de padronização surgiram em 1978. Em 1985, foi iniciado o desenvolvimento da norma com o título de norma internacional ISO/IEC 9126 - "Information Technology - Software product evaluation Quality characteristics and guidelines for their use". Os modelos propostos inicialmente introduziram propriedades de software que dependiam de aspectos de aplicação ou implementação (ou ambos) para descrever a qualidade de software.

O primeiro passo do comitê técnico da ISO para definir essas propriedades de forma sistemática falhou por falta de definições. Os termos foram interpretados de formas diferentes por diversos especialistas. Todas as estruturas discutidas eram, por isso, de natureza arbitrária, sem uma base comum (ISO, 2001). 
Como resultado, decidiu-se que a melhor condição para o estabelecimento de uma norma consistia em estipular um conjunto de características baseadas na definição de qualidade. Os requisitos para a escolha das características descritas na norma ISO/IEC 9126 foram os seguintes:

- Cobrir conjuntamente todos os aspectos de qualidade de software resultantes da definição de qualidade da ISO.

- Descrever a qualidade do produto com um mínimo de sobreposição.

- Ficar o mais próximo possível da terminologia estabelecida.

- Formar um conjunto de não mais de seis a oito características, por questões de clareza e manuseio.

- Identificar áreas de atributos de produtos de software para posterior refinamento.

\section{口 Norma ISO/IEC 9126: 1991 (primeira versão)}

A primeira versão da norma ISO/IEC 9126 foi publicada em 1991. Na norma foram definidas seis características principais de qualidade, e suas subcaracterísticas, que devem ser verificadas em um software para que ele seja considerado um "software de qualidade". Na tabela 3.1 são apresentadas as seis características de qualidade da norma ISO/IEC 9126.

Tabela 3.1 - Características de Qualidade de Produto de Software ISO/IEC 9126

\begin{tabular}{|l|l|}
\hline \multicolumn{1}{|c|}{ Característica } & \multicolumn{1}{c|}{ Descrição } \\
\hline Funcionalidade & $\begin{array}{l}\text { Evidencia que o conjunto de funções atenda às necessidades } \\
\text { explícitas e implícitas para a finalidade a que se destina o produto. }\end{array}$ \\
\hline Confiabilidade & $\begin{array}{l}\text { Evidencia que o desempenho se mantém ao longo do tempo e em } \\
\text { condições estabelecidas. }\end{array}$ \\
\hline Usabilidade & Evidencia a facilidade para utilização do software. \\
\hline Eficiência & $\begin{array}{l}\text { Evidencia que os recursos e os tempos envolvidos são compatíveis } \\
\text { com o nível de desempenho requerido para o produto. }\end{array}$ \\
\hline Manutenibilidade & $\begin{array}{l}\text { Evidencia que há facilidade para correções, atualizações e } \\
\text { alterações. }\end{array}$ \\
\hline Portabilidade & $\begin{array}{l}\text { Evidencia que é possível utilizar o produto em diversas plataformas } \\
\text { com pequeno esforço de adaptação. }\end{array}$ \\
\hline
\end{tabular}


Para que a norma pudesse oferecer apoio suficiente aos usuários no julgamento da qualidade de software, foi incluída uma descrição de como proceder na avaliação de um produto de software, por meio de um modelo de processo de avaliação.

A simples existência de características não são suficientes para a avaliação de um produto de software na prática. É necessário também que existam métricas para cada uma das características. O estado da arte naquele momento não permitia a elaboração dessas métricas, pois teria atrasado substancialmente a publicação da norma internacional.

\section{口 Norma ISO/IEC 9126: 1994 (primeira revisão)}

Em 1994, foi percebido que outras normas produzidas na área de avaliação de qualidade de software demandavam a revisão da ISO/IEC 9126. A revisão manteve as mesmas seis características de qualidade, e as principais diferenças nessa revisão foram:

- inclusão de métricas internas e externas;

- inclusão de características de qualidade em uso;

- inclusão das subcaracterísticas em caráter normativo;

- remoção do modelo do processo de avaliação (especificado separadamente na norma ISO/IEC 14598 (ISO, 2001a));

\subsubsection{Norma ISO/IEC 9126: Engenharia de Software - Qualidade do Produto (versão atual)}

Na versão atualmente utilizada, desenvolvida entre 2001 e 2004, três novos relatórios técnicos foram elaborados em complemento à norma:

- Parte 1: ISO/IEC 9126-1:(ISO, 2001) - Modelo de Qualidade; 
- Parte 2: ISO/IEC TR 9126-2:(ISO, 2003) - Métricas Externas;

- Parte 3: ISO/IEC TR 9126-3:(ISO, 2003a) - Métricas Internas;

- Parte 4: ISO/IEC TR 9126-4:(ISO, 2004) - Métricas de Qualidade em Uso;

\section{a Parte 1: ISO/IEC 9126-1:2001 - Modelo de Qualidade}

A parte 1 da norma descreve um modelo de qualidade de produto de software, composto de duas partes:

(i) qualidade externa e interna $e$

(ii) qualidade em uso.

As características de qualidade externas são observadas quando os produtos de software são executados, isto é, medidas e avaliadas quando os produtos são testados, resultando em uma visão dinâmica do software. A avaliação das características internas de qualidade é realizada através da verificação do projeto e de códigos fontes do software, resultando em uma visão estática. Qualidade em uso é a capacidade do produto de software de permitir que usuários especificados atinjam metas especificadas com eficácia, produtividade, segurança e satisfação em contextos de uso especificados, ou seja, qualidade em uso é a visão da qualidade sob a perspectiva do usuário do sistema.

A obtenção da qualidade em uso é dependente da obtenção da qualidade externa, a qual, por sua vez, é dependente da obtenção da qualidade interna. Atributos internos adequados do software são pré-requisitos para atingir o comportamento externo requerido e, o comportamento externo adequado do software é um pré-requisito para obter a qualidade em uso, conforme é mostrado na Figura 3.1. 


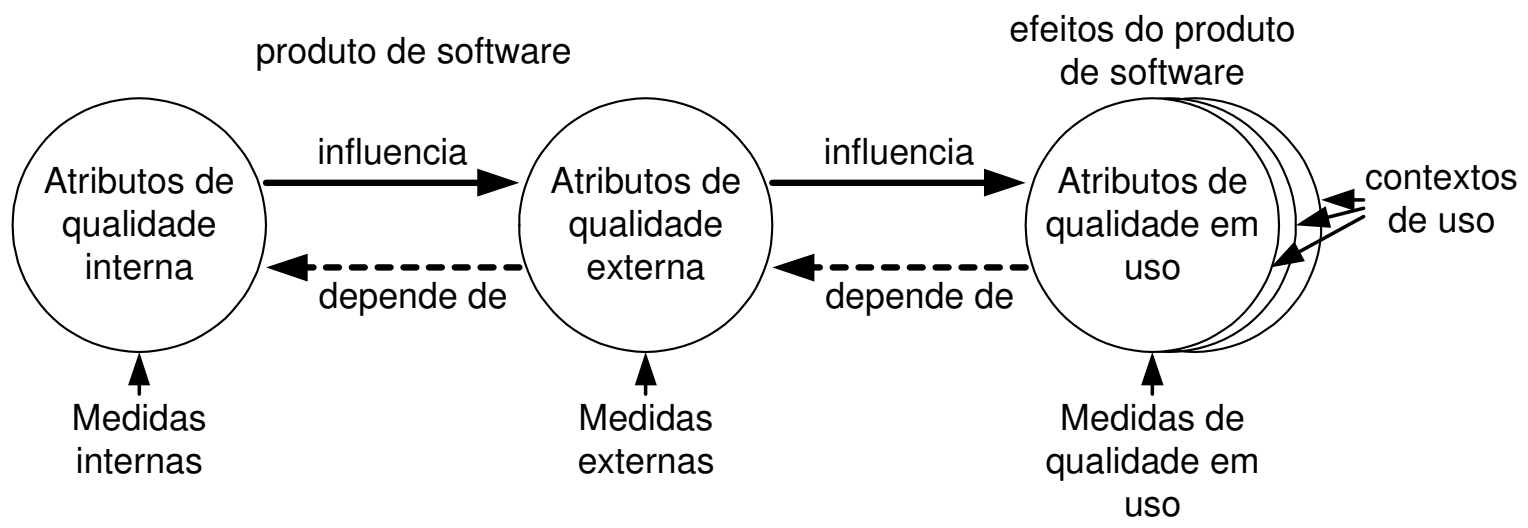

Figura 3.1 - Três níveis de qualidade (Adaptado de (ISO, 2001)).

Normalmente, são necessárias medidas em todos os três níveis, pois atender aos critérios para medidas internas em geral não é suficiente para garantir $o$ atendimento aos critérios para medidas externas e, atender aos critérios para medidas externas, em geral não é suficiente para garantir o atendimento aos critérios para qualidade em uso.

A primeira parte do modelo especifica seis características para qualidade interna e externa, as quais são por sua vez subdivididas em subcaracterísticas. Uma característica pode ter vários níveis de subcaracterísticas, sendo as de nível mais baixo as que são realmente medidas, e são chamadas de subcaracterísticas mensuráveis. Na Figura 3.2 é apresentado o modelo de qualidade para qualidade externa e interna. 




Figura 3.2 - Modelo de qualidade para qualidade externa e interna.(Adaptado de (ISO, 2001))

As características e subcaracterísticas externas e internas definidas pela norma são apresentadas na Tabela 3.2.

Tabela 3.2 - Características e Subcaracterísicas Externas e Internas da norma ISO/IEC 9126-1

\begin{tabular}{|c|c|}
\hline Característica & Subcaracterística \\
\hline \multirow{4}{*}{$\begin{array}{l}\text { Funcionalidade: } \\
\text { Capacidade do produto } \\
\text { de software prover } \\
\text { funções que atendam } \\
\text { necessidades } \\
\text { explícitas e implícitas, } \\
\text { quando o software for } \\
\text { utilizado sob condições } \\
\text { especificadas. }\end{array}$} & $\begin{array}{l}\text { Adequação: Capacidade do produto de software de prover um conjunto } \\
\text { apropriado de funções para tarefas e objetivos do usuário especificados. } \\
\text { Acurácia: Capacidade do produto de software de prover, com grau de } \\
\text { precisão necessário, resultados ou efeitos corretos ou conforme } \\
\text { acordados. }\end{array}$ \\
\hline & $\begin{array}{l}\text { Interoperabilidade: Capacidade do produto de software de interagir com } \\
\text { um ou mais sistemas especificados. }\end{array}$ \\
\hline & $\begin{array}{l}\text { Segurança de acesso: Capacidade do produto de software de proteger } \\
\text { informações e dados, de forma que pessoas ou sistemas não autorizados } \\
\text { não possam lê-los nem modificá-los e que não seja negado o acesso às } \\
\text { pessoas ou sistemas autorizados. }\end{array}$ \\
\hline & $\begin{array}{l}\text { Conformidade relacionada à funcionalidade: Capacidade do produto } \\
\text { de software de estar de acordo com normas, convenções ou } \\
\text { regulamentações previstas em leis e prescrições similares relacionadas à } \\
\text { funcionalidade. }\end{array}$ \\
\hline \multirow{4}{*}{$\begin{array}{l}\text { Confiabilidade: } \\
\text { Capacidade do produto } \\
\text { de software de manter } \\
\text { um nível de } \\
\text { desempenho } \\
\text { especificado, quando } \\
\text { usado em condições } \\
\text { especificadas. }\end{array}$} & $\begin{array}{l}\text { Maturidade: Capacidade do produto de software de evitar falhas } \\
\text { decorrentes de defeitos no software. }\end{array}$ \\
\hline & $\begin{array}{l}\text { Tolerância a falhas: Capacidade do produto de software de manter um } \\
\text { nível de desempenho especificado em casos de defeitos no software ou } \\
\text { de violação de sua interface especificada. }\end{array}$ \\
\hline & $\begin{array}{l}\text { Recuperabilidade: Capacidade do produto de software de restabelecer } \\
\text { seu nível de desempenho especificado em casos de defeitos no software } \\
\text { ou de violação de sua interface especificada. }\end{array}$ \\
\hline & $\begin{array}{l}\text { Conformidade relacionada à confiabilidade: Capacidade do produto de } \\
\text { software de estar de acordo com normas, convenções ou } \\
\text { regulamentações relacionadas à confiabilidade. }\end{array}$ \\
\hline
\end{tabular}


Usabilidade:

Capacidade do produto de software de ser compreendido, aprendido, operado e atraente ao usuário, quando usado sob condições

especificadas.

\section{Eficiência:}

Capacidade do produto de software de

apresentar desempenho apropriado, relativo à quantidade de recursos usados, sob condições especificadas. Manutenibilidade: Capacidade do produto de software ser modificado. Modificações podem incluir correções, melhorias ou adaptações do software devido mudanças no ambiente e nos requisitos e especificações funcionais.

Portabilidade:

Capacidade do produto de software ser transferido de um ambiente para outro.
Inteligibilidade: Capacidade do produto de software de possibilitar ao usuário compreender se o software é apropriado e como ele pode ser usado para tarefas e condições de uso específicas.

Apreensibilidade: Capacidade do produto de software de possibilitar ao usuário aprender sua aplicação.

Operacionalidade: Capacidade do produto de software de possibilitar ao usuário operá-lo e controlá-lo.

Atratividade: Capacidade do produto de software de ser atraente ao usuário.

Conformidade relacionado à usabilidade: Capacidade do produto de software de estar de acordo com normas, convenções, guias de estilo ou regulamentações relacionadas à usabilidade.

Comportamento em relação ao tempo: Capacidade do produto de software de fornecer tempos de resposta e de processamento, além de taxas de transferência, apropriados, quando o software executa suas funções, sob condições estabelecidas.

Utilização de recursos: Capacidade do produto de software de usar tipos e quantidades apropriados de recursos, quando o software executa suas funções sob condições estabelecidas.

Conformidade relacionada à eficiência: Capacidade do produto de software de estar de acordo com normas e convenções relacionadas à eficiência.

Analisabilidade: Capacidade do produto de software de permitir o diagnóstico de deficiências ou causas de falhas no software, ou a identificação de partes a serem modificadas.

Modificabilidade: Capacidade do produto de software de permitir que uma modificação especificada seja implementada.

Estabilidade: Capacidade do produto de software de evitar efeitos inesperados decorrentes de modificações no software.

Testabilidade: Capacidade do produto de software de permitir que o software, quando modificado, seja validado.

Conformidade relacionada à manutenibilidade: Capacidade do produto de software de estar de acordo com normas ou convenções relacionadas à manutenibilidade.

Adaptabilidade: Capacidade do produto de software de ser adaptado para diferentes ambientes especificados, sem necessidade de aplicação de outras ações ou meios além daqueles fornecidos para essa finalidade pelo software considerado.

Capacidade para ser instalado: Capacidade do produto de software para ser instalado em um ambiente especificado.

Coexistência: Capacidade do produto de software de coexistir com outros produtos de software independentes, em um ambiente comum, compartilhando recursos comuns.

Capacidade para substituir: Capacidade do produto de software para ser usado em substituição a outro produto de software especificado, com o mesmo propósito e no mesmo ambiente.

Conformidade relacionada à portabilidade: Capacidade do produto de software de estar de acordo com normas ou convenções relacionadas à portabilidade. 
Exemplos de métricas para as subcaracterísticas das seis características de qualidade externa e interna são apresentadas nas partes 2 e 3 da norma respectivamente.

A segunda parte do modelo especifica quatro características de qualidade em uso (eficácia, produtividade, segurança e satisfação). Na Figura 3.3, é apresentado o modelo de qualidade para qualidade em uso.

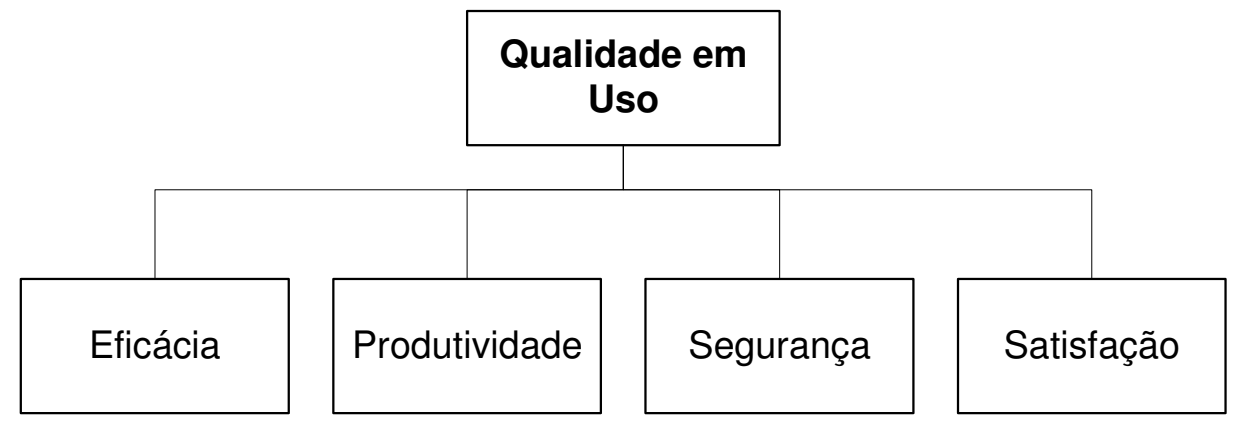

Figura 3.3 - Modelo de qualidade para qualidade em uso (Adaptado de (ISO, 2001)).

A norma não apresenta o modelo de qualidade em uso além do nível de características. As definições das características de qualidade em uso são apresentadas na Tabela 3.3.

Tabela 3.3 - Características de Qualidade em Uso da norma ISO/IEC 9126-1.

\begin{tabular}{|c|l|}
\hline Característica & \multicolumn{1}{c|}{ Descrição } \\
\hline Eficácia & $\begin{array}{l}\text { Capacidade do produto de software de permitir que usuários atinjam } \\
\text { metas especificadas com acurácia e completitude, em um contexto } \\
\text { de uso especificado. }\end{array}$ \\
\hline Produtividade & $\begin{array}{l}\text { Capacidade do produto de software de permitir que seus usuários } \\
\text { empreguem quantidade apropriada de recursos em relação à eficácia } \\
\text { obtida, em um contexto de uso especificado. }\end{array}$ \\
\hline Segurança & $\begin{array}{l}\text { Capacidade do produto de software de apresentar níveis aceitáveis } \\
\text { de riscos de danos a pessoas, negócios, software, propriedades ou } \\
\text { ao ambiente, em um contexto de uso especificado. }\end{array}$ \\
\hline Satisfação & $\begin{array}{l}\text { Capacidade do produto de software de satisfazer usuários, em um } \\
\text { contexto de uso especificado. }\end{array}$ \\
\hline
\end{tabular}

A utilização da norma ISO/IEC 9126-1 permite que a qualidade do produto de software seja especificada e avaliada pelos envolvidos com aquisição, requisitos, desenvolvimento, uso, avaliação, apoio, manutenção, 
garantia de qualidade e auditoria de software. Ela pode, por exemplo, ser utilizada por desenvolvedores, adquirentes, pessoal de garantia de qualidade e avaliadores independentes, particularmente, os responsáveis por especificar e avaliar qualidade do produto de software. Exemplos de usos do modelo de qualidade definido nesta parte da norma são para:

- validar a completitude de uma definição de requisitos;

- identificar requisitos de software;

- identificar objetivos de projeto de software;

- identificar objetivos para teste de software;

- identificar critérios para garantia de qualidade;

- identificar critérios de aceitação para produtos finais de software.

\subsubsection{Norma ISO/IEC 12119: Information technology - Software packages -} Quality requirements and testing

A norma internacional ISO/IEC 12119 (1994) foi publicada em 1994 e sua versão brasileira foi lançada em outubro de 1998 pela Associação Brasileira de Normas e Técnicas (ABNT) com o título de NBR ISO/IEC 12119 Tecnologia da informação - Pacotes de software - Teste e requisitos de qualidade.

A norma tem como objetivo estabelecer os requisitos de qualidade de um software tipo pacote e também fornecer instruções para testar esse software em relação aos requisitos definidos. Ela não trata de processos de produção de software, somente de pacotes de software na forma como são oferecidos e liberados para uso.

Segundo a definição dada pela ISO/IEC 12119 (1994), um pacote de software é: "um conjunto completo e documentado de programas fornecido a diversos usuários para uma aplicação ou função genérica". Pacote de software é conhecido também como "produto de prateleira" e são exemplos de pacotes: processadores de texto, planilhas eletrônicas, bancos de dados, software gráficos, programas para funções técnicas ou científicas e programas utilitários. 
De acordo com a norma ISO/IEC 12119, um pacote de software deve ser composto pelos seguintes itens:

- Descrição do Produto.

- Documentação do Usuário.

- Programa e Dados.

A Descrição do Produto e a Documentação do Usuário formam a documentação do pacote. A seguir são descritos os requisitos de qualidade para cada um dos componentes definidos pela norma.

\section{口 Descrição do Produto}

A Descrição do Produto é um documento que expõe as principais propriedades de um pacote de software, com os objetivos de auxiliar o usuário ou os potenciais compradores, na avaliação da adequação do produto às suas reais necessidades; e servir como base para testes.

Esse documento deve estar disponível ao usuário, independentemente da aquisição do produto, através de um catálogo, de um disquete de apresentação ou qualquer outro meio disponível que alcance esse objetivo. A descrição deve ser clara, compreensível e harmônica com os outros documentos associados. A norma propõe aspectos práticos e diretos, indicando "o quê" deve conter essa descrição. Na Tabela 3.4, são apresentados os itens que compõem os requisitos do documento "Descrição do Produto". 
Tabela 3.4 - Requisitos de Qualidade para a Descrição do Produto.

\begin{tabular}{|l|l|}
\hline \multicolumn{1}{|c|}{ Item } & \multicolumn{1}{c|}{ Requisitos } \\
\hline $\begin{array}{l}\text { Requisitos Gerais sobre } \\
\text { O Conteúdo da } \\
\text { Descrição de Produto }\end{array}$ & $\begin{array}{l}\text { O conteúdo da descrição deve ser inteligível, completo e possuir boa } \\
\text { organização e apresentação, auxiliando os compradores em potencial } \\
\text { na avaliação da adequação do produto às suas necessidades, antes } \\
\text { de adquiri-lo. }\end{array}$ \\
\hline $\begin{array}{l}\text { Identificações e } \\
\text { Indicações }\end{array}$ & $\begin{array}{l}\text { O conteúdo da descrição deve apresentar o nome do produto, sua } \\
\text { versão, os requisitos de hardware e software, as principais atividades } \\
\text { realizadas e os componentes entregues com o pacote. }\end{array}$ \\
\hline $\begin{array}{l}\text { Declaração sobre } \\
\text { Funcionalidade }\end{array}$ & $\begin{array}{l}\text { O conteúdo da descrição deve apresentar uma visão geral das } \\
\text { funções disponíveis, os valores-limite, se existirem, e os dispositivos } \\
\text { de segurança de acesso ao produto, quando necessários. }\end{array}$ \\
\hline $\begin{array}{l}\text { Declaração sobre } \\
\text { Confiabilidade }\end{array}$ & $\begin{array}{l}\text { O conteúdo da descrição deve apresentar as informações sobre os } \\
\text { procedimentos para salvar e recuperar dados. }\end{array}$ \\
\hline $\begin{array}{l}\text { Declaração sobre } \\
\text { Usabilidade }\end{array}$ & $\begin{array}{l}\text { O conteúdo da descrição deve apresentar o tipo de interface com o } \\
\text { usuário, se é necessário algum conhecimento técnico específico para } \\
\text { seu uso e se o produto pode ser adaptado às necessidades do } \\
\text { usuário. }\end{array}$ \\
\hline $\begin{array}{l}\text { Declaração sobre } \\
\text { Eficiência }\end{array}$ & $\begin{array}{l}\text { O conteúdo da descrição pode incluir informações a respeito do tempo } \\
\text { de resposta e taxa de throughput. }\end{array}$ \\
\hline $\begin{array}{l}\text { Declaração sobre } \\
\text { Manutenibilidade }\end{array}$ & $\begin{array}{l}\text { O conteúdo da descrição pode conter declarações sobre a } \\
\text { manutenibilidade do produto. }\end{array}$ \\
\hline $\begin{array}{l}\text { Declaração sobre } \\
\text { Portabilidade }\end{array}$ & $\begin{array}{l}\text { O conteúdo da descrição pode conter declarações sobre a } \\
\text { portabilidade do produto. }\end{array}$ \\
\hline
\end{tabular}

\section{- Documentação do Usuário}

A Documentação do Usuário compreende o conjunto completo de documentos que é fornecido para utilização de um produto. Essa documentação deve incluir todos os dados para a instalação, para o uso da aplicação e para a manutenção do produto de software. Os principais requisitos da documentação do usuário estão descritos na Tabela 3.5. 
Tabela 3.5 - Requisitos de Qualidade para a Documentação do Usuário.

\begin{tabular}{|l|l|}
\hline Item & Requisitos \\
\hline Completitude & $\begin{array}{l}\text { A documentação do usuário deve conter todas as informações necessárias } \\
\text { para o uso do produto, tais como estabelecer todas as funções do pacote, } \\
\text { procedimentos de instalação e os valores-limite. }\end{array}$ \\
\hline Correção & $\begin{array}{l}\text { Na documentação do usuário a informação apresentada deve estar correta } \\
\text { e sem ambigüidade. }\end{array}$ \\
\hline Consistência & $\begin{array}{l}\text { A documentação do usuário deve haver plena coerência entre a } \\
\text { documentação e a descrição do produto. Cada termo deve ter um único } \\
\text { significado. }\end{array}$ \\
\hline Inteligibilidade & $\begin{array}{l}\text { A documentação deve ser compreensível pela classe de usuários que } \\
\text { desenvolve atividades com o produto, utilizando termos apropriados, } \\
\text { exibições gráficas e explicações detalhadas. }\end{array}$ \\
\hline $\begin{array}{l}\text { Apresentação e } \\
\text { Organização }\end{array}$ & $\begin{array}{l}\text { A documentação do usuário deve ser apresentada através de uma forma } \\
\text { que facilite uma visão geral, através de índices e tabelas de conteúdo. Se o } \\
\text { documento não estiver na forma impressa, deve haver indicação de como } \\
\text { efetuar a impressão. }\end{array}$ \\
\hline
\end{tabular}

\section{口 Programas e Dados}

O último componente dos requisitos de qualidade é formado pelos Programas e Dados, que utilizam as mesmas definições das características de qualidade da norma ISO/IEC 9126-1. São consideradas apenas as características de Funcionalidade, Confiabilidade e Usabilidade que devem ser verificadas por meio do uso do produto. Não há requisitos específicos para Eficiência, Manutenibilidade e Portabilidade, que, se citadas, devem estar em conformidade com a norma ISO/IEC 9126-1. Os requisitos para Programas e Dados estão descritos na Tabela 3.6. 
Tabela 3.6 - Requisitos de Qualidade para Programas e Dados.

\begin{tabular}{|l|l|}
\hline \multicolumn{1}{|c|}{ Item } & \multicolumn{1}{c|}{ Requisitos } \\
\hline Funcionalidade & $\begin{array}{l}\text { Devem ser verificados os procedimentos para instalação do produto; a } \\
\text { presença de todas as funções mencionadas; a execução correta dessas } \\
\text { funções; a ausência de contradições entre a descrição do produto e a } \\
\text { documentação do usuário. }\end{array}$ \\
\hline Confiabililidade & $\begin{array}{l}\text { O usuário deve manter o controle do produto, sem corromper ou perder } \\
\text { dados, mesmo que a capacidade declarada seja explorada até os limites ou } \\
\text { fora deles; observar se uma entrada incorreta é efetuada, ou ainda se } \\
\text { instruções explícitas na documentação são violadas. }\end{array}$ \\
\hline Usabilidade & $\begin{array}{l}\text { A comunicação entre o programa e o usuário deve ser de fácil entendimento, } \\
\text { através das entradas de dados, mensagens e apresentação dos resultados, } \\
\text { utilizando um vocabulário apropriado, representações gráficas e funções de } \\
\text { auxílio (help), entre outras; o programa também deve proporcionar uma } \\
\text { apresentação e organização que facilite uma visão geral das informações, } \\
\text { além de procedimentos operacionais que o auxiliem: por exemplo, a reversão } \\
\text { de uma função executada e o uso de recursos de hipertexto em funções de } \\
\text { auxílio, entre outros. }\end{array}$ \\
\hline
\end{tabular}

Na norma ISO/IEC 12119 também são fornecidas instruções para testar pacotes de software de acordo com os requisitos de funcionalidade, confiabilidade e usabilidade. Somente o produto, no seu ambiente de hardware e software é testado. Na Tabela 3.7 estão apresentadas as instruções de testes definidos pela norma ISO/IEC 12119.

Tabela 3.7 - Instruções para teste.

\begin{tabular}{|l|l|}
\hline \multicolumn{1}{|c|}{ Instrução } & \multicolumn{1}{|c|}{ Descrição } \\
\hline Pré-requisitos de teste & $\begin{array}{l}\text { Lista de itens necessários ao teste, incluindo documentos incluídos no } \\
\text { pacote, componentes do sistema e material de treinamento. }\end{array}$ \\
\hline Atividades de teste & $\begin{array}{l}\text { Instruções detalhadas sobre os procedimentos de teste, inclusive } \\
\text { instalação e execução de cada uma das funções descritas. }\end{array}$ \\
\hline Registro de teste & $\begin{array}{l}\text { Informações sobre como os testes foram realizados, de tal forma a } \\
\text { permitir uma reprodução destes testes. Deve incluir parâmetros } \\
\text { utilizados, resultados associados, falhas ocorridas e até a identidade do } \\
\text { pessoal envolvido. }\end{array}$ \\
\hline Relatório de teste & $\begin{array}{l}\text { Relatório incluindo: identificação do produto, hardware e software } \\
\text { utilizado, documentos utilizados, resultados dos testes, lista de não } \\
\text { conformidade com os requisitos, lista de não conformidade com as } \\
\text { recomendações, datas, etc. }\end{array}$ \\
\hline Teste de acompanhamento & $\begin{array}{l}\text { Instruções para testar novamente um produto que já foi testado } \\
\text { anteriormente, mas levando em consideração o teste anterior. }\end{array}$ \\
\hline
\end{tabular}


A utilização da norma ISO/IEC 12119 pode incluir diversos possíveis usuários com suas mais variadas necessidades, por exemplo:

a) fornecedores que estejam:

- especificando os requisitos para um pacote de software;

- projetando um modelo para descrever produtos;

- julgando seus próprios produtos;

- emitindo declarações de conformidade;

- submetendo produtos à certificação ou à obtenção de marcas de conformidade;

b) entidades de certificação que pretendam estabelecer um esquema de certificação por terceiros;

c) laboratórios de teste que terão de seguir as instruções de teste durante a execução de testes para certificação ou para emissão de marca de conformidade;

d) entidades de credenciamento que credenciam entidades de certificação e laboratórios de testes;

e) auditores quando julgam a competência de laboratórios de testes;

f) compradores que pretenciam:

- comparar seus próprios requisitos com os da norma;

- comparar os requisitos necessários para executar uma determinada tarefa com a informação presente nas descrições de produtos existentes;

- procurar por produtos certificados;

- verificar se os requisitos foram atendidos;

g) usuários que pretendam se beneficiar com produtos melhores; 
Segundo Tsukumo (Tsukumo et al., 1997) um dos grandes méritos da norma ISO/IEC 12119 está na profundidade com que são descritas cada uma das características e subcaracterísticas mencionadas na norma 9126. Outro ponto importante é a ênfase nos testes, o que facilita o trabalho do avaliador.

\subsection{Considerações Finais}

Neste capítulo foi apresentada uma visão geral sobre qualidade e sobre qualidade de produtos de software. Foi apresentada a definição de qualidade segundo a norma ISO 8402 e também a definição de qualidade de produto de software segundo a norma ISO 9126.

Vimos que avaliar a qualidade de um produto de software é verificar, através de técnicas e atividades operacionais, o quanto que os requisitos são atendidos. Nesse sentido, vimos duas normas internacionais cujo objetivo é auxiliar na averiguação da qualidade desses produtos por meio de suas estruturas de qualidade bem definidas e amplamente aceitas.

A primeira norma é a ISO/IEC 9126, que define um modelo de qualidade que é utilizado como referência para o processo de avaliação da qualidade de produto de software, e sua utilização não é restrita apenas na avaliação da qualidade de um produto, mas também auxilia na definição e validação de requisitos de software, testes e aceitação do produto final. As características e subcaracterísticas definidas pela norma fornecem terminologia consistente para tratar de qualidade do produto de software e por isso são aplicáveis a todo tipo de software, incluindo programas de computador e dados contidos em firmware.

A segunda norma apresentada é a ISO/IEC 12119, a qual é aplicável à produtos do tipo pacotes de software, também conhecidos como "produtos de prateleira". Ela tem como objetivo estabelecer requisitos de qualidade de pacotes e também fornecer instruções para testar esses pacotes em relação aos requisitos definidos.

As normas ISO/IEC 9126 e ISO/IEC 12119 são utilizadas neste trabalho fornecendo a base para a formalização do modelo de qualidade para 
componentes de software, através de suas estruturas bem definidas e conhecidas internacionalmente.

Para auxiliar na formalização desse modelo de qualidade, algumas pesquisas relacionadas à qualidade de componentes foram estudadas e são apresentadas no próximo capítulo. 


\section{Capítulo 4}

\section{Qualidade de Componentes de Software}

\subsection{Considerações Iniciais}

As normas internacionais ISO/IEC 9126 e ISO/IEC 12119 apresentam características de qualidade destinadas a produtos do software de uma forma geral, não satisfazendo assim alguns requisitos específicos de componentes de sofware.

No contexto deste trabalho, e com o objetivo de auxiliar na identificação desses requisitos de qualidade específicos para componentes, este capítulo apresenta e discute algumas pesquisas relacionadas ao tema de qualidade de componentes de software.

\subsection{Introdução}

Aplicações de software são produtos complexos, difíceis de desenvolver e testar. Muito freqüentemente, produtos de software apresentam comportamentos inesperados e indesejados, que podem causar muitos problemas (Fuggetta, 2000). Councill (2001) sugere que as melhores soluções para cada problema são aquelas que utilizam passos pequenos e simples, e maximizam a eficiência e minimizam custos. Ele acrescenta ainda que o Desenvolvimento Baseado em Componentes (DBC) soluciona problemas, quebrando-os em porções menores e implementa soluções como componentes independentes. 
Cheesman (2000) e Hopkins (2000) enfatizam o DBC como uma técnica para o desenvolvimento de produtos de software complexos, que priorizam a redução dos custos e o aumento da produtividade e da qualidade. Desse modo, desenvolver ou selecionar componentes de software de alta qualidade é de primordial importância. As informações sobre a qualidade dos componentes são importantes para que seus usuários possam ganhar confiança e avaliar seus possíveis usos (Preiss, 2002).

A importância na observação da qualidade dos componentes tem sido percebida e demonstrada em vários ramos de pesquisa, tais como Bertoa (Bertoa, 2002), Simão (Simão, 2003), Almeida (Almeida, 2005), (Lee, 2005), Alvaro (Alvaro, 2006), Mäki-Asiala (Mäki-Asiala, 2006) entre outros.

\subsection{Qualidade de Componentes}

Quando se fala em qualidade de software baseada em componentes ou mesmo, a qualidade dos próprios componentes, é possível encontrar na literatura alguns trabalhos com importantes contribuições na área, como é o caso de Bertoa (2002).

Com o objetivo de definir características de qualidades para um modelo de qualidade específico para componentes de software, o trabalho de Bertoa (2002) é um dos pioneiros e de grande contribuição para a comunidade de DBC. Bertoa define características de qualidade para um tipo especial de componente (COTS) o qual é especialmente projetado, desenvolvido, e comercializado para ser usado em ambientes de Desenvolvimento Baseado em Componentes (DBC). O objetivo é permitir a avaliação e a seleção de COTS pelos desenvolvedores e projetistas de software, e também de auxiliar na descrição de informações de qualidade como parte da documentação dos componentes pelos seus vendedores.

Para identificar os vários tipos de características de qualidade para componentes, Bertoa sugere uma classificação de acordo com diferentes critérios: 
- Separação das características em locais e globais: características locais são aquelas que fazem sentido para os componentes isoladamente (por exemplo: maturidade) e características globais são as que devem ser valoradas em nível da arquitetura de software (por exemplo: tolerância a falhas).

- Separação das características conforme o momento em que podem ser medidas: por exemplo, o desempenho pode ser observado em tempo de execução, enquanto que a manutenibilidade pode ser observada durante 0 ciclo de vida do produto.

- Definição dos usuários para as quais o modelo é dirigido: fundamentalmente, envolve os arquitetos de software e projetistas, pois são esses os responsáveis por avaliar e selecionar os componentes que comporão a aplicação final.

- Separação das métricas em internas e externas: as métricas internas medem os atributos internos do produto final ou dos produtos intermediários (por exemplo, especificação e código fonte). As métricas externas medem o comportamento do sistema durante os testes e a operação dos componentes. O autor afirma que somente as métricas externas são relevantes, quando se trata de componentes COTS, devido ao caráter de caixa-preta desses componentes.

Bertoa define seu modelo de qualidade baseado na norma ISO/IEC 9126-1 (ISO, 2001), mas menciona que nem todas as características de um produto de software, como definidas pela ISO/IEC 9126-1, são aplicadas para componentes COTS. (Por exemplo, a característica portabilidade sugerida pela norma ISO/IEC 9126-1, não é aplicável a componentes COTS.) O autor acrescenta duas novas subcaracterísticas: compatibilidade e complexidade. Segundo Simão (2003), em uma análise sobre o modelo, portabilidade é uma característica importante e deve ser mantida, pois se refere à capacidade do componente de ser transferido de um ambiente para outro e essa capacidade é fundamental para a reutilização dos componentes. Na Tabela 4.01, é apresentado a estrutura do modelo de qualidade de componentes COTS definido por Bertoa. 
Tabela 4.1 - Características, subcaracterísticas e atributos para componentes COTS (Adaptado de (Bertoa, 2002))

\begin{tabular}{|c|c|c|}
\hline Características & Subcaracterísticas & Atributos \\
\hline \multirow{12}{*}{ Funcionalidade } & \multirow{3}{*}{ Adequação } & Cobertura \\
\hline & & Excesso \\
\hline & & $\begin{array}{l}\text { Cobertura da implementação do } \\
\text { serviço }\end{array}$ \\
\hline & \multirow{2}{*}{ Acurácia } & Precisão \\
\hline & & Acurácia Computacional \\
\hline & Interoperabilidade & Compatibilidade dos dados \\
\hline & \multirow{2}{*}{ Conformidade } & Padronização \\
\hline & & Certificação \\
\hline & \multirow{3}{*}{ Segurança } & Criptografia dos dados \\
\hline & & Controlabilidade \\
\hline & & Auditabilidade \\
\hline & Compatibilidade & $\begin{array}{l}\text { Compatibilidade com as versões } \\
\text { anteriores }\end{array}$ \\
\hline \multirow{7}{*}{ Confiabilidade } & \multirow{4}{*}{ Recuperabilidade } & Serialização \\
\hline & & Persistência \\
\hline & & Suporte a transação \\
\hline & & Tratamento de erros \\
\hline & \multirow{3}{*}{ Maturidade } & Volatilidade \\
\hline & & Evolutibilidade \\
\hline & & Remoção de falhas \\
\hline \multirow{15}{*}{ Usabilidade } & \multirow{4}{*}{ Apreensibilidade } & Tempo de uso \\
\hline & & Tempo de configuração \\
\hline & & Tempo de administração \\
\hline & & Tempo de domínio de uso \\
\hline & \multirow{5}{*}{ Inteligibilidade } & Documentação de usuário \\
\hline & & Sistema de ajuda \\
\hline & & Documentação computacional \\
\hline & & Treinamento \\
\hline & & Cobertura da demonstração \\
\hline & \multirow{3}{*}{ Operabilidade } & Esforço de operação \\
\hline & & Adaptação \\
\hline & & Administrabilidade \\
\hline & \multirow{3}{*}{ Complexidade } & Interfaces providas \\
\hline & & Interfaces requeridas \\
\hline & & Taxa de complexidade \\
\hline \multirow{5}{*}{ Eficiência } & \multirow{3}{*}{$\begin{array}{l}\text { Comportamento em relação } \\
\text { ao tempo }\end{array}$} & Tempo de resposta \\
\hline & & $\begin{array}{l}\text { Capacidade de recepção e } \\
\text { processamento de informações }\end{array}$ \\
\hline & & $\begin{array}{l}\text { Capacidade de geração de } \\
\text { informações (Throughput) }\end{array}$ \\
\hline & \multirow{2}{*}{$\begin{array}{l}\text { Comportamento em relação } \\
\text { aos recursos }\end{array}$} & Utilização de memória \\
\hline & & Utilização de discos \\
\hline \multirow{5}{*}{ Manutenibilidade } & \multirow{3}{*}{ Modificabilidade } & Customização \\
\hline & & Taxa de customização \\
\hline & & $\begin{array}{l}\text { Capacidade de controle de } \\
\text { mudanças }\end{array}$ \\
\hline & \multirow[b]{2}{*}{ Testabilidade } & Autoteste de inicialização \\
\hline & & $\begin{array}{l}\text { Disponibilidade de um pacote para } \\
\text { testes }\end{array}$ \\
\hline
\end{tabular}


Bertoa define características e subcaracterísticas em seu modelo de qualidade para componentes COTS, e para cada subcaracterística são definidos seus atributos de qualidade. Bertoa também define para cada atributo de qualidade uma métrica que possui a escala de medição para a característica de qualidade correspondente.

Os significados de algumas características, de acordo com a norma ISO/IEC 9126-1, foram alterados por Bertoa, como, por exemplo, usabilidade e manutenibilidade. A usuabilidade, segundo o autor, é considerada no desenvolvimento de software utilizando componentes. Os usuários finais de componentes são os desenvolvedores e projetistas que os utilizam para construir a aplicação, e não apenas usuários finais que interagem com a aplicação. Em relação à manutenibilidade, Bertoa ressalta que os usuários de componentes (desenvolvedores) não necessitam fazer modificações internas, mas eles precisam adaptá-lo, reconfigurá-lo e executar os testes no componente antes que ele seja incluído em um produto final. Assim, modificabilidade e testabilidade são definidas como subcaracterísticas que devem ser medidas para a característica manutenibilidade.

Outro trabalho realizado na área de qualidade de componentes é o de Simão (2003). Ele identificou e organizou características de qualidade de maior relevância para componentes de software baseado em um levantamento bibliográfico especializado da área. Realizou ainda, uma pesquisa de campo, com especialistas em DBC, visando uma categorização dessas características de qualidade, cujos resultados foram obtidos através de um modelo de avaliação da qualidade de software.

As características de qualidade apresentadas por Simão também foram organizadas segundo a norma ISO/IEC 9126-1, por ser um padrão estabelecido internacionalmente. Em seu trabalho foram levantados cento e vinte e quatro atributos de qualidade para componentes de software, que estão organizados nas seis características de qualidade da ISO/IEC 9126-1. Foram propostas noventa e uma novas subcaracterísticas de qualidade somadas com as vinte e sete da norma ISO/IEC 9126-1 totalizando cento e dezoito subcaracterísticas de qualidade. 
O autor ressalta que, houve a necessidade de definir novas subcaracterísticas para componentes de software, além das já definidas para produtos de software em geral. Entretanto, não houve a necessidade de se acrescentar novas características de qualidade ao padrão ISO, observando-se a aplicabilidade de todas as características e subcaracterísticas já definidas nessa norma.

Segundo Simão (2003), devido à especificidade de componentes de software, alguns conceitos utilizados tomaram um caráter mais abrangente do que os propostos pela norma ISO/IEC 9126-1 e por algumas bibliografias especializadas. Por exemplo, a usabilidade, deve abranger não somente a interação com o usuário final, mas também a manipulação do componente, pelos desenvolvedores, durante as diversas atividades do ciclo de vida de desenvolvimento de uma aplicação baseada em componentes. Outro exemplo é a característica portabilidade, que visa o transporte do produto de software entre ambientes. Sua interpretação foi estendida para capturar os aspectos técnicos necessários à reutilização de componentes em diversas aplicações.

O trabalho realizado por Simão define um conjunto de características de qualidade de componentes de software relativamente extenso, mas, de acordo com o autor, ele pode ser usado total ou parcialmente para a definição de guias de qualidade e para a avaliação da qualidade de componentes de software.

Foram definidas também no trabalho de Simão, três dimensões de qualidade que podem influenciar diretamente no grau de importância das características de qualidade para os componentes de software:

- domínio da aplicação: corresponde ao conjunto de características peculiares do domínio de aplicação;

- função arquitetural: distribuída pelas camadas de interface, negócio, dados, e infra-estrutura, envolvendo seus padrões de interação; 
- nível de abstração: o componente pode ser reutilizado em suas formas de especificação, projeto e código.

Com o objetivo de investigar meios efetivos para demonstrar a aplicabilidade da certificação de componentes para a indústria de software, Alvaro (Alvaro, 2006) propõe em seu trabalho um modelo de qualidade de componentes de software, identificando características, subcaracterísticas, atributos de qualidade e métricas relacionadas que compõe o modelo. Seu trabalho, diferentemente dos anteriores, foi desenvolvido em conjunto com a indústria e a academia, com o propósito de gerar um modelo bem definido capaz de avaliar componentes da indústria de software.

Segundo o autor, o modelo de qualidade de componentes é parte de um framework para certificação de componentes de software que está sendo investigado em conjunto com o grupo RiSE (Reuse in Software Engineering group) grupo de pesquisa sobre reuso da Universidade Federal de Pernambuco (UFPE)(http://www.cin.ufpe.br/ rise).

O modelo de qualidade de componentes proposto por Alvaro, também é baseado na norma ISO/IEC 9126-1 e algumas adaptações para componentes foram efetuadas. Assim como o modelo de Bertoa (2002), o modelo de qualidade de componentes proposto por Álvaro também está dividido em duas classes: características de qualidade que podem ser observadas em tempo de execução, e características de qualidade que podem ser observadas durante 0 ciclo de vida do produto. O modelo proposto possui também as mesmas características da norma ISO/IEC 9126-1: funcionalidade, confiabilidade, usabilidade, eficiência, manutenibilidade e portabilidade.

De acordo com Alvaro, embora o modelo proposto esteja baseado na norma ISO/IEC 9126-1, algumas mudanças foram feitas com o objetivo de desenvolver um modelo consistente para avaliar componentes de software. Foram identificadas algumas características relevantes para o contexto de componentes, eliminando outras características e subcaracterísticas não interessantes para a avaliação de componentes. Na Tabela 4.2 é apresentado o modelo proposto por Alvaro. 
Tabela 4.2 - Modelo de Qualidade de Componentes. Adaptado de (Alvaro, 2006))

\begin{tabular}{|c|c|c|}
\hline Característica & $\begin{array}{l}\text { Subcaracterística } \\
\text { (tempo de execução) }\end{array}$ & $\begin{array}{l}\text { Subcaracterística } \\
\text { (ciclo de vida) }\end{array}$ \\
\hline Funcionalidade & $\begin{array}{l}\text { Acurácia } \\
\text { Segurança }\end{array}$ & $\begin{array}{l}\text { Adequabilidade } \\
\text { Interoperabilidade } \\
\text { Conformidade } \\
\text { Autocontido }\end{array}$ \\
\hline Confiabilidade & $\begin{array}{l}\text { Tolerância a falhas } \\
\text { Recuperabilidade }\end{array}$ & Maturidade \\
\hline Usabilidade & Configurabilidade & $\begin{array}{l}\text { Inteligibilidade } \\
\text { Apreensibilidade } \\
\text { Operabilidade }\end{array}$ \\
\hline Eficiência & $\begin{array}{lll}\text { Comportamento em relação } \\
\text { ao tempo } \\
\text { Comportamento em relação } \\
\text { aos recursos } & & \\
\text { Escalabilidade } & & \\
\end{array}$ & \\
\hline Manutenibilidade & Estabilidade & $\begin{array}{l}\text { Modificabilidade } \\
\text { Testabilidade }\end{array}$ \\
\hline Portabilidade & Implantabilidade(Deployability) & $\begin{array}{l}\text { Substituibilidade } \\
\text { Adaptabilidade } \\
\text { Reusabilidade }\end{array}$ \\
\hline
\end{tabular}

As novas subcaracterísticas identificadas por Alvaro são apresentadas na Tabela 4.02 em negrito. Segundo o autor, essas subcaracterísticas foram adicionadas pela necessidade de avaliar propriedades que não foram cobertas pela ISO/IEC 9126-1. Por exemplo, a subcaracterística autocontido é intrínseca de um componente e deve ser analisada. Outras subcaracterísticas, a configurabilidade é essencial para o desenvolvedor analisar se o componente pode ser facilmente configurado. A escalabilidade é relevante porque expressa a habilidade do componente de prover suporte a maiores volumes de dados, e pensando que componentes são desenvolvidos para serem reutilizados, a subcaracterística reusabilidade é também considerada.

$\mathrm{Na}$ característica manutenibilidade, a subcaracterística analisabilidade desapareceu para adequar o modelo para o contexto de componentes. Nesse contexto, o autor fala que o resultado da avaliação dessa subcaracterística será insignificante, porque um componente é desenvolvido para atender certas 
funcionalidades da aplicação e, raramente são desenvolvidos métodos para sua auto-análise ou para identificar partes para serem modificadas.

Uma subcaracterística do modelo proposto por Alvaro teve seu nome e significado mudado nesse novo contexto, ela está apresentada em itálico na Tabela 4.2. A subcaracterística Instalabilidade passou a ser chamada de implantabilidade (Deployability). Depois de desenvolvido, os componentes são implantados (deployed), e não instalados, em um ambiente de execução para tornar possível seu uso por outras aplicações que serão desenvolvidas futuramente. Através dessa modificação, 0 entendimento dessa subcaracterística se torna mais claro para o contexto de componentes.

Alvaro, em seu trabalho, criou também um outro nível de característica que não foi apresentado na Tabela 4.2. Esse novo nível chama-se Business. Essa característica, segundo Alvaro, apresenta algumas subcaracterísticas que são importantes para um processo de certificação, tais como: Tempo de Desenvolvimento, Custo, Tempo de mercado, Mercado alvo e Disponibilidade. O autor comenta que essas informações não são importantes para avaliar a qualidade do componente em si, mas são importantes para analisar alguns fatores que trazem credibilidade para os clientes de componentes (desenvolvedores e projetistas).

\subsection{Considerações Finais}

Este capítulo destacou a importância na observação da qualidade dos componentes de software e apresentou alguns trabalhos e pesquisas relacionadas ao tema de qualidade de componentes. Um dos trabalhos de grande contribuição para a comunidade de componentes é o de Bertoa, que define um conjunto de características de qualidade, baseado na norma ISO/IEC 9126-1, para um modelo de qualidade para componentes COTS.

Apesar de Bertoa definir seu modelo baseado na norma ISO/IEC 9126-1, algumas características e subcaracterísticas da norma não foram adotadas por Bertoa para seu modelo, por exemplo, a característica portabilidade, sendo que suas subcaracterísticas são relevantes para avaliar a reutilização de componentes. 
Outro trabalho citado é o de Simão que identificou e organizou características de qualidade de componentes, baseado em um levantamento bibliográfico especializado da área. Simão não definiu um modelo de qualidade, apenas identificou características de maior relevância para componentes de software. Assim como Bertoa, Simão também se baseou na norma ISO/IEC 9126-1, mas manteve todas as características e subcaracterísticas da norma e ainda acrescentou novas subcaracterísticas devido a especificidade de componentes.

Com o foco na certificação, Alvaro também define um modelo de qualidade para componentes de software que é utilizado como parte de um framework para certificação de componentes.

Apesar da importância desses trabalhos para o alcance da qualidade de componentes de software, um ponto relevante que eles não trataram com a importância necessária é a qualidade da documentação dos componentes de software, que é fundamental para a reutilização e aceitação dos componentes na indústria de software.

Com base nessas pesquisas relacionadas à qualidade de componentes de software, também nas normas internacionais apresentadas no capítulo 3, e de acordo com a definição de componentes adotada no capítulo 2, é apresentado, no próximo capítulo, o modelo de qualidade para componentes de software formalizado neste trabalho. 


\section{Capítulo 5}

\section{Modelo de Qualidade para Componentes de Software}

\subsection{Considerações Iniciais}

Segundo a norma internacional ISO/IEC 9126-1, é recomendado que, para a avaliação da qualidade de um produto de software, seja definido um modelo de qualidade e que esse modelo seja usado na definição das metas de qualidade para o produto avaliado.

De acordo com o objetivo deste trabalho, neste capítulo é apresentado o modelo de qualidade definido para componentes de software e sua estrutura que é composta por: características, subcaracterísticas, atributos e métricas de qualidade específicas para avaliar a qualidade de componentes de software.

\subsection{Introdução}

Desde que se tornou freqüente 0 uso de componentes no desenvolvimento de sistemas, as empresas passaram a se preocupar com a qualidade dos componentes de software, pois as características dos mesmos influenciam na qualidade do produto de software final.

A definição de um modelo de qualidade específico para componentes de software é o passo principal para avaliar a qualidade desses componentes que serão utilizados em diferentes ambientes e contextos. É possível encontrar na literatura a existência de normas internacionais que definem vários modelos ou diretrizes de qualidade, sendo porém gerais e não orientadas a domínios específicos, como por exemplo, o DBC. 
Com o intuito de auxiliar na avaliação da qualidade dos componentes de software desenvolvidos com a finalidade de serem reutilizados, um modelo de qualidade específico para componentes foi definido, a fim de atender a essa necessidade.

\subsection{Modelo de Qualidade para Componentes de Software}

O modelo de qualidade proposto está embasado nas normas internacionais ISO/IEC 9126-1 (ISO, 2001) e NBR ISO/IEC 12119 (ISO, 1994), em pesquisas realizadas na área de qualidade de componentes de software, tais como (Bertoa, 2002), (Simão, 2003) e (Alvaro, 2006), e também no modelo de qualidade de produtos de software MEDEPROS (Rêgo, 1996)

O modelo proposto é formado por características, subcaracterísticas, atributos e métricas de qualidade. Além disso, para definir e categorizar melhor essas características de qualidade seguiu-se uma terminologia padrão também definida pela norma ISO/IEC 9126-1.

De acordo com a ISO/IEC 9126-1, uma característica de qualidade é um conjunto de propriedades de um produto de software pela qual sua qualidade pode ser descrita e avaliada. Uma característica pode ser refinada em múltiplos níveis de subcaracterísticas.

Um atributo é uma propriedade mensurável, física ou abstrata, de uma entidade, no caso um componente de software. Uma métrica é composta por um método (procedimento cujo objetivo é examinar o componente para produzir um único resultado) e uma escala de medição (conjunto de valores com propriedades definidas). Uma métrica está associada a um atributo para poder medir esse atributo.

Um modelo de qualidade é um conjunto de características, assim como os relacionamentos entre elas, que fornecem a base para especificar requisitos de qualidade e para avaliar a qualidade. $O$ modelo de qualidade usado dependerá do tipo de produto alvo a ser avaliado. 
Na Figura 5.1, é ilustrada a estrutura da terminologia definida pela ISO/IEC 9126-1.

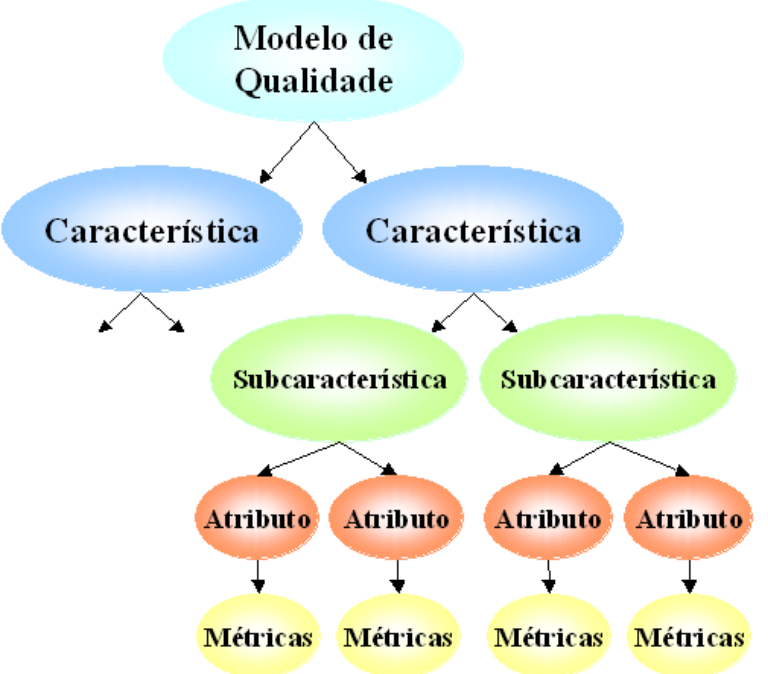

Figura 5.1 - Estrutura definida pela Norma ISO/IEC 9126-1. (Adaptado de (ISO, 2001)).

De acordo com a definição de Villela (2000), adotada neste trabalho, um componente de software reutilizável são artefatos autocontidos, claramente identificáveis, que descrevem ou realizam uma função específica e têm interfaces claras em conformidade com um dado modelo de arquitetura de software, documentação apropriada e um grau de reutilização definido". Notase que, um componente $n$ é formado apenas de um pacote executável, ele é composto também de um conjunto de documentos apropriados para a sua reutilização. Holanda (Holanda et al., 2001) e Kallio (Kallio, 2001), também abordam a necessidade de uma documentação de qualidade para componentes de software.

Assim, para que um componente de software seja de qualidade, ele necessita ter uma documentação apropriada e assim, para avaliar a qualidade de um componente de software é necessário avaliar também a sua documentação. 
Como o foco deste trabalho é nos componentes de software reutilizáveis do tipo caixa-preta, a norma internacional ISO/IEC 12119, específica para produtos disponíveis como pacotes fechados, sugere a existência de um documento de descrição do produto, que é parte do conjunto de documentação, fornecendo informações importantes antes da aquisição do produto.

Dessa forma, o modelo de qualidade proposto apresenta características, subcaracterísticas, atributos e métricas de qualidade para três tipos de artefatos que compõem o "produto" componente de software:

1) Documento de Descrição do Componente;

2) Documentação do Componente; e

3) Componente.

1) Descrição do componente: é um documento expondo as propriedades de um componente, com o principal objetivo de auxiliar os potenciais compradores/usuários na avaliação da adequação do componente antes de sua aquisição (adaptado da ISO/IEC 12119 (ISO, 1994)).

2) Documentação do componente: é um conjunto de documentos que contém toda informação necessária para a utilização / reutilização do componente, por exemplo: especificação do componente, manuais de implantação e configuração, manuais de ajuda, etc.

3) Componente de software: é o artefato executável, autocontido, que realiza uma função específica e provê interfaces claras em conformidade com um dado modelo de arquitetura de software. Em outras palavras, é a implementação do componente.

Como este trabalho está focado em componentes de software do tipo caixa-preta, as características e atributos de qualidade interna não são tratadas, somente características de qualidade externa (qualidade das características do ponto de vista externo) e também de qualidade em uso (visão da qualidade sob a perspectiva do usuário). 
A identificação das características e subcaracterísticas de qualidade para componentes de software foram o primeiro passo para obtenção do modelo de qualidade. Para isso, foram pesquisados trabalhos na área de qualidade de produtos (ISO, 1994), (Rêgo, 1996), (ISO, 2001), e também trabalhos na área de qualidade de componentes de software, tais como (Bertoa, 2002), (Simão, 2003) e (Alvaro, 2006).

As características e subcaracterísticas de qualidade para os atributos "Descrição" e "Documentação" do componente foram definidas principalmente com base nas normas ISO/IEC 12119 (ISO, 1994) e IEEE 1063 (IEEE, 2001). As características e subcaracterísticas de qualidade externa e qualidade em uso para o artefato "Componente de Software" são basicamente as mesmas do modelo da ISO/IEC 9126-1, com algumas mudanças nos significados para se adequar ao novo contexto de componentes. A retirada da característica manutenibilidade e de algumas subcaracterísticas deve-se ao fato das mesmas não serem aplicadas ao contexto de componentes adotado neste trabalho.

O modelo completo é composto de doze características de qualidade refinadas em vinte e duas subcaracterísticas para os três artefatos do modelo proposto. O modelo pode ser aplicado de forma completa ou parcial, utilizando apenas as características mais pertinentes, atendendo da melhor maneira os objetivos das avaliações.

$\mathrm{Na}$ Figura 5.2, é apresentada a estrutura do modelo de qualidade externa para componentes de software até o nível de subcaracterísticas. As características de qualidade em uso do modelo de qualidade definido são as mesmas características da norma ISO/IEC 9126-1 e são apresentadas na Figura 5.3. 




Figura 5.2 - Modelo de Qualidade Externa para Componentes de Software.

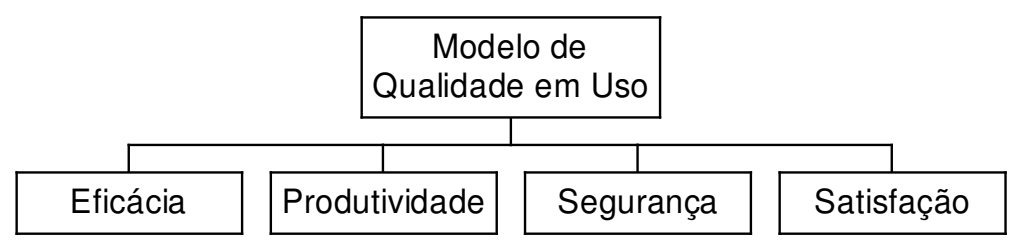

Figura 5.3 - Modelo de Qualidade em Uso para Componentes de Software (Adaptado de (ISO, 2001)). 
Como pode-se observar na Figura 5.2, os três tipos de artefatos que formam o componente estão no primeiro nível da hierarquia. Abaixo de cada um estão suas características, representadas dentro do retângulo e as respectivas subcaracterísticas, em um nível abaixo, fora do retângulo.

No modelo de qualidade, algumas características são aplicadas em mais de um artefato, como é o caso de "Usabilidade" e "Existência". Outras, dependendo do artefato, podem estar em diferentes níveis de refinamento, como é o caso de "Identificações e Indicações".

As características de qualidade em uso da norma ISO/IEC 9126-1 são aplicadas também a componentes de software pois avaliam a satisfação do usuário em contextos de uso de uma forma geral, por isso, são adotadas no modelo de qualidade para componentes, como é possível observar na Figura 5.3.

Nas subseções a seguir, são apresentadas as definições das características e subcaracterísticas de qualidade externa e qualidade em uso do modelo de qualidade para componentes.

\subsubsection{Características e Subcaracterísticas de Qualidade do Modelo}

A descrição de cada característica e subcaracterística do modelo de qualidade proposto são dadas a seguir, juntamente com a explicação das mudanças realizadas com relação à norma ISO/IEC 9126-1.

\section{Descrição do Componente}

1.1. Existência: Essa característica tem por objetivo verificar a existência do documento de descrição do componente.

1.2. Conteúdo: Essa característica tem por objetivo verificar a clareza e organização do conteúdo da descrição do componente.

1.2.1. Inteligibilidade: Capacidade da descrição do componente de permitir uma fácil compreensão de seu conteúdo.

1.3. Identificação e Indicação: Essa característica tem por objetivo verificar se a descrição do componente possui indicações sobre o componente, suas funcionalidades, seu produtor, etc. 
1.4. Declaração: Essa característica tem por objetivo verificar se a descrição do componente possui declarações sobre requisitos funcionais e não funcionais do componente.

\section{Documentação do Componente}

2.1. Existência: Essa característica tem por objetivo verificar se 0 componente tem uma documentação que o acompanha.

2.2. Completitude: Essa característica tem por objetivo verificar se na documentação do componente contém todas as informações necessárias para a sua utilização/reutilização.

2.2.1. Identificação e Indicações: Essa subcaracterística tem por objetivo verificar se na documentação contém identificações e indicações importantes sobre o componente, como por exemplo, nome do componente, versão e data de criação do componente, produtor/fornecedor do componente, composição do componente, etc.

2.2.2. Descrição sobre Funcionalidade: Essa subcaracterística tem por objetivo verificar se na documentação do componente possui descrições sobre sua funcionalidade, suas interfaces, etc.

2.2.3. Descrição sobre Usabilidade: Essa subcaracterística tem por objetivo verificar se na documentação do componente possui descrições de como utilizar o componente, por exemplo, informações sobre implantação, adaptação, direitos autorais, etc.

2.3. Usabilidade: Essa característica tem por objetivo verificar a usabilidade da documentação, ou seja, se ela é de fácil compreensão e manuseio pelos seus usuários.

\section{Componente de Software}

3.1. Funcionalidade: Capacidade do componente de prover serviços (funções) que satisfaçam as necessidades especificadas para sua funcionalidade.

A característica Funcionalidade mantém o mesmo significado da ISO/IEC 9126 para componentes, pois o componente, assim como o software, também tem que ter suas funções adequadas em relação à sua especificação, precisão nos resultados, segurança das informações e dados 
e, ser capaz de interagir com outros componentes para que juntos possam compor um sistema como um todo.

3.1.1. Adequação: Capacidade do componente de prover um conjunto apropriado de interfaces para atender o seu objetivo especificado.

3.1.2. Acurácia: Capacidade do componente prover, com o grau de precisão necessário, resultados ou efeitos corretos ou conforme acordados.

3.1.3. Interoperabilidade: Capacidade do componente interagir com um ou mais componentes ou sistemas especificados.

3.1.4. Segurança de acesso: Capacidade do componente de proteger informações e dados, de forma que pessoas, componentes ou sistemas não autorizados não possam lê-los nem modificá-los e que não seja negado o acesso às pessoas, componentes ou sistemas autorizados.

3.1.5. Conformidade relacionada à funcionalidade: Capacidade do componente de estar de acordo com normas, convenções ou regulamentações previstas em leis e prescrições similares relacionadas à sua funcionalidade.

3.2. Confiabilidade: Capacidade do componente de evoluir, ser tolerante a falhas e se recuperar.

A característica Confiabilidade é diretamente aplicada a componentes, pois para que um componente seja reutilizado, é essencial que ele seja confiável.

3.2.1. Maturidade: Capacidade do componente de evoluir, entre suas versões, por meio de correções de falhas e atualizações de suas funcionalidades.

3.2.2. Tolerância a falhas: Capacidade do componente de manter um nível de desempenho especificado (prevenindo falhas e tratando erros) em casos de defeitos no componente ou de violação de suas interfaces.

3.2.3. Recuperabilidade: Capacidade do componente de, no caso de uma falha, restabelecer seu nível de desempenho especificado e recuperar seu estado.

3.3. Usabilidade: Capacidade do componente de ser compreendido, aprendido e operado pelo usuário, sob condições especificadas.

A característica Usabilidade e suas subcaracterísticas têm um significado diferente para componentes de software. A razão é que, no 
desenvolvimento de software baseado em componentes, os usuários finais de componentes são, na maioria das vezes, os desenvolvedores e projetistas de aplicações, ao invés de usuários que interagem com a aplicação. Assim, a usabilidade de um componente deverá ser interpretada como a habilidade de ser usado por um desenvolvedor na construção (ou montagem) de um produto de software ou sistema, ou seja, durante o projeto da aplicação.

No contexto de componentes a subcaracterística "Atratividade" não é aplicada, pois atratividade está relacionada com interação do sistema com os usuários finais, o que não acontece com os tipos de componentes considerados neste trabalho, e componentes de interface gráfica não fazem parte da categoria de componentes de software reutilizáveis. A interação entre os componentes já é analisada em outras subcaracterísticas, como por exemplo interoperabilidade.

3.3.1. Inteligibilidade: Capacidade do componente de possibilitar ao usuário compreender se o mesmo é apropriado e como ele pode ser usado para tarefas e condições de uso específicas. A inteligibilidade dependerá da documentação (como, exemplos de uso, demos, etc).

3.3.2. Apreensibilidade: Capacidade do componente de possibilitar ao usuário aprender sua utilização.

Aprender sua utilização diz respeito a onde utilizar e como utilizar o componente (por exemplo, em qual camada da arquitetura e com qual finalidade e, como ele pode ser integrado).

3.3.3. Operacionalidade: Capacidade do componente de possibilitar ao usuário operá-lo e controlá-lo.

Os componentes são operados e controlados pelas suas interfaces (providas e requeridas).

3.4. Eficiência: Capacidade do componente de apresentar desempenho apropriado, relativo à quantidade de recursos usados, sob condições especificadas (recurso diz respeito à configuração de hardware e software).

A característica Eficiência e suas subcaracterísticas também são aplicadas aos componentes com o mesmo significado que é dado pela 
norma ISO/IEC 9126, pois os componentes, assim como um produto de software, também têm que apresentar um desempenho apropriado com relação aos recursos utilizados.

3.4.1. Comportamento em relação ao tempo: Capacidade do componente de fornecer tempos de resposta e de processamento, além de taxas de transferência, apropriados, quando o componente executa suas funções, sob condições estabelecidas.

3.4.2. Utilização de recursos: Capacidade do componente de usar tipos e quantidades apropriados de recursos, quando o componente executa suas funções sob condições estabelecidas.

A característica Manutenibilidade diz respeito à capacidade do produto de ser modificado. As modificações podem incluir correções, melhorias ou adaptações do produto devido a mudanças no ambiente e nos seus requisitos ou especificações funcionais.

O usuário do componente (ex. desenvolvedor) não consegue fazer modificações internas no componente (devido à sua característica de caixapreta), mas um componente pode ser adaptado ou substituído por um outro para se adequar ao seu novo ambiente. Como essas características "Adaptabilidade" e "Capacidade para ser substituído" estão relacionadas mais com a portabilidade, a característica manutenibilidade não será aplicada neste contexto de componentes de software reutilizáveis.

3.5. Portabilidade: Capacidade do componente de ser transferido de um ambiente para outro. $\mathrm{O}$ ambiente pode ser organizacional, de hardware ou de software.

A característica Portabilidade é uma propriedade essencial para a natureza dos componentes, os quais são em princípio projetados e desenvolvidos para serem reutilizados em diferentes ambientes. É importante notar que, no desenvolvimento de software baseado em componentes, reutilização significa não somente usar mais que uma vez, mas também usar em diferentes ambientes. 
Devido ao fato dos componentes não serem instalados e sim implantados (Deployed) em um ambiente de execução, a subcaracterística capacidade para ser instalado foi renomeada para capacidade para ser implantado (Deployed) tornando o seu entendimento mais claro para o contexto de componentes.

Dentro da característica portabilidade uma nova subcaracterística foi acrescentada - a Reusabilidade, que tem por objetivo verificar a capacidade do componente de poder ser reutilizado em várias aplicações de diferentes contextos e domínios.

3.5.1. Adaptabilidade: Capacidade do componente de ser adaptado para diferentes ambientes especificados, sem necessidade de aplicação de outras ações ou meios além daqueles fornecidos para essa finalidade pelo componente considerado.

3.5.2. Capacidade para ser implantado: Capacidade do componente para ser implantado em um ambiente de execução especificado.

3.5.3. Coexistência: Capacidade do componente de coexistir com outros produtos de software independentes, em um ambiente comum, compartilhando recursos comuns.

3.5.4. Capacidade para substituir: Capacidade do componente para ser usado em substituição a outro componente especificado, com o mesmo propósito e mesmo ambiente.

3.5.5. Reusabilidade: Capacidade do componente de poder ser reutilizado em várias aplicações de diferentes contextos e domínios.

\section{Qualidade em Uso}

Avaliar a qualidade em uso de componente de software segue o mesmo princípio de avaliar a qualidade em uso de um produto de software, que é, permitir que usuários (no caso de componentes, desenvolvedores e integradores) atinjam metas especificadas com eficácia, produtividade, segurança e satisfação em contextos de uso especificados. 
Dessa forma, as características de qualidade em uso da norma ISO/IEC 9126-1 são aplicadas aos componentes com o mesmo significado que é dado pela norma.

4.1. Eficácia: Eficácia é a capacidade do componente de software de permitir que seus usuários atinjam metas especificadas com acurácia e completitude, em um contexto de uso especificado.

4.2. Produtividade: Produtividade é a capacidade do componente de software de permitir que seus usuários empreguem quantidade apropriada de recursos em relação à eficácia obtida, em um contexto de uso especificado.

Recursos relevantes podem incluir tempo para completar a tarefa, esforço do usuário, materiais ou custos financeiros.

4.3. Segurança (Safety): Segurança é a capacidade do componente de software de apresentar níveis aceitáveis de riscos de danos a pessoas, negócios e software, em um contexto de uso especificado.

Geralmente, os riscos são decorrentes das deficiências na funcionalidade (incluindo segurança de acesso), confiabilidade ou usabilidade, podendo levar a conseqüências econômicas não intencionais.

4.4. Satisfação: Satisfação é a capacidade do componente de software de satisfazer usuários, em um contexto de uso especificado.

Satisfação é a resposta do usuário relacionado ao uso do produto (componente).

Como foi dito anteriormente o modelo de qualidade definido está organizado em uma estrutura hierárquica. O nível mais alto desta estrutura consiste de características de qualidade e o nível mais baixo consiste de atributos de qualidade. Na seção a seguir, são apresentados os atributos e as métricas de qualidade definidos para o modelo de qualidade de componentes. 


\subsubsection{Atributos e Métricas de Qualidade do Modelo}

O segundo e último passo para completar o modelo de qualidade para componentes é a definição dos atributos e métricas de qualidade. Para isso, utilizou-se como base a norma 9126 parte 2 (ISO, 2003) e parte 4 (ISO, 2004) e, principalmente, pesquisas sobre qualidade de componentes de software e DBC, através do entendimento de seus contextos, pois em boa parte, os atributos e suas métricas não estavam explicitamente definidos.

Para cada subcaracterística do modelo de qualidade, foram definidos um ou mais atributos de qualidade e para cada atributo uma ou mais métricas foram propostas, com a finalidade de medir a qualidade externa e qualidade em uso dos componentes de software.

De acordo com a definição da norma ISO/IEC 9126-1, uma métrica é composta de um método e uma escala de medição.

Nas Tabelas 5.1, 5.2, 5.3 e 5.4 são apresentados exemplos de atributos de qualidade e suas respectivas métricas. O modelo de qualidade completo está apresentado no anexo A e é composto de sessenta e cinco atributos e oitenta e três métricas de qualidade para os três artefatos do modelo proposto.

Na primeira coluna das tabelas estão os atributos propriamente ditos. As colunas restantes correspondem à métrica, cujo seu propósito está expressado como uma questão (coluna "Propósito da Métrica") para ser respondida por meio de sua aplicação. A coluna "Método de Aplicação", provê as diretrizes para a aplicação da métrica. Na coluna "Fórmula e/ou elementos de dados para medição", como o próprio nome diz, estão os elementos para a resposta da questão que podem ser tanto dados qualitativos, através de elementos nominais (ex. respostas Sim ou Não), quanto quantitativos, através do uso de fórmulas. Na coluna "Escala de medição" está o conjunto de valores para os tipos de respostas definidos em porcentagem. 
Tabela 5.1 - Atributos para a característica "Funcionalidade / Adequação". (Adaptado de (ISO, 2003))

\begin{tabular}{|c|c|c|c|c|}
\hline \multirow[b]{2}{*}{ Atributo } & \multicolumn{4}{|c|}{ Métrica } \\
\hline & $\begin{array}{l}\text { Propósito da } \\
\text { Métrica } \\
\text { (Questão) }\end{array}$ & Método de Aplicação & $\begin{array}{c}\text { Fórmula e/ou } \\
\text { elementos de } \\
\text { dados para } \\
\text { medição }\end{array}$ & $\begin{array}{l}\text { Escala de } \\
\text { medição }\end{array}$ \\
\hline $\begin{array}{c}\text { Adequação } \\
\text { Funcional }\end{array}$ & $\begin{array}{l}\text { Os serviços das } \\
\text { interfaces do } \\
\text { componente são } \\
\text { suficientemente } \\
\text { adequados para a } \\
\text { funcionalidade que o } \\
\text { mesmo se propõe a } \\
\text { realizar? }\end{array}$ & $\begin{array}{l}\text { O avaliador deve } \\
\text { verificar se os serviços } \\
\text { disponíveis nas } \\
\text { interfaces do } \\
\text { componente atendem a } \\
\text { necessidade específica } \\
\text { do componente. } \\
\text { Confrontar o número de } \\
\text { interfaces adequadas } \\
\text { pelo total de avaliadas. }\end{array}$ & $\begin{array}{l}\text { - Sim; } \\
\text { - Não; }\end{array}$ & $\begin{array}{l}0-100 \% \\
\text { Sim }=100 \% \\
\text { Não }=0 \%\end{array}$ \\
\hline $\begin{array}{l}\text { Cobertura da } \\
\text { Implementação } \\
\text { Funcional }\end{array}$ & $\begin{array}{l}\text { O componente } \\
\text { implementa todos os } \\
\text { serviços de suas } \\
\text { interfaces conforme } \\
\text { especificado em sua } \\
\text { documentação? }\end{array}$ & $\begin{array}{l}\text { O avaliador deve } \\
\text { verificar o número de } \\
\text { serviços implementados } \\
\text { no componente } \\
\text { comparado com o } \\
\text { número de serviços } \\
\text { especificados. }\end{array}$ & $\begin{array}{l}\mathrm{X}=100^{\star}(\mathrm{A} / \mathrm{B}) \\
\text { A: Número de } \\
\text { serviços das } \\
\text { interfaces } \\
\text { implementadas } \\
\text { B: Número total de } \\
\text { serviços das } \\
\text { interfaces descritas } \\
\text { na especificação }\end{array}$ & $\begin{array}{l}0<=X<=100 \% \\
\text { Quanto mais } \\
\text { próximo de } \\
100 \% \text {, melhor }\end{array}$ \\
\hline
\end{tabular}


Tabela 5.2 - Atributo e métricas para a característica "Conteúdo" do artefato Descrição do Componente. (Adaptado de (Rêgo, 1996))

\begin{tabular}{|c|c|c|c|c|}
\hline \multirow[b]{2}{*}{ Atributo } & \multicolumn{4}{|c|}{ Métrica } \\
\hline & $\begin{array}{l}\text { Propósito da } \\
\text { Métrica } \\
\text { (Questão) }\end{array}$ & $\begin{array}{l}\text { Método de } \\
\text { Aplicação }\end{array}$ & $\begin{array}{c}\text { Fórmula e/ou } \\
\text { elementos de } \\
\text { dados para } \\
\text { medição }\end{array}$ & $\begin{array}{c}\text { Escala de } \\
\text { medição }\end{array}$ \\
\hline & $\begin{array}{l}\text { O conteúdo da } \\
\text { descrição do } \\
\text { componente, } \\
\text { permite uma fácil } \\
\text { identificação das } \\
\text { funcionalidades? }\end{array}$ & $\begin{array}{l}\text { O avaliador deve } \\
\text { verificar o conteúdo } \\
\text { da descrição do } \\
\text { componente. }\end{array}$ & $\begin{array}{l}\text { - Sim; } \\
\text { - Não; }\end{array}$ & $\begin{array}{l}0 \text { e } 100 \% \\
\text { Sim }=100 \\
\text { Não }=0\end{array}$ \\
\hline Organização & $\begin{array}{l}\text { O conteúdo da } \\
\text { descrição do } \\
\text { componente, } \\
\text { destaca } \\
\text { informações } \\
\text { relevantes. Ex.: } \\
\text { através do uso de } \\
\text { negrito, itálico, } \\
\text { palavras em letra } \\
\text { maiúscula, } \\
\text { numeração, } \\
\text { sombreamento de } \\
\text { texto? }\end{array}$ & $\begin{array}{l}\text { O avaliador deve } \\
\text { verificar o conteúdo } \\
\text { da descrição do } \\
\text { componente. }\end{array}$ & $\begin{array}{l}\text { - Sim; } \\
\text { - Não; }\end{array}$ & $\begin{array}{l}0 \text { e } 100 \% \\
\text { Sim }=100 \\
\text { Não }=0\end{array}$ \\
\hline
\end{tabular}


Tabela 5.3 - Atributo e métricas para a característica "Completitude / Identificação e Indicação" do artefato Documentação do Componente. (Adaptado da (ISO, 1994), (Rêgo, 1996))

\begin{tabular}{|c|c|c|c|c|}
\hline \multirow[b]{2}{*}{ Atributo } & \multicolumn{4}{|c|}{ Métrica } \\
\hline & $\begin{array}{l}\text { Propósito da } \\
\text { Métrica } \\
\text { (Questão) }\end{array}$ & $\begin{array}{l}\text { Método de } \\
\text { Aplicação }\end{array}$ & $\begin{array}{l}\text { Fórmula e/ou } \\
\text { elementos de } \\
\text { dados para } \\
\text { medição }\end{array}$ & $\begin{array}{l}\text { Escala de } \\
\text { medição }\end{array}$ \\
\hline \multirow{3}{*}{$\begin{array}{l}\text { Identificação do } \\
\text { Componente }\end{array}$} & $\begin{array}{l}\text { As documentações } \\
\text { do componente } \\
\text { estão identificadas } \\
\text { em sua página } \\
\text { inicial com o nome } \\
\text { do componente? }\end{array}$ & $\begin{array}{l}\text { O avaliador deve } \\
\text { verificar o conteúdo } \\
\text { da documentação } \\
\text { do componente. }\end{array}$ & $\begin{array}{l}\text { - Todos; } \\
\text { - Quase Todos; } \\
\text { - Alguns; } \\
\text { - Nenhum; }\end{array}$ & $\begin{array}{l}0-100 \% \\
\text { Todos }=100 \\
\text { Quase Todos = } 70 \\
\text { Alguns }=40 \\
\text { Nenhum }=0\end{array}$ \\
\hline & $\begin{array}{l}\text { Com a versão ou } \\
\text { data de criação do } \\
\text { componente? }\end{array}$ & $\begin{array}{l}\text { O avaliador deve } \\
\text { verificar o conteúdo } \\
\text { da documentação } \\
\text { do componente. }\end{array}$ & $\begin{array}{l}\text { - Todos; } \\
\text { - Quase Todos; } \\
\text { - Alguns; } \\
\text { - Nenhum; }\end{array}$ & $\begin{array}{l}0-100 \% \\
\text { Todos }=100 \\
\text { Quase Todos = } 70 \\
\text { Alguns }=40 \\
\text { Nenhum }=0\end{array}$ \\
\hline & $\begin{array}{l}\text { Com o tipo do } \\
\text { documento? (ex. } \\
\text { manual do usuário, } \\
\text { manual de } \\
\text { implantação, etc.) }\end{array}$ & $\begin{array}{l}\text { O avaliador deve } \\
\text { verificar o conteúdo } \\
\text { da documentação } \\
\text { do componente. }\end{array}$ & $\begin{array}{l}\text { - Todos; } \\
\text { - Quase Todos; } \\
\text { - Alguns; } \\
\text { - Nenhum; }\end{array}$ & $\begin{array}{l}0-100 \% \\
\text { Todos }=100 \\
\text { Quase Todos = } 70 \\
\text { Alguns }=40 \\
\text { Nenhum = } 0\end{array}$ \\
\hline
\end{tabular}


Tabela 5.4 - Atributo e métrica para a característica "Eficácia" de qualidade em uso. (Adaptado de (ISO, 2004))

\begin{tabular}{|c|c|c|c|c|}
\hline \multirow[b]{2}{*}{ Atributo } & \multicolumn{4}{|c|}{ Métrica } \\
\hline & $\begin{array}{c}\text { Propósito da } \\
\text { Métrica } \\
\text { (Questão) }\end{array}$ & $\begin{array}{l}\text { Método de } \\
\text { Aplicação }\end{array}$ & $\begin{array}{l}\text { Fórmula e/ou } \\
\text { elementos de } \\
\text { dados para } \\
\text { medição }\end{array}$ & $\begin{array}{c}\text { Escala de } \\
\text { medição }\end{array}$ \\
\hline Eficácia da tarefa & $\begin{array}{l}\text { Os objetivos das } \\
\text { tarefas do sistema, } \\
\text { no qual o } \\
\text { componente } \\
\text { participa } \\
\text { diretamente, são } \\
\text { alcançados } \\
\text { corretamente? }\end{array}$ & $\begin{array}{l}\text { Teste de usuário } \\
\text { Verificar se os } \\
\text { valores das saídas } \\
\text { da tarefa, na qual o } \\
\text { componente } \\
\text { participa } \\
\text { diretamente, são } \\
\text { completos e } \\
\text { precisos. }\end{array}$ & $\begin{array}{l}\text { - Sim; } \\
\text { - Não; }\end{array}$ & $\begin{array}{l}0-100 \% \\
\text { Sim }=100 \% \\
\text { Não }=0 \%\end{array}$ \\
\hline $\begin{array}{l}\text { Conclusão da } \\
\text { tarefa }\end{array}$ & $\begin{array}{l}\text { As tarefas do } \\
\text { sistema, no qual o } \\
\text { componente } \\
\text { participa } \\
\text { diretamente, são } \\
\text { completadas } \\
\text { conforme } \\
\text { esperadas? }\end{array}$ & $\begin{array}{l}\text { Teste de usuário } \\
\text { Verificar se as } \\
\text { tarefas do sistema } \\
\text { no qual o } \\
\text { componente tem } \\
\text { participação são } \\
\text { completadas } \\
\text { conforme } \\
\text { esperadas }\end{array}$ & $\begin{array}{l}\text { - Sim; } \\
\text { - Não; }\end{array}$ & $\begin{array}{l}0-100 \% \\
\text { Sim }=100 \% \\
\text { Não }=0 \%\end{array}$ \\
\hline
\end{tabular}

\section{4) Considerações Finais}

Neste capítulo, foi apresentado o modelo de qualidade para componentes de software composto por características, subcaracterísticas, atributos e métricas de qualidade específicas para componentes de software. Essas propriedades foram organizadas em uma estrutura hierárquica segundo a estrutura definida na norma ISO/IEC 9126-1, podendo o modelo ser utilizado total ou parcialmente na avaliação da qualidade de componentes de software reutilizáveis.

Vale ressaltar que o modelo de qualidade define características de qualidade não apenas para o artefato componente, mas também para a sua documentação que é essencial para sua reutilização. 
Uma vez definido as características, subcaracterísticas, atributos e métricas de qualidade se faz necessário verificar a aplicabilidade e utilidade do modelo de qualidade através de seu uso por meio de avaliações de componentes de software. As avaliações realizadas são relatadas no capítulo 7 de estudos de casos.

No próximo capítulo, é apresentada a ferramenta desenvolvida para apoiar, não apenas avaliações de qualidade dos componentes, mas também qualquer tipo de avaliação de produtos de software que sejam guiadas por meio de uma estrutura de características e subcaracterísticas de qualidade, semelhante ao da norma ISO/IEC 9126-1. Essa ferramenta será utilizada na execução das avaliações dos estudos de casos. 


\section{Capítulo 6}

\section{Ferramenta de Apoio a Avaliações - BMA}

\subsection{Considerações Iniciais}

Neste capítulo é apresentada a ferramenta de apoio a avaliações - BMA Biblioteca de Módulos de Avaliações - cujo objetivo principal é gerenciar modelos de qualidades e auxiliar na execução de avaliações apoiadas por esses modelos. A ferramenta foi desenvolvida para auxiliar não apenas nas avaliações de componentes, mas de produtos de software em geral, reduzindo assim os esforços, custos e tempo envolvidos.

A ferramenta foi desenvolvida dentro da Divisão de Qualificação de Software (DQS) do Centro de Pesquisa Renato Archer - CenPRA (www.cenpra.gov.br), onde será utilizada para gerenciar os modelos de qualidade definidos pela DQS, e também, automatizar a execução das avaliações realizadas pelos laboratórios credenciados.

Além de seu próprio laboratório de avaliação de produto de software LAQS, a DQS conta atualmente com quatro laboratórios credenciados, distribuídos geograficamente pelo território nacional, os quais na maioria das vezes, realizam a troca de informações através de correios e mensagens eletrônicas. A ferramenta irá minimizar isso, através de sua base de dados central, disponibilizando as avaliações via internet a todos os seus laboratórios credenciados.

\subsection{Visão Geral das Funcionalidades da ferramenta BMA}

O controle e execução manual das atividades de avaliação de um produto de software nem sempre é uma tarefa fácil, principalmente quando a avaliação envolve vários laboratórios de avaliações credenciados em diferentes localidades. Nesse contexto, a disponibilização das informações para 
avaliação, o controle da execução, a coleta e o processamento dos resultados dessas avaliações são onerosas e passíveis de erros ou inconsistências.

Para facilitar essas tarefas, e principalmente facilitar a avaliação da aplicabilidade do modelo de qualidade de componentes, foi desenvolvida a BMA - Biblioteca de Módulos de Avaliações, uma ferramenta que auxilia na automatização de avaliações de produtos de software em geral, não apenas de componentes de software.

Na Figura 6.1 são apresentadas, através de um diagrama de contexto de casos de uso (Larman, 2004), as principais funcionalidades disponíveis na Ferramenta BMA. As funcionalidades destacadas com um preenchimento de fundo, são disponibilizadas via web. O restante das funcionalidades é acessado localmente (computador desktop).

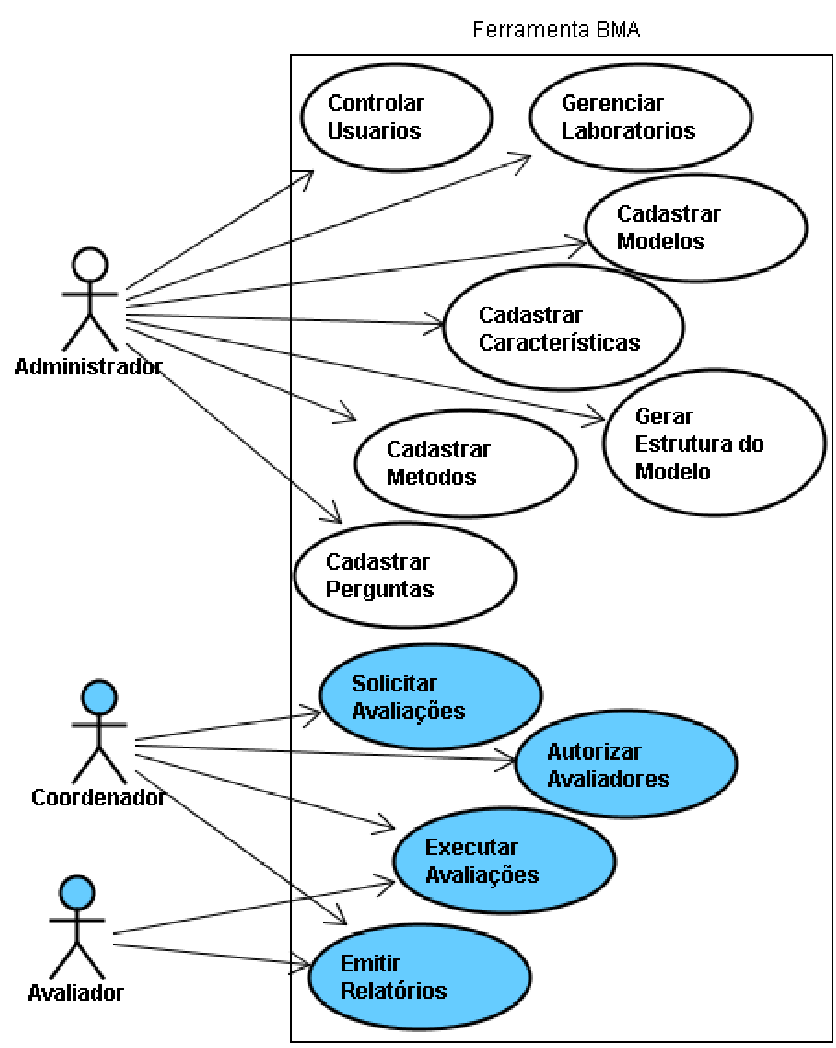

Figura 6.1 - Principais Funcionalidades da Ferramenta BMA. 
Como pode ser observado na Figura 6.1, a ferramenta BMA possui um controle de usuários para gerenciar o acesso as suas funcionalidades de acordo com três tipos de papéis desses usuários:

- Administrador do Sistema: possui um controle geral das funcionalidades da Ferramenta, mas somente ele pode acessar algumas funcionalidades como exemplo: controlar usuários, gerenciar laboratórios credenciados, gerar estrutura do modelo de qualidade, cadastrar método de avaliação, etc.;

- Coordenador de avaliações: o coordenador de avaliações é capaz de gerenciar avaliações através de solicitações de avaliações, autorização de avaliadores para uma avaliação, execução de avaliações aprovadas, emissão de relatórios das avaliações, etc.;

- Avaliador: o avaliador tem acesso somente à execução das avaliações disponibilizadas para ele pelo coordenador e também na emissão de alguns relatórios de avaliações disponíveis na ferramenta.

Uma das principais características da ferramenta BMA é a capacidade de gerenciar diversos modelos de qualidades através das funcionalidades: Cadastrar Modelos e Características de Qualidade e Gerar Estrutura do Modelo, onde é possível inserir, alterar e remover as descrições dos modelos e de suas características de qualidade e também montar a estrutura desse mesmo modelo de qualidade, agrupando suas características em níveis hierárquicos de acordo com a estrutura definida pela ISO/IEC 9126-1. Nas Figuras 6.2, 6.3 e 6.4, são apresentadas as interfaces gráficas (GUIs) para o cadastro de modelo, cadastro de características de qualidade e para a geração da estrutura hierárquica dos modelos de qualidades, respectivamente. 


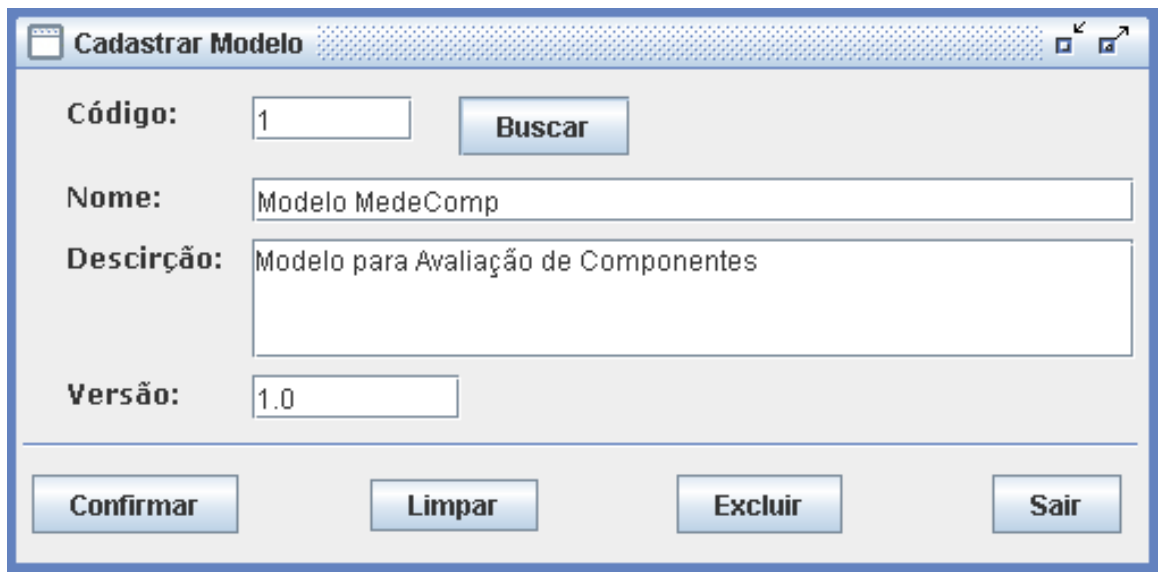

Figura 6.2 - Interface GUI - Cadastrar Modelo.

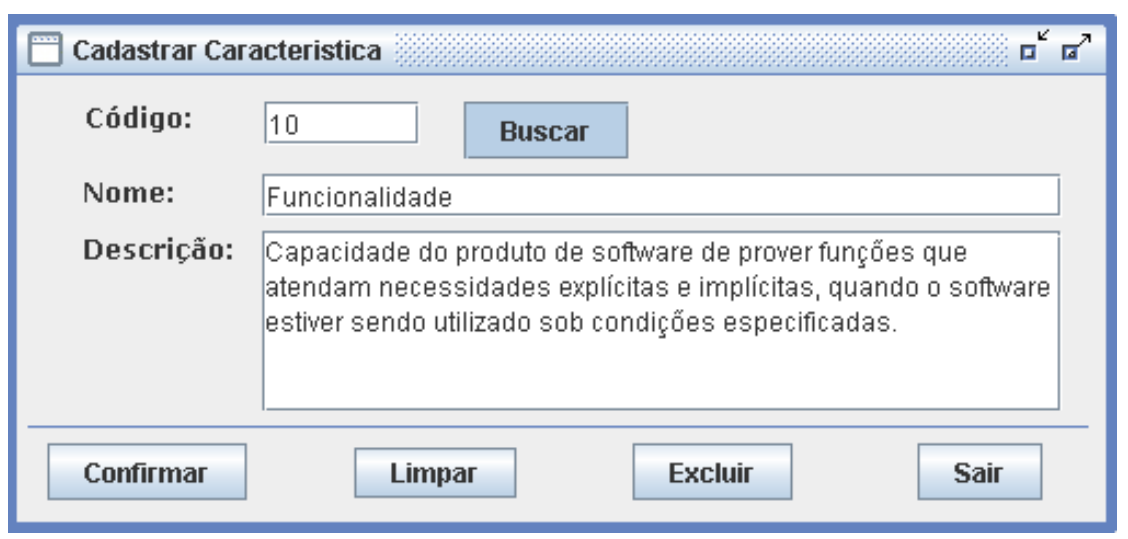

Figura 6.3 - Interface GUI - Cadastrar Característica.

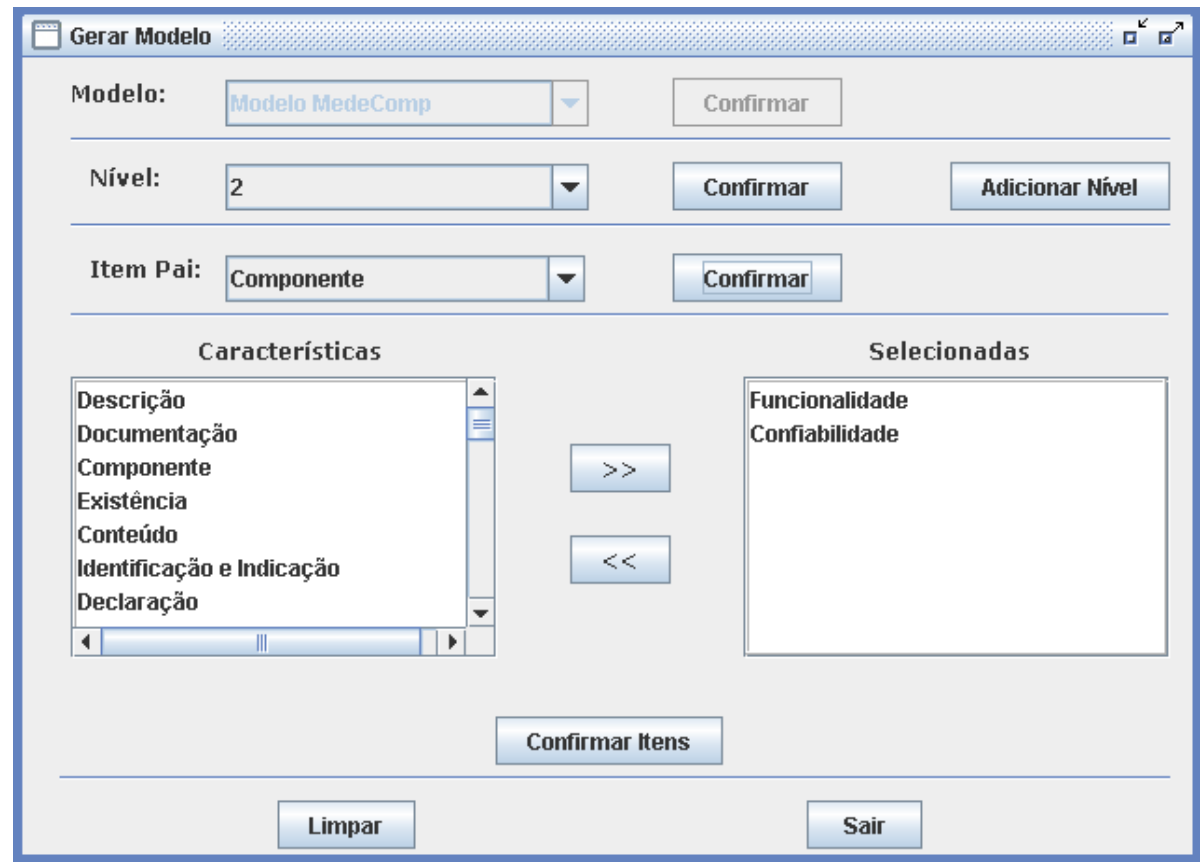

Figura 6.4 - Interface GUI - Gerar Modelo. 
Como pode ser observado na Figura 6.4, para montar a estrutura hierárquica de um modelo, primeiramente, é preciso selecionar o modelo desejado, logo depois, deve-se escolher o nível da hierarquia ao qual as características vão ser adicionadas. Com o nível definido, seleciona qual o item pai, ou seja, característica do nível imediatamente acima que receberá as subcaracterísticas selecionadas. Se o nível for o primeiro, o item pai é o próprio modelo de qualidade. Por fim, selecionam-se as características (ou subcaracterísticas dependendo do nível) e confirma-se a seleção gerando o nível da hierarquia definido.

$\mathrm{Na}$ Figura 6.5, é apresentado o relatório de modelos de qualidade, disponibilizado pela ferramenta, mostrando o resultado da geração da estrutura de um modelo de qualidade.

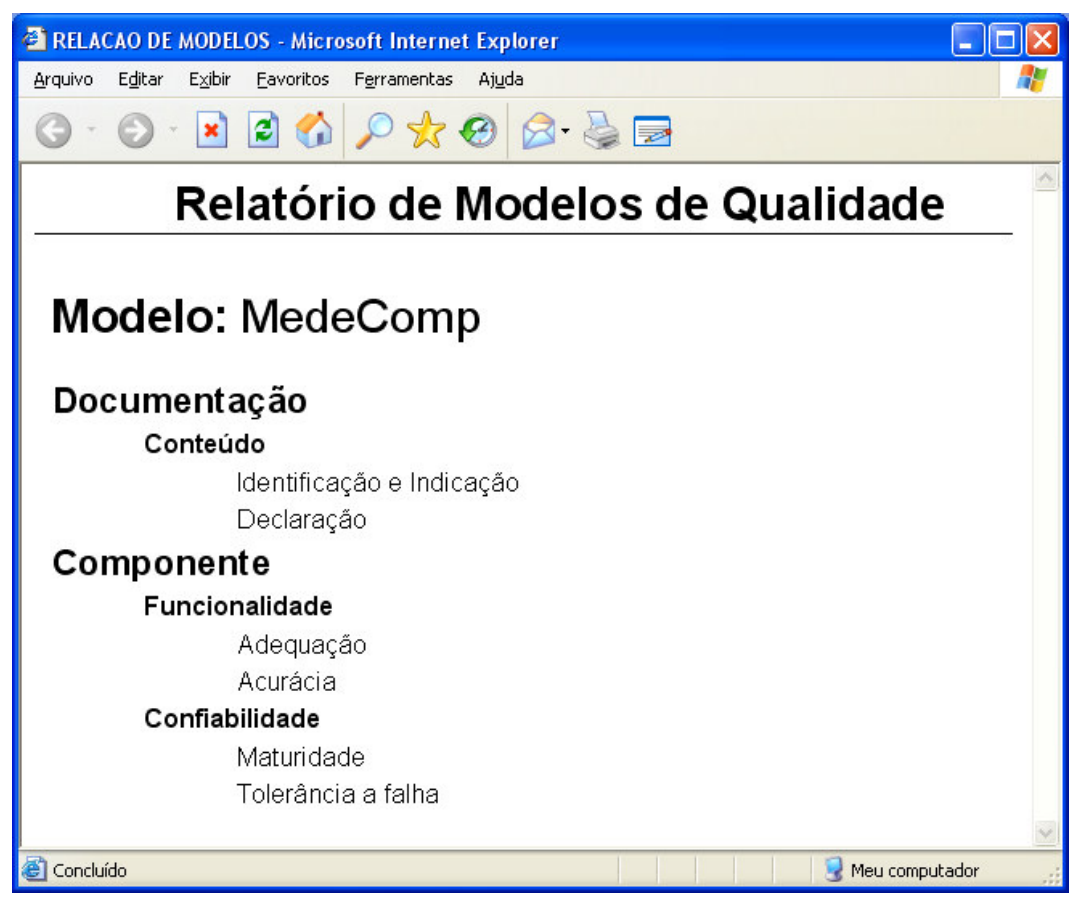

Figura 6.5 - Relatório do Modelo de Qualidade gerado pela Ferramenta BMA.

$\mathrm{Na}$ ferramenta BMA, um modelo de qualidade pode estar associado a um ou mais métodos de avaliação, onde, um método de avaliação é formado por um conjunto de questões e suas respectivas respostas (que são utilizadas como escalas de medidas). Essas questões por sua vez, são associadas aos atributos de qualidade do nível mais baixo (folha) da estrutura do modelo de 
qualidade. As principais funcionalidades da ferramenta que implementam essas regras descritas são: "Cadastrar Métodos" e "Cadastrar Perguntas". As interfaces gráficas dessas funcionalidades são apresentadas nas Figuras 6.6 e 6.7 , respectivamente.

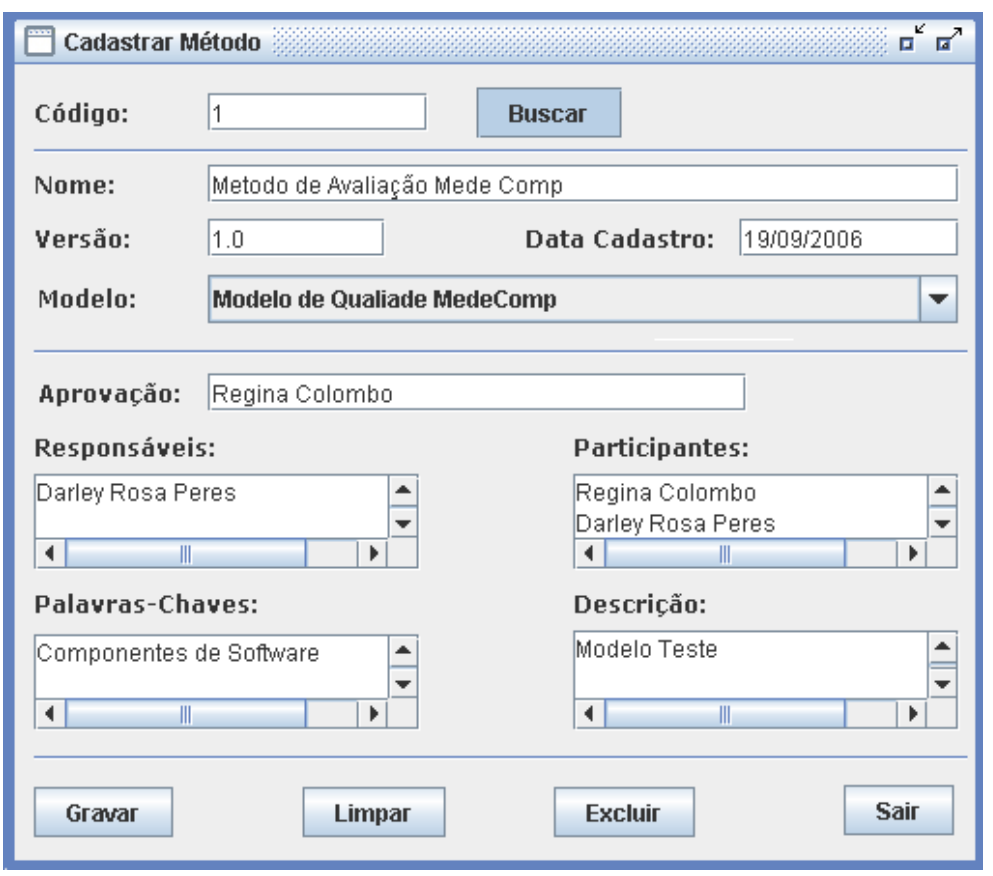

Figura 6.6 - Interface GUI - Cadastrar Método.



Figura 6.7 - Interface GUI - Cadastrar Perguntas. 
Ao cadastrar um método, um modelo deve ser associado a ele. Com isso, no cadastro de perguntas (Figura 6.7), ao selecionar o método referente, os atributos de qualidade (folhas da estrutura do modelo) ficam disponíveis para que suas respectivas perguntas possam ser definidas. Nenhum método pode ser cadastrado sem um modelo. Da mesma forma, as perguntas não podem ser definidas sem um método e os seus atributos de qualidade.

Com o método e, principalmente, o modelo cadastrado a ferramenta está pronta para apoiar a execução de avaliações. Para a disponibilização e execução das avaliações, a ferramenta possui um controle de solicitações de avaliações, realizado via web, onde é informado o produto a ser avaliado e seus dados e também os requisitos necessários para a avaliação, por exemplo, os requisitos de hardware e software. Na Figura 6.8, é apresentada a página web para solicitação de uma avaliação. Essa página só é disponibilizada para um coordenador de avaliação, conforme foi dito anteriormente.

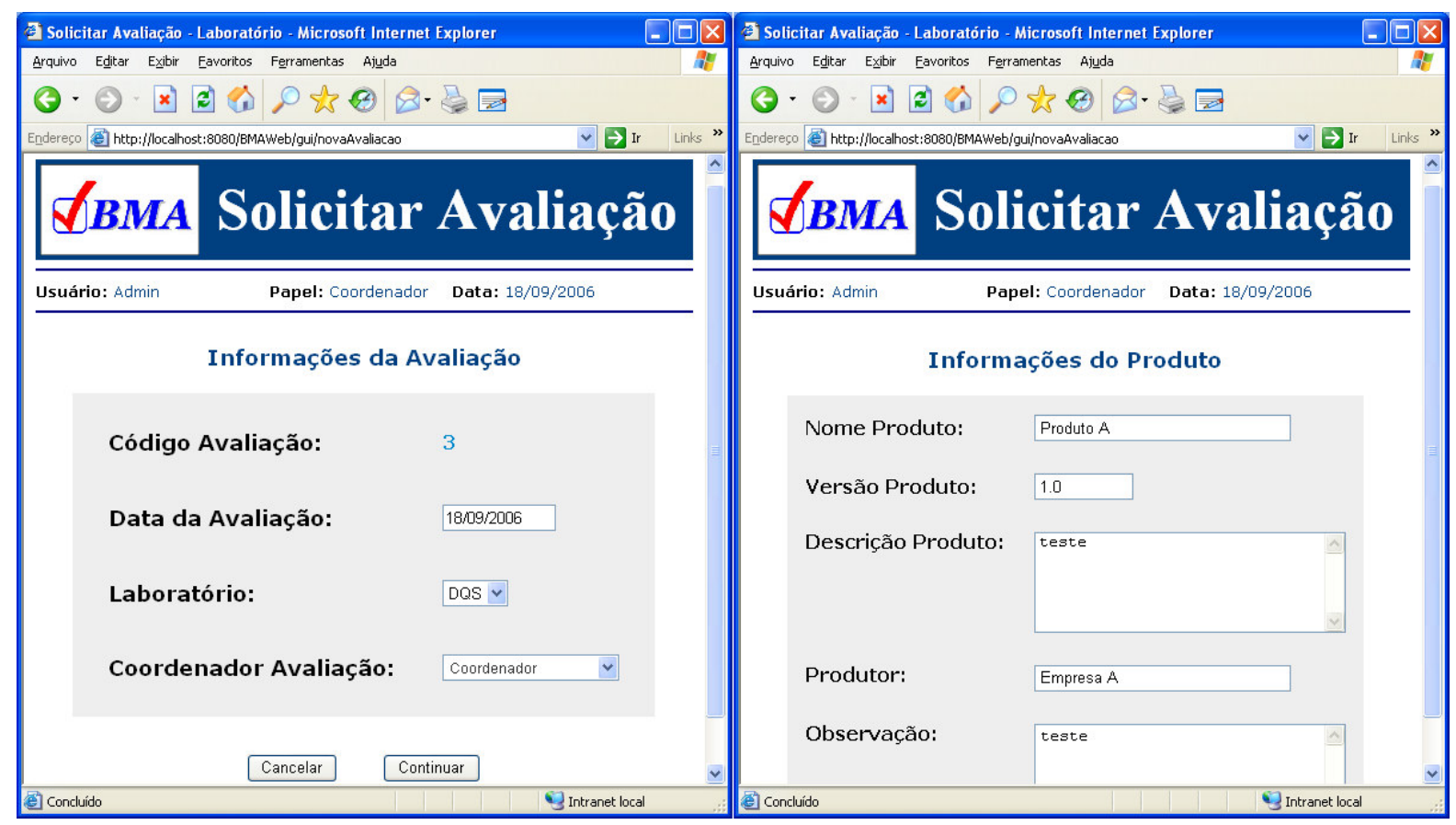

Figura 6.8 - Página de solicitação de uma avaliação. 
Um controle de laboratórios credenciados e de seus avaliadores também é disponibilizado pela ferramenta, pois as avaliações solicitadas só serão disponibilizadas para avaliadores credenciados que forem alocados para a mesma. Na Figura 6.9, são apresentadas as páginas de manutenção de laboratórios e avaliadores.

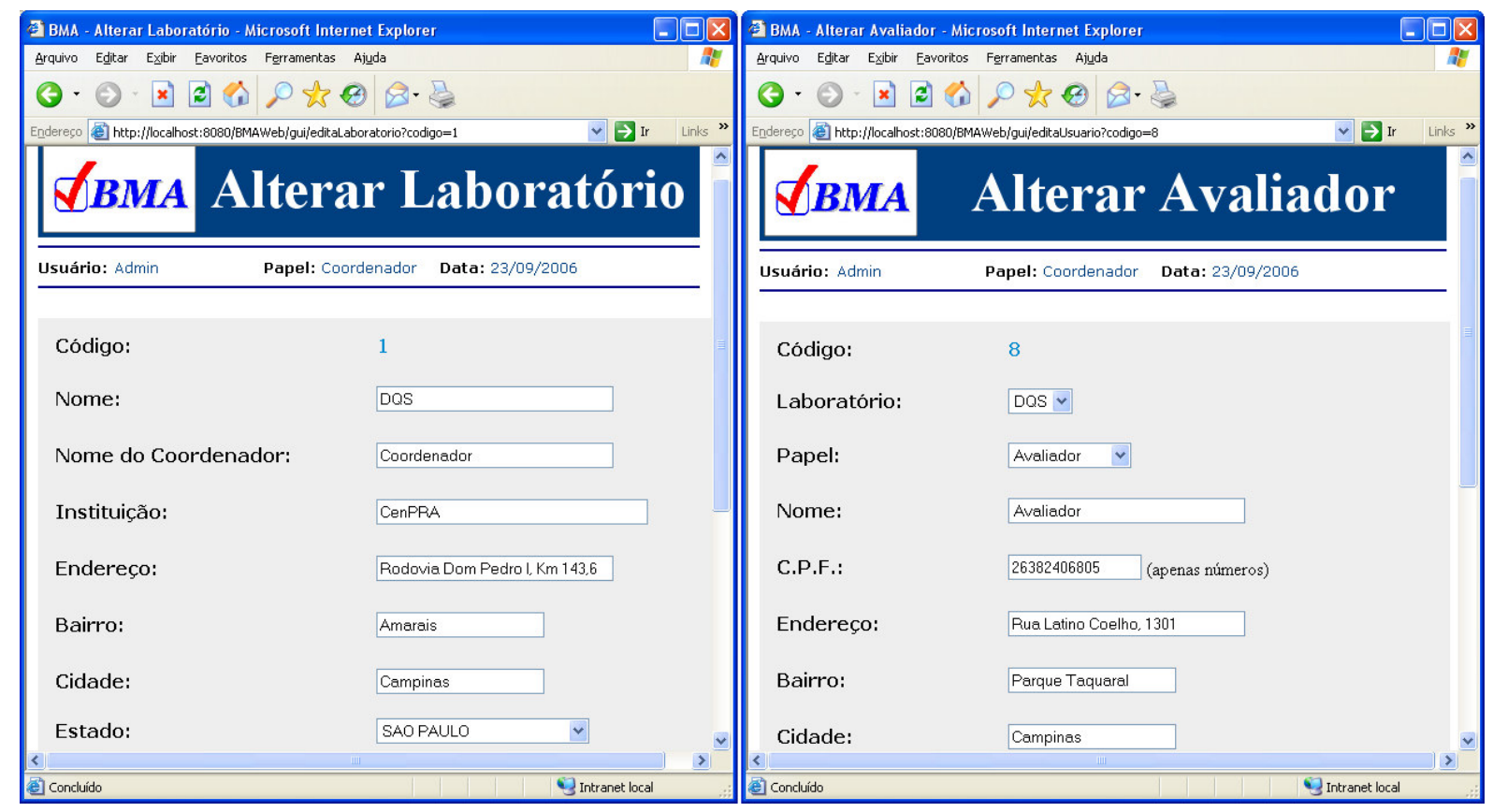

Figura 6.9 - Páginas de manutenção de Laboratórios e Avaliadores.

Com a solicitação e aprovação de uma avaliação, o coordenador solicitante deve autorizar os avaliadores que irão realizar a avaliação. Na figura 6.10 é apresentada a página web de autorização dos avaliadores para uma avaliação. 


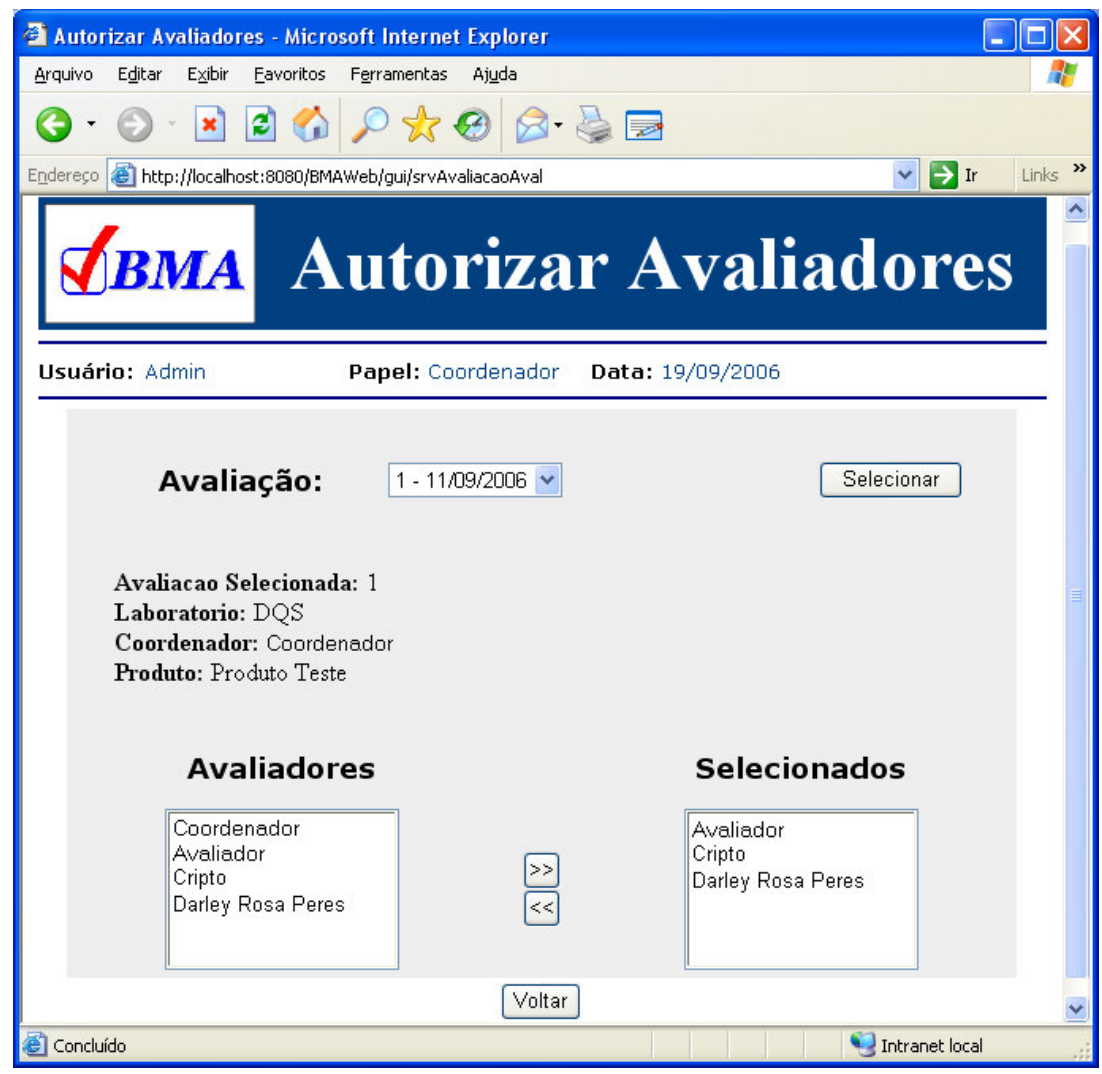

Figura 6.10 - Página de autorização de avaliadores para uma avaliação.

A execução das avaliações através da ferramenta BMA também é realizada via web. Cada avaliador, ao acessar a ferramenta via web através de seu login e senha, visualiza todas as avaliações a ele alocadas, e assim, o avaliador pode iniciar uma nova avaliação ou dar continuidade a uma avaliação já iniciada. A execução de uma avaliação em andamento é apresentada nas Figuras 6.11 e 6.12 . 


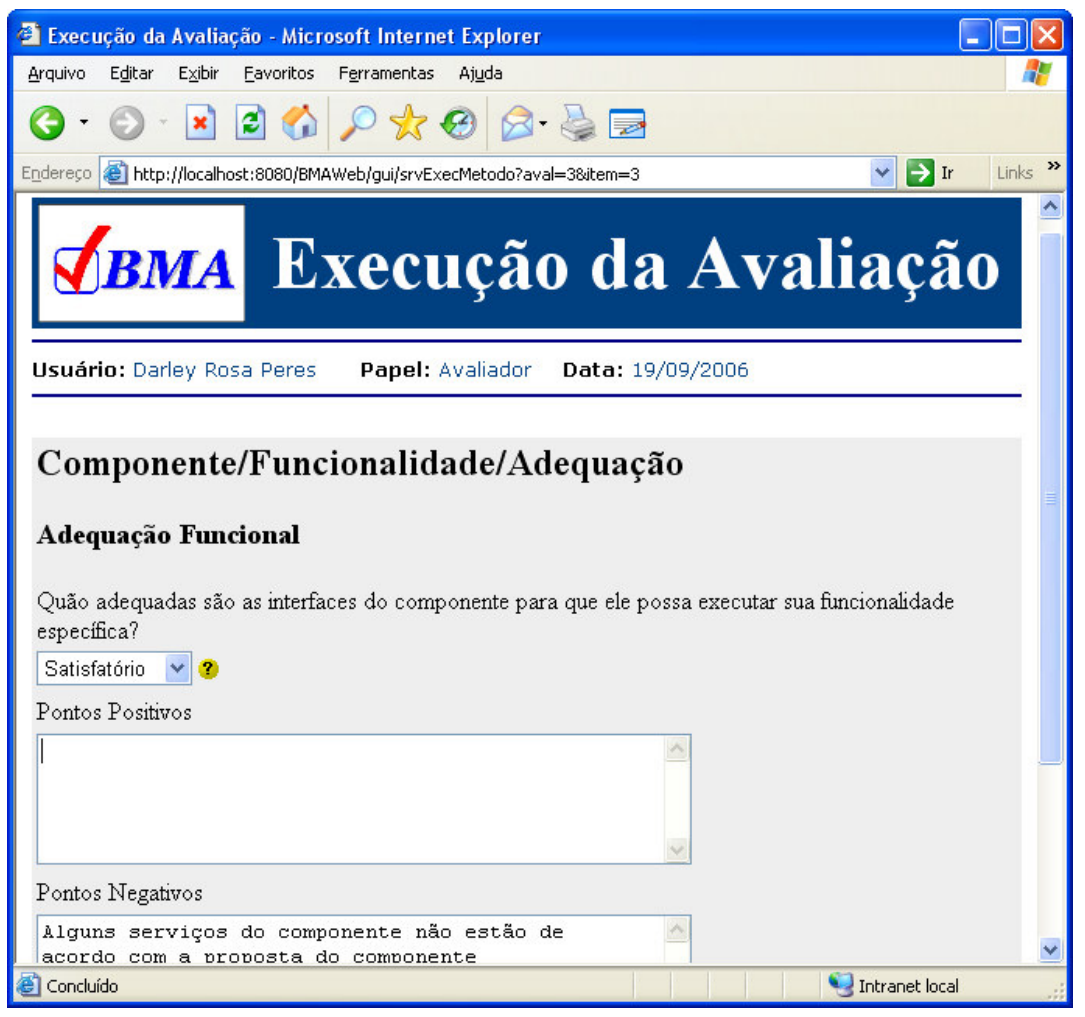

Figura 6.11 - Execução de uma avaliação por meio da Ferramenta BMA.

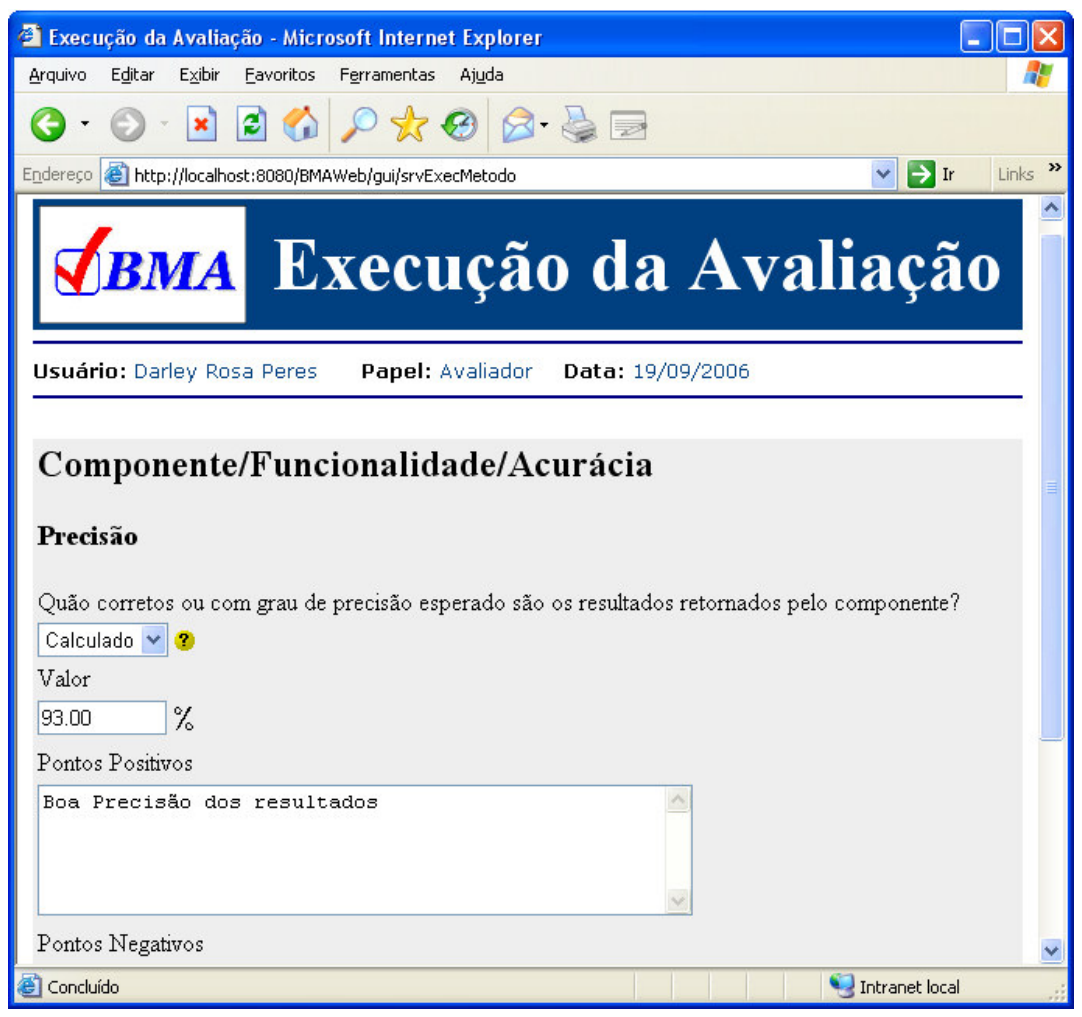

Figura 6.12 - Execução de uma avaliação por meio da Ferramenta BMA (continuação). 
Com o término da execução das avaliações, os resultados ficam armazenados numa base de dados central e podem ser consultados através de relatórios disponibilizados pela própria ferramenta ou exportados, por exemplo, para ferramentas estatísticas ou planilhas eletrônicas para que análises dos resultados através de critérios de julgamento de aprovação possam ser realizadas, uma vez que a ferramenta não trata ainda critérios para julgamento de aprovação e nem relatórios estatísticos.

\subsection{Considerações Finais}

Neste capítulo foi apresentada a ferramenta BMA - Biblioteca de Módulos de Avaliação, cuja finalidade é gerenciar modelos e métodos de qualidades para diferentes tipos de produtos de software, e também, controlar e automatizar execuções de avaliações por diferentes laboratórios credenciados facilitando e melhorando o controle dessas avaliações e dos resultados obtidos.

É importante destacar que, como apresentado neste capítulo, a ferramenta BMA auxilia na execução das avaliações disponibilizando os métodos de avaliação apoiados por modelos de qualidades (características, subcaracterísticas, atributos e métricas de qualidade) cadastrados na ferramenta.

No próximo capítulo, são apresentados os estudos de casos, realizados com a utilização da ferramenta BMA, para a verificação da aplicabilidade e utilidade do modelo de qualidade proposto neste trabalho. 


\section{Capítulo 7}

\section{Verificação da Aplicabilidade e Utilidade do Modelo de Qualidade e da Ferramenta BMA}

\subsection{Considerações Iniciais}

Com o objetivo de verificar a aplicabilidade e utilidade do modelo de qualidade, ou seja, verificar a capacidade do modelo em apoiar avaliações de componentes conduzindo a resultados adequados e satisfatórios quanto à análise da qualidade dos mesmos, são apresentados neste capítulo quatro estudos de casos. Nesses estudos foram avaliados cinco componentes de software de diferentes funcionalidades sendo que, cada avaliação foi de responsabilidade de avaliadores específicos. Além do modelo de qualidade e da ferramenta disponibilizada aos avaliadores, dois questionários, disponibilizados no anexo $\mathrm{B}$, foram elaborados, um para o modelo de qualidade e outro para a ferramenta, e entregue aos avaliadores para coletar suas considerações sobre os usos do modelo de qualidade e da ferramenta, dando um retorno importante para alcançar o objetivo principal deste capítulo, verificar a aplicabilidade e utilidade do modelo de qualidade e da ferramenta e também indicar melhorias na ferramenta.

Para a execução dos estudos de casos, um processo de avaliação simples foi definido com base na norma ISO/IEC 14598-1(ISO, 2001a), que possui um processo de avaliação bem definido e aceito na comunidade de software internacional. 


\subsection{Visão Geral do Processo de Avaliação apresentado na Norma ISO/IEC 14598-1}

A norma ISO/IEC 14598-1 é uma norma internacional que fornece um processo para implementação prática de avaliações de produtos de software. 0 processo de avaliação proposto pela norma pode ser usado para avaliar produtos já existentes ou produtos intermediários, isto é, em desenvolvimento. Seu público alvo é: avaliadores de laboratório, fornecedores de software, compradores de software, usuários e entidades certificadoras, cada qual com seu objetivo.

O processo de avaliação proposto pela norma 14598-1 inclui quatro etapas de avaliação: 1) Estabelecer os requisitos de avaliação; 2) Especificar a Avaliação; 3) Projetar a Avaliação; e 4) Executar a Avaliação - essas quatro etapas definem dez atividades, como pode ser observado na Figura 7.1, proposta em (ISO, 2001a).



Figura 7.1 - Processo de Avaliação segundo ISO 14598-1. (Adaptado de (ISO, 2001a))

A seguir, é dada uma breve descrição de cada etapa do processo e suas respectivas atividades: 


\section{a) Estabelecer Requisitos de Avaliação}

Nessa etapa, descreve-se o propósito da avaliação, identifica-se os tipos de produtos a serem avaliados e especifica-se qual o modelo de qualidade a ser utilizado na avaliação. Vários pontos de vista podem ser considerados, dependendo dos diferentes usuários do produto, tais como: comprador, fornecedor, desenvolvedor e operador. As atividades dessa etapa são:

- Estabelecer o propósito da avaliação: definir qual o objetivo principal da avaliação. $O$ objetivo de uma avaliação pode ser para: i) decidir quanto à aceitação de um produto intermediário ou final; ii) prever ou estimar a qualidade de um produto final; iii) comparar o produto com produtos competidores; etc.

- Identificar tipos de produtos a serem avaliados: identificar quais e que tipos de produtos vão ser avaliados. O tipo de produto de software a ser avaliado, quer seja um dos produtos intermediário ou final, dependerá do estágio no ciclo de vida e do propósito da avaliação.

- Especificar o Modelo de Qualidade: consiste em selecionar as características de qualidade relevantes, utilizando um modelo de qualidade que desdobre a qualidade de software em diferentes características.

\section{b) Especificar a Avaliação}

Nessa etapa, deve-se definir o escopo da avaliação e as medidas a serem executadas no produto submetido à avaliação. Essa etapa é composta pelas seguintes atividades:

- Selecionar métricas: o objetivo dessa atividade é estabelecer métricas, com base no modelo de qualidade escolhido, que se correlacionam às características do produto avaliado.

- Estabelecer níveis de pontuação para as métricas: as particularidades quantificáveis podem ser medidas quantitativamente usando-se métricas de qualidade. O resultado, isto é, o valor medido, é mapeado numa escala. Esse valor, por si só, não mostra o nível de satisfação. Para isso, a escala precisa ser dividida em faixas correspondentes aos diversos graus de satisfação dos requisitos. 
- Estabelecer critérios para julgamento: o objetivo desta atividade é definir os critérios para julgar os resultados da avaliação do produto definindo se o mesmo está de acordo com o que se esperava ou não.

\section{c) Projetar a Avaliação}

Nessa etapa, deve-se produzir o plano de avaliação que descreve os métodos de avaliação e o cronograma das ações do avaliador.

\section{d) Execução da Avaliação}

Nessa etapa, deve-se obter resultados da execução de ações, para medir e verificar o produto de software de acordo com os requisitos de avaliação, como descrito na especificação da avaliação e como planejado no plano de avaliação. Ao executar essas ações, obtém um relatório de avaliação e os registros da avaliação. As atividades são:

- Obter as medidas: como resultado da aplicação das métricas ao produto de software, obtém-se os valores nas escalas das métricas.

- Comparar com critérios: na etapa de pontuação, o valor medido é comparado com critérios predeterminados.

- Julgar os resultados: aqui o conjunto de níveis pontuados são resumidos. O resultado é uma declaração de quanto o produto de software atende aos requisitos de qualidade.

\subsection{Processo de Avaliação para Componentes de Software}

Tomando como base as etapas do processo de avaliação da Norma ISO 14598-1, a seguir são apresentadas as etapas do processo de avaliação dos componentes que guiaram os avaliadores na execução dos estudos de caso:

\section{a) Estabelecer os Requisitos da Avaliação}

\section{a-1) Propósito da Avaliação}

Como o objetivo é verificar a aplicabilidade do modelo, 2 diferentes propósitos são definidos para as avaliações realizadas neste capítulo. O primeiro é avaliar o quanto os componentes estão em conformidade com os requisitos de qualidade desejados, identificando-se pontos positivos e pontos a 
serem melhorados. Outro propósito é avaliar o nível de qualidade entre vários componentes com a mesma funcionalidade em relação aos requisitos desejados, auxiliando assim a seleção e adoção dos componentes mais adequados.

\section{a-2) Tipos de produtos(artefatos) a serem avaliados:}

Nos dois casos, serão avaliados, além do código executável dos componentes, também os documentos de descrição dos componentes e as documentações dos componentes (documento de especificação, manual do usuário, etc).

\section{a-3) Definição do modelo de qualidade}

O modelo de qualidade a ser adotado será o modelo de qualidade de componentes desenvolvido neste trabalho, discutido no capítulo 5 .

\section{b) Especificação da Avaliação}

b-1) Selecionar Métricas: todas as métricas especificadas no modelo de qualidade desenvolvido fazem parte das avaliações. Assim, para cada métrica do modelo proposto existem questões e também requisitos para medição, ou seja, a forma como deve ser a resposta referente à métrica. Com isso um questionário de avaliação é gerado com explicação de como devem ser dadas as respostas, como é mostrado no exemplo da Tabela 7.1 .

Tabela 7.1 - Questionário de avaliação

\begin{tabular}{|l|l|l|}
\hline \multicolumn{1}{|c|}{ Atributo } & \multicolumn{1}{|c|}{ Questão } & Tipo de Resposta \\
\hline $\begin{array}{l}\text { Disponibilidade da } \\
\text { Descrição do Componente }\end{array}$ & $\begin{array}{l}\text { Existe um documento (ou página) de descrição } \\
\text { do componente disponibilizado no repositório? }\end{array}$ & - Não \\
\hline
\end{tabular}

Para cada tipo de resposta do questionário de avaliação há um valor correspondente associado numa escala de medição entre 0 e $100 \%$. Por exemplo: Sim (100\%) e Não (0\%); Excelente (100\%), Satisfatório (50\%) e Insatisfatório $(0 \%)$, etc. 
b-2) Identificação de Níveis de pontuação: Para as avaliações, os níveis de pontuação estão definidos em uma escala divididos em 4 categorias, de acordo com o exemplo apresentado na Norma ISO/IEC 14598-1: Insatisfatório que vai de $0 \%$ a $40 \%$, Regular que vai de $41 \%$ a $60 \%$, Bom de $61 \%$ a $90 \%$ e Excelente de $91 \%$ a $100 \%$. Esses valores foram estipulados nessas escalas com o objetivo de tentar representar da forma mais adequada suas categorias. Na Figura 7.2, é apresentado um gráfico de faixas ilustrando os níveis de pontuação.



Figura 7.2 - Níveis de pontuação para a avaliação.

b-3) Identificação de Critérios para admissão: Os critérios para admissão serão definidos de acordo com o propósito da avaliação e de acordo com o solicitante da avaliação. Por exemplo, os requisitos de um componente estão em conformidade caso eles atinjam uma pontuação acima de $60 \%$, ou seja, entre bom e excelente. Outro exemplo, de acordo com o segundo propósito de avaliação é, o componente escolhido será aquele que atingir as maiores pontuações nos requisitos de qualidade desejados. 


\section{c) Projeto da Avaliação}

O Plano de Avaliação definido para as avaliações dos componentes deste capítulo consiste das seguintes informações:

- Dados do componente para avaliação: as informações contidas neste item são: o nome do componente, o seu tipo e a sua funcionalidade.

- Identificação do avaliador: o nome do avaliador e a sua familiaridade quanto à especialidade do componente avaliado.

- Identificação dos recursos de hardware: ex.: Processador, Memória, RAM e Espaço em Disco.

- Identificação dos recursos de software: ex.: Sistema Operacional, Infraestrutura de execução.

- Instrumentos para a execução da avaliação: os instrumentos são: Lista de Verificação, Método de Aplicação e a Ferramenta de Apoio à Avaliação. A execução da avaliação se dará por meio de uma Lista de Verificação, que é composta pelo conjunto de métricas do modelo de qualidade desenvolvido, formando assim o questionário que deverá ser respondido de acordo com o método de aplicação, que é formado por explicações de como deve ser respondido cada questão da lista de verificação. Tanto a apresentação e coleta das respostas da lista de verificação quanto a disponibilização do método de aplicação são automatizadas pela ferramenta BMA que auxilia na execução da avaliação.

\section{d) Execução da Avaliação}

Como mencionado acima, a execução da avaliação é apoiada pela ferramenta BMA, que disponibiliza de forma automatizada a lista de verificação (questionário com as perguntas e os possíveis tipos de resposta) e o método de aplicação que auxilia o avaliador na obtenção das respostas do questionário.

O julgamento dos resultados será feito de acordo com os dois propósitos estabelecidos para as avaliações: 1) analisar quais os pontos positivos e 
pontos a serem melhorados; e 2) identificar o melhor nível de qualidade entre os componentes, de mesma funcionalidade, avaliados.

\subsection{Estudos de Caso}

Quatro avaliações foram realizadas seguindo o processo definido. A primeira avaliação foi uma avaliação piloto, realizada pelo próprio autor para identificar possíveis falhas e assim realizar os ajustes necessários no modelo de qualidade e na ferramenta, para que nada prejudicasse as avaliações externas. As duas avaliações seguintes foram realizadas com o propósito de verificar a conformidade dos componentes com relação aos requisitos de qualidade desejados. A quarta e última avaliação foi realizada com o propósito de verificar e comparar a qualidade de dois componentes com a mesma funcionalidade. Com exceção da primeira avaliação, as três últimas avaliações foram realizadas por avaliadores externos.

Como já mencionado nas considerações iniciais deste capítulo, para coletar as considerações dos avaliadores referentes à utilização do modelo de qualidade e da ferramenta de apoio à avaliação, dois questionários foram elaborados para serem respondidos pelos avaliadores participantes das avaliações, um para o modelo e outro para a ferramenta. Os questionários foram disponibilizados aos avaliadores juntamente com o modelo de qualidade e a ferramenta de avaliação. Ao término das avaliações os questionários foram respondidos coletando as considerações dos avaliadores que utilizaram tanto a ferramenta, quanto $\mathrm{o}$ modelo de qualidade. Os questionários podem ser encontrados no anexo B.

Os resultados das avaliações e as considerações dos avaliadores sobre a utilização do modelo de qualidade desenvolvido e também sobre a ferramenta são apresentados a seguir.

\subsubsection{Estudo de Caso 1 - Componente JBarcodeBean}

O primeiro estudo de caso foi realizado com o caráter de uma avaliação piloto, com o objetivo de verificar possíveis pontos críticos que possam 
prejudicar a execução dos outros estudos de caso tanto por parte da ferramenta quanto por parte do modelo de qualidade desenvolvido.

Componente utilizado na avaliação piloto: JBarcodeBean

Descrição: Componente para geração e visualização de diferentes tipos de código de barras.

Página: http://jbarcodebean.sourceforge.net/

Categoria: Desenvolvimento, Negócios(business).

Licença: GNU (LGPL).

Experiência do avaliador: Desenvolvimento e pesquisa.

Grau de familiaridade com a aplicação do componente: bom conhecimento.

\section{Resultado da Avaliação:}

O resultado da avaliação do componente JBarcodeBean é apresentado na Figura 7.3. A medição obtida dos artefatos do componente e de suas características de qualidade é resumida nesse relatório, onde é possível observar quais características, dos três artefatos do componente avaliado, possuem um nível maior de conformidade (pontos positivos) e quais características possuem pontos a serem melhoradas de acordo com requisitos desejados. De acordo com o resultado final da avaliação, a característica declaração do artefato descrição do componente possui pontos a serem melhorados com base em seu nível de pontuação que foi insatisfatório.

Outras características que precisam ser melhoradas são: identificação e indicação, do artefato descrição, e, confiabilidade do artefato componente. Pontos que se destacam positivos, de acordo com o resultado, são as 
características existência, dos artefatos descrição e documentação, e eficiência do artefato componente.

\begin{tabular}{|c|c|c|c|}
\hline \multicolumn{4}{|c|}{$\underline{\text { Resumo do Resultado Final da Avaliação }}$} \\
\hline Artefatos & Características & Medição & Níveis de Pontuação \\
\hline \multirow[t]{5}{*}{ Descrição } & & 60,75 & Regular \\
\hline & Existência & 100,00 & Excelente \\
\hline & Conteúdo & 75,00 & Bom \\
\hline & Identificação e Indicação & 50,00 & Regular \\
\hline & Declaração & 18,00 & Insatisfatório \\
\hline \multicolumn{2}{|c|}{ Documentação } & 76,42 & Bom \\
\hline & Existência & 100,00 & Excelente \\
\hline & Completitude & 62,58 & Bom \\
\hline & Usabilidade & 66,67 & Bom \\
\hline \multicolumn{2}{|l|}{ Componente } & 72,70 & Bom \\
\hline & Funcionalidade & 59,00 & Regular \\
\hline & Confiabilidade & 57,22 & Regular \\
\hline & Usabilidade & 61,25 & Bom \\
\hline & Eficiência & 100,00 & Excelente \\
\hline & Portabilidade & 86,00 & Bom \\
\hline
\end{tabular}

Figura 7.3 - Resultado final da avaliação do componente JBarcodeBean.

\section{Considerações do avaliador:}

Como eram previstos, principalmente por ser uma primeira versão, tanto do modelo quanto da ferramenta, alguns pontos falhos foram detectados e melhorados.

No modelo de qualidade, muitas das questões das métricas e os textos dos métodos de aplicação tiveram que ser reformulados, pois visualizou-se que não estavam muito claros podendo dificultar o entendimento quanto a finalidade da questão e também de como proceder para avaliar o componente e assim obter a resposta adequada.

Alguns conjuntos de respostas (elementos de dados para medição) não estavam adequados à sua respectiva questão (propósito da métrica) e tiveram que ser alinhados de acordo com sua questão para facilitar o entendimento e aplicação da avaliação. 
No uso da ferramenta BMA foram detectados alguns pontos a serem melhorados quanto à usabilidade, mas que não influenciava na execução da avaliação, com exceção de uma falha. Durante a execução da avaliação, a ferramenta apresentou problemas na visualização do método de aplicação da métrica, dificultando assim o entendimento da questão da lista de verificação e de como respondê-la.

Concluindo, este estudo de caso piloto, se mostrou fundamental para um primeiro alinhamento do modelo de qualidade e da ferramenta BMA, pois os pontos detectados foram corrigidos antes da execução dos demais estudos de caso.

\subsubsection{Estudo de Caso 2: Componente TurboPower Async Professional}

Componente utilizado na avaliação: TurboPower Async Pro

Descrição: Componente para comunicação direta em portas seriais

Página: http://sourceforge.net/projects/tpapro/

Categoria: Infra-estrutura.

Licença: GNU (MPL 1.1).

Experiência do avaliador: Desenvolvimento e Pesquisa na área de qualidade, Avaliador credenciado MEDEPROS (CenPRA).

Grau de familiaridade com a aplicação do componente: bom conhecimento. Resultado da Avaliação:

$\mathrm{Na}$ Figura 7.4, é apresentado o resultado final da avaliação do componente Turbo Power. De acordo com os níveis de pontuação obtidos na avaliação, a característica confiabilidade do artefato componente obteve o nível mais baixo, indicando que precisa ser melhorada para ficar em conformidade com os requisitos desejados. Assim como a característica funcionalidade, também do artefato componente, não obteve uma pontuação muito boa e precisa ser melhorada. Já as características dos artefatos descrição e 
documentação, se destacaram como pontos positivos do componente, obtendo uma boa pontuação.

\begin{tabular}{|cccc|}
\hline \multicolumn{4}{c}{ Resumo do Resultado Final da Avaliação } \\
Produto: & Componente TurboPower & \\
\hline Artefatos & \multicolumn{1}{c|}{ Características } & Medição & Níveis de Pontuação \\
\hline Descrição & Existência & $\mathbf{8 2 , 1 1}$ & Bom \\
& Conteúdo & 100,00 & Excelente \\
Identificação e Indicação & 95,00 & Excelente \\
Declaração & 71,43 & Bom \\
& & 62,00 & Bom \\
Documentação & & \\
Existência & $\mathbf{9 0 , 2 7}$ & Bom \\
Completitude & 100,00 & Excelente \\
Usabilidade & 70,83 & Bom \\
& 100,00 & Excelente \\
Componente & & \\
Funcionalidade & $\mathbf{5 9 , 8 8}$ & Regular \\
Confiabilidade & 57,00 & Regular \\
Usabilidade & 20,56 & Insatisfatório \\
Eficiência & 78,33 & Bom \\
Portabilidade & 72,50 & Bom \\
\hline
\end{tabular}

Figura 7.4 - Resultado final da avaliação do componente TurboPower.

\section{Considerações do avaliador:}

As considerações do avaliador foram bem positivas tanto do ponto de vista da aplicabilidade do modelo de qualidade quanto de sua utilidade com relação aos resultados obtidos através de sua execução. Para o avaliador, por meio dos atributos de qualidade do modelo, apresentados através do questionário de avaliação, foi possível rastrear vários aspectos (alguns positivos, outros negativos) sobre o componente avaliado.

De acordo com o avaliador, por ser uma primeira versão do modelo, em poucos casos houve certa dificuldade no entendimento de algumas questões, e, de como coletar os dados para respondê-la, mas isso, não prejudicou a avaliação do componente. 
O avaliador conclui que, o modelo de qualidade mostrou-se aplicável, e bem pertinente na verificação da qualidade de componentes de software.

Sobre a ferramenta, o avaliador cita alguns pontos falhos relacionados à sua usabilidade, por exemplo, houve uma certa dificuldade em navegar de uma questão para a outra, quando as mesmas não são adjacentes. A dificuldade ainda é maior, quando o avaliador quer navegar entre questões que não pertencem ao mesmo artefato. Apesar disso, cita o avaliador, a ferramenta mostrou-se eficiente e eficaz durante a execução da avaliação.

\subsubsection{Estudo de Caso 3: Componente FolderMgr}

Componente utilizado na avaliação: FolderMgr - Componente de gerenciamento de pastas

Descrição: Componente de gerenciamento de pastas tem como funcionalidade criar, renomear, excluir pastas e gerenciar a lixeira (lixeira é um tipo especial de pasta).

Categoria: Negócio

Licença: GPL GNU

Experiência do avaliador: Gerente de projeto baseado em componentes.

Grau de familiaridade com a aplicação do componente: especialista no assunto.

\section{Resultado da Avaliação:}

De acordo com os níveis de pontuação obtidos na avaliação, o Componente FolderMgr apresentou-se de uma forma geral com uma baixa pontuação em seus três artefatos. Na Figura 7.5 , são apresentados os resultados das características de qualidade dos três artefatos do componente FolderMgr. 


\begin{tabular}{|cccc|}
\hline \multicolumn{3}{c}{ Resumo do Resultado Final da Avaliação } \\
Produto: & Componente FolderMgr & \\
\hline Artefatos & \multicolumn{1}{c|}{ Características } & Medição & Níveis de Pontuação \\
\hline Descrição & & $\mathbf{3 8 , 9 9}$ & Insatisfatório \\
& Existência & 100,00 & Excelente \\
& Conteúdo & 25,00 & Insatisfatório \\
& Identificação e Indicação & 14,29 & Insatisfatório \\
& Declaração & 16,67 & Insatisfatório \\
& & & \\
Documentação & $\mathbf{6 6 , 2 0}$ & Bom \\
Existência & 100,00 & Excelente \\
Completitude & 31,94 & Insatisfatório \\
Usabilidade & 66,67 & Bom \\
& & \\
Componente & $\mathbf{5 8 , 2 2}$ & Regular \\
Funcionalidade & 50,00 & Regular \\
Confiabilidade & 50,00 & Regular \\
Usabilidade & 27,78 & Insatisfatório \\
Eficiência & 100,00 & Excelente \\
Portabilidade & 63,33 & Bom \\
\hline
\end{tabular}

Figura 7.5 - Resultado final da avaliação do componente FolderMgr.

É possível observar por meio do resultado da avaliação realizada que, o artefato descrição do componente ficou com em um nível insatisfatório indicando que existem pontos, analisados por suas características, que precisam ser melhorados para alcançar um nível de qualidade adequado. $O$ artefato documentação obteve a melhor pontuação dos três artefatos, mas a completitude de seu conteúdo precisa ser melhorada, assim como a usabilidade do artefato componente precisa ser melhorada.

\section{Considerações do avaliador:}

De acordo com o avaliador a forma como o questionário foi estruturado e a presença do método de aplicação das métricas contendo as informações para auxiliar nas respostas das questões, tornou fácil a sua aplicação. Outro ponto que contribuiu foi a utilização da ferramenta que se mostrou útil na execução da avaliação. $O$ avaliador ainda sugere a utilização de ferramentas de testes para agilizar na obtenção de algumas respostas em casos onde é necessário testar o componente para obter esses resultados. 
O avaliador em suas considerações destaca também a utilidade do modelo, pois através da avaliação, foi possível identificar alguns pontos que prejudicam na qualidade dos componentes e que devem ser levados em consideração durante o desenvolvimento dos mesmos.

\subsubsection{Estudo de Caso 4: Comparação entre 2 componentes de criptografia}

O objetivo deste estudo de caso é avaliar 2 componentes que possuem as mesmas finalidades e assim, identificar qual o componente oferece um melhor nível de qualidade entre os requisitos avaliados.

Componentes utilizados nas avaliações: JSecurity e vH Crypto

Descrição: Componentes responsáveis por criptografar e descriptografar dados.

Categorias: Infra-estrutura

Licenças: GNU (GPL)

Experiência do avaliador: Desenvolvimento e Pesquisa na área de qualidade, Avaliador credenciado MEDEPROS (CenPRA).

Grau de familiaridade com a aplicação do componente: bom conhecimento.

\section{Resultado da Avaliação:}

De acordo com o modelo, os resultados obtidos nas avaliações dos componentes, demonstraram que o componente vH Crypto apresenta um nível maior de qualidade em comparação com o componente JSecurity. Na Figura 7.6, são apresentados os gráficos de comparação entre os dois componentes. No primeiro gráfico - Média de Pontuação Total - é apresentada a pontuação média obtido pelos dois componentes. No segundo gráfico - Comparação por Características - são comparadas as principais características de qualidade avaliadas. 
De acordo com o gráfico "Comparação por Características" apresentado na Figura 7.6, é possível verificar que as características de qualidade: Descrição, Documentação, Funcionalidade e Confiabilidade do componente vH Crypto obtiveram um melhor desempenho se comparadas às mesmas características do componente JSecurity, assim, o componente vH Crypto possui um nível melhor de qualidade em relação ao seu concorrente JSecurity.
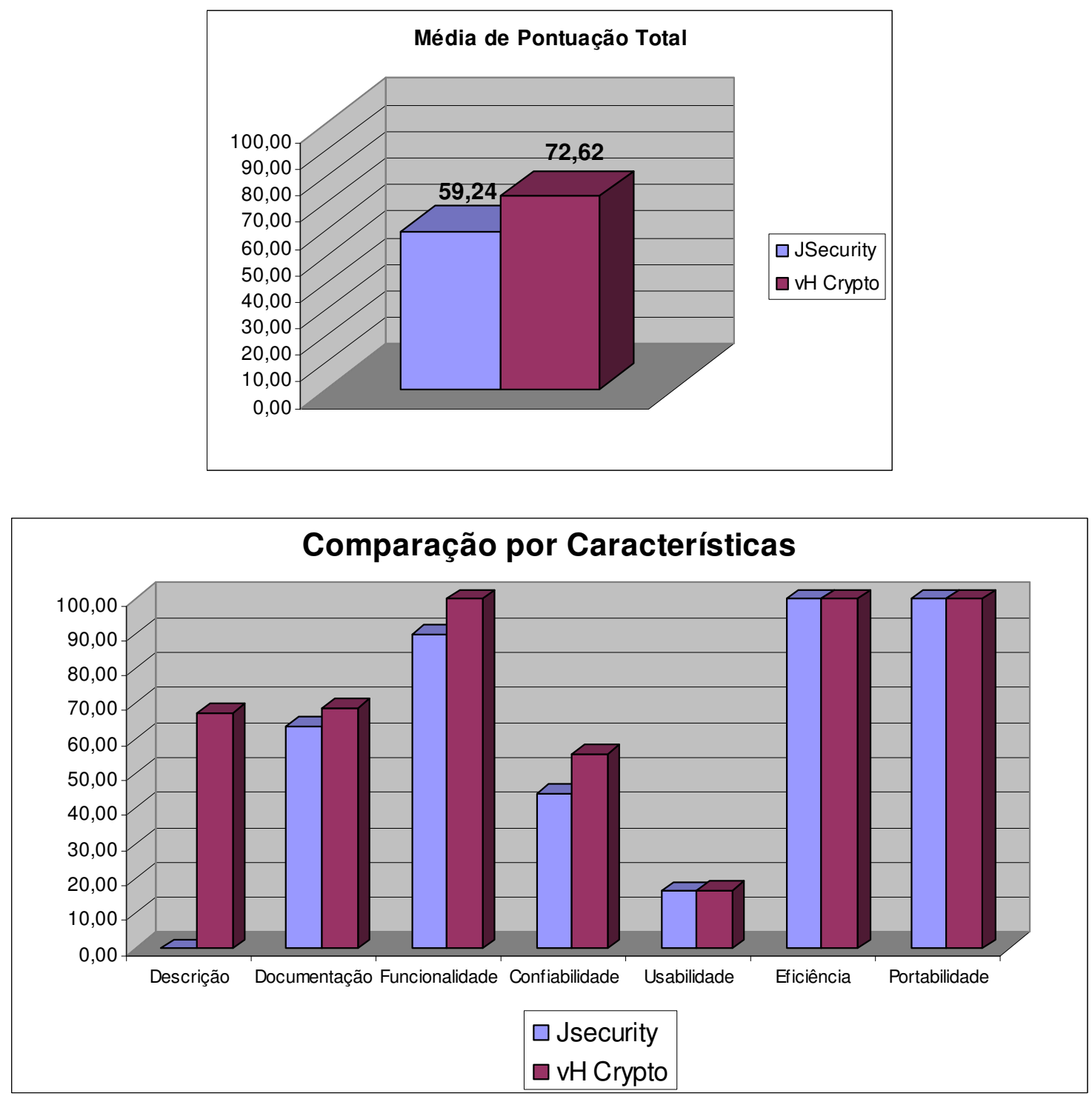

Figura 7.6 - Resultado final da avaliação dos componentes JSecurity e vH Crypto. 


\section{Considerações do avaliador:}

De acordo com o avaliador, o modelo de qualidade e a ferramenta BMA cumpriram com seus papéis durante o estudo de caso, dando dados suficientes para que seja possível selecionar o componente que melhor atende os requisitos pré-estabelecidos em um processo de seleção. Apesar de sua consideração, o avaliador deu algumas sugestões para melhoria da ferramenta e dos relatórios disponibilizados por ela.

\subsection{Conclusão sobre as considerações dos avaliadores}

De acordo com as respostas obtidas entre todos os questionários respondidos pelos avaliadores participantes dos estudos de casos, o modelo de qualidade obteve uma pontuação de $71,43 \%$ de respostas positivas contra $28,57 \%$ de respostas que apontavam alguma restrição do modelo de qualidade com relação ao objetivo que ele estava sendo analisado. Já a ferramenta de apoio obteve uma pontuação mais equiparada, com $55,49 \%$ de respostas positivas contra $44,51 \%$ de respostas que apontavam algum tipo de restrição.

Assim, analisando as respostas e as considerações obtidas pelos questionários respondidos durante os estudos de casos, conclui-se que o modelo de qualidade e a ferramenta de apoio tiveram a aprovação dos avaliadores, não apenas quanto a sua aplicabilidade, mas também quanto a sua adequação e utilidade na avaliação da qualidade dos componentes de software.

\subsection{Considerações Finais}

Neste capítulo foram realizados alguns estudos de caso com o objetivo de verificar a capacidade do modelo e da ferramenta BMA em apoiar avaliações de componentes de software, averiguando se os resultados quanto à qualidade dos mesmos, são adequadas e satisfatórias. 
Foram realizadas quatro avaliações nos estudos de caso, onde a primeira avaliação foi realizada pelo próprio autor como uma avaliação piloto e as três avaliações restantes foram feitas por avaliadores externos.

Para coletar as considerações desses avaliadores externos quanto à aplicabilidade e utilidade tanto do modelo de qualidade quanto da ferramenta, dois questionários foram elaborados e respondidos pelos mesmos.

Como resultado final dessas considerações, foi possível constatar que o modelo de qualidade e a ferramenta mostraram-se satisfatórios quanto a sua aplicabilidade e utilidade para apoiar avaliações de qualidade de componentes de software reutilizáveis, apesar de apresentarem alguns pontos que necessitam ser melhorados.

Para finalizar esta dissertação, são apresentadas no capítulo a seguir as conclusões deste trabalho desenvolvido e também alguns trabalhos futuros. 


\section{Capítulo 8}

\section{Conclusões e Trabalhos Futuros}

Há alguns anos, muitas empresas desenvolvedoras de software vêm investindo em soluções tecnológicas que aumentem seus índices de qualidade e produtividade com redução de custos. Nesse sentido, o Desenvolvimento Baseado em Componentes (DBC), através da reutilização de componentes, tem sido almejado por diversas organizações como uma maneira eficaz de alcançar esses objetivos.

Entretanto, apesar de avanços no uso de processos de DBC, componentes de software e arquiteturas de software, ainda existem muitos riscos funcionais e de qualidade envolvidos em sua utilização (Stallinger et al., 2002), (Bertoa, 2002), (Kallio, 2002). Na tentativa de alcançar os principais benefícios prometidos pelo DBC, na construção de aplicações, observou-se que há uma grande necessidade por componentes de software de qualidade (Preiss et al., 2001), (Preiss, 2002), (Gill, 2006), (Mäki-Asiala, 2006).

Para contribuir com o sucesso do DBC, através da avaliação da qualidade dos componentes de software reutilizáveis, foram desenvolvidos neste trabalho de mestrado, um modelo de qualidade para componentes de software e também uma ferramenta de apoio a avaliação (BMA), não apenas de componentes mas de produtos de software em geral.

O modelo de qualidade definido tem como essência servir de base para avaliações de componentes de software, pois, permite que a qualidade dos componentes de software seja especificada e avaliada por meio de suas características, subcaracterísticas, atributos e métricas. $O$ objetivo da ferramenta BMA é gerenciar diversos modelos e métodos de qualidades para que ela possa apoiar avaliações de diferentes tipos de produtos de software e não apenas componentes de software. 
Para validar a aplicabilidade do modelo e a usabilidade da ferramenta, foram realizados quatro estudos de casos, onde cinco componentes foram avaliados por avaliadores externos a este trabalho com dois propósitos de avaliações diferentes. A primeira avaliação foi uma avaliação piloto, com o objetivo de detectar possíveis falhas que prejudicassem as avaliações externas. As outras duas avaliações tiveram a finalidade de avaliar a qualidade do componente em relação aos requisitos estabelecidos, identificando pontos positivos e pontos a serem melhorados. Na última avaliação, dois componentes com a mesma finalidade foram avaliados, sobre os mesmos critérios para relatar o nível de qualidade dos dois componentes, auxiliando assim a seleção/aquisição dos componentes mais adequados.

Um questionário sobre o modelo e sobre a ferramenta foi disponibilizado para coletar as considerações dos avaliadores quanto ao modelo e à ferramenta.

De acordo com as considerações dos avaliadores, o modelo e a ferramenta apresentaram-se satisfatórios de acordo com suas finalidades nas avaliações realizadas, pois o modelo conseguiu abranger as principais metas de qualidade para componentes de software através de sua estrutura de características, subcaracterísticas, atributos e métricas de qualidade. Já a ferramenta, mostrou-se útil na execução das avaliações com a automatização da apresentação da Lista de Verificação e da coleta das respostas diminuindo o tempo de avaliação, e facilitando o controle e tratamento das respostas obtidas.

É importante ressaltar que, não houve nenhuma crítica ao modelo em si, apenas algumas sugestões para a melhoria do mesmo. A ferramenta por sua vez, recebeu algumas críticas quanto a sua usabilidade mas nada que prejudicasse a execução das avaliações. 


\subsection{Lições Aprendidas}

Percebeu-se durante o desenvolvimento deste trabalho a falta de um consenso sobre o que é um componente de software, exigindo que uma definição clara e específica fosse adotada do que vem a ser um componente de software, para que os atributos do modelo de qualidade de componentes fossem determinados.

Durante a execução dos estudos de caso percebeu-se que a avaliação de um componente exige um grau de conhecimento (técnico) maior de seus avaliadores do que das avaliações de produtos de software. Isso devido à destinação de ambos: o componente é destinado a desenvolvedores, integradores de sistemas, e já o software é destinado aos usuários finais que apenas utilizam suas funcionalidades.

Durante a execução dos estudos de caso, percebeu-se também que a utilização do modelo pode ser útil para as seguintes finalidades, como:

- guia de auxilio na estruturação de um documento de descrição de um componente de software reutilizável;

- auxílio na validação da completitude de uma definição de requisitos de componentes;

- identificação de requisitos não-funcionais para componentes de software reutilizáveis;

- identificação de objetivos para testes de caixa preta de componentes;

- identificação de critérios para garantia da qualidade do componente em desenvolvimento, provendo a confiança adequada de que a qualidade do componente está satisfazendo suas metas; e

- auxiliar os processos de busca e seleção através da identificação de critérios de aceitação dos componentes. 


\subsection{Contribuições}

As contribuições deste trabalho podem ser resumidas nos seguintes itens:

- A identificação de um conjunto de características e subcaracterísticas de qualidade para componentes de software e para suas documentações;

- A definição de atributos e métricas de qualidade externa e de qualidade em uso específicos para componentes de software;

- Relacionamento dessas características, subcaracterísticas, atributos e métricas de qualidade formando assim um modelo de qualidade específico para componentes de software;

- A criação de uma ferramenta de gerência de diversos modelos de qualidade e de apoio a avaliações que são baseadas nesses modelos.

- A instanciação de um processo simples de avaliação para componentes com base no processo de avaliação definido pela norma ISO/IEC 14598-1.

É importante destacar que os resultados da pesquisa deste trabalho de mestrado foram apresentados em dois Workshops: no primeiro (Peres, 2006) foi apresentada apenas uma proposta de um modelo de qualidade para componentes de software, com algumas características e subcaracterísticas de qualidade. Esse trabalho foi publicado no IV Workshop de Teses e Dissertações em Qualidade de Software do V Simpósio Brasileiro de Qualidade de Software, ocorrido em Maio de 2006 - Vila Velha-ES. No segundo (Colombo et al., 2006), foi apresentado uma discussão sobre a qualidade e confiabilidade de componentes de software e também foi apresentado o modelo de qualidade com suas características, subcaracterísticas e atributos. Esse trabalho foi publicado no I Workshop de Componentes para o domínio e-gov, ocorrido em Agosto de 2006 - Porto Alegre-RS. 


\subsection{Trabalhos futuros}

Como neste trabalho desenvolveu-se um modelo de qualidade específico para componentes de software e uma ferramenta de apoio a avaliações e, sabendo-se da importância de uma validação e evolução dos mesmos, sugere-se outros estudos para a melhoria contínua tanto do modelo de qualidade quanto da ferramenta.

Sugere-se também que sejam feitos estudos e comparações do modelo de qualidade desenvolvido, com outros trabalhos relacionados, relatando os pontos fracos e pontos fortes entre os modelos estudados, como por exemplo: Bertoa (Bertoa, 2002), Alvaro (Alvaro, 2006).

Sabendo-se que a qualidade externa é influenciada pela qualidade interna, sugere-se a ampliação do modelo de qualidade definindo atributos e métricas de qualidade interna para avaliar internamente o componente.

Com o foco na certificação de componentes, definir um processo de avaliação e certificação que utilize o modelo de qualidade como base.

Adaptação e evolução da ferramenta BMA para que ela possa se adequar ao processo de avaliação e certificação de componentes e produtos de software (baseado em normas internacionais, como exemplo ISO/IEC 14598-1), e também a melhoria na variedade de relatórios gerenciais e estatísticos para a tomada de decisões. 


\section{Referências Bibliográficas}

(Almeida et al., 2005)

(Alvaro et al., 2005)

(Alvaro, 2006)

(Alvaro et al., 2006)

(Bachman et al., 2000)
Almeida, E. S., Alvaro, A., Lucredio, D., Garcia, V, C., Meira, S. R. L., 2005. A Survey on Software Reuse Processes. In the IEEE International Conference on Information Reuse and Integration (IRI), Las Vegas, Nevada, USA.

Alvaro, A., Almeida, E. S., Meira, S. R. L., 2005. Quality Attributes for a Component Quality Model, $10^{\text {th }}$ International Workshop on Component-Oriented Programming(WCOP) em conjunto com a $19^{\text {th }}$ European Conference on Object Oriented Programming (ECOOP), Glasgow, Escócia.

Alvaro, A., Meira, S. R. L., 2006. Software Component Certification: A Component Quality Model, In the VI CTDSBQS (Dissertation and Thesis Award - Brazilian Symposium on Software Quality), Vila Velha, Espírito Santo, Brazil, 2006.

Alvaro, A., Almeida, E.S., Meira, S. L., 2006. Component Quality Model: A Formal Case Study, In 5th ACM-IEEE International Symposium on Empirical Software Engineering (ISESE), Poster Session, Rio de Janeiro, Brazil.

Bachman, F., Bass, L., Buhman, C., Comella-Dorda, S., Long, F., Robert, J., Seacord, R., Wallnau, K., 2000. Volume II: Technical Concepts of Component-Based Software Engineering Institute, Carnegie Mellon University, Pittsburgh, PA. 
(Bass et al., 2000) Bass L., Buhman C., Dorda, S., Long, F., Robert, J., Seacord, R., Wallnau, K., 2000. Volume I: Market Assessment of Component-Based Software Engineering, Software Engineering Institute (SEI), Technical Report, Vol. 1, Maio.

(Bertoa, 2002) Bertoa, M., Vallecillo, A., 2002. Quality Attributes for COTS Components. In the Proceedings of the $6^{\text {th }}$ International ECOOP Workshop on Quantitative Approaches in ObjectOriented Software Engineering (QAOOSE), Spain.

(Boehm et al., Boehm, B. W., Brown, J. R., Kaspar, H., Lipow, M., Machleod, 1978) G. J., Merrritt, M.J., 1978. Characteristics of Software Quality.

(Brito et al., 2006) Brito, K.S., Alvaro, A., Lucrédio, D., Almeida, E.S., Meira, S. L., 2006. Software Reuse: A Brief Overview of the Brazilian Industry's Case, In 5th ACM-IEEE International Symposium on Empirical Software Engineering (ISESE), Short Paper, Rio de Janeiro, Brazil.

(Brown, 1998) Brown, A., Wallnau, K., 1998. The Current State of CBSE, IEEE Software, Outubro.

(Cheesman, 2000) Cheesman, J.; Daniels, J., 2000. UML components: A simple process for specifying component-based software. AddisonWesley.

(Colombo et al., Colombo, R. M. T., Peres, D. R., Aguayo, M. T. V., Eleutério, 2006) S. V., Guerra, A. C., 2006. Qualidade e Confiabilidade de Componentes de Software. I Workshop de Componentes para o domínio e-gov. Porto Alegre-RS, Brasil, Agosto. 
(Councill, 2001) Councill, B., Heineman, G. T., 2001. Definition of a Software Component and its Elements, In Component-Based Software Engineering: Putting the Pieces Together, Addison-Wesley.

(D'Souza, 1999) D'Souza, D. F., Wills, A. C., 1999. Objects, Components, and Frameworks with UML, The Catalysis Approach. AddisonWesley. USA. ISBN: 0-201-31012-0.

(Fuggetta, 2000) Fuggetta, A., 2000. Software process: a roadmap. In Anthony Finkelstein, ed. The future of Software Engineering. ACM Press.

(Gill, 2006) Gill, N. S., 2006. Importance of software component characterization for better software reusability. SIGSOFT Softw. Eng. ACM Press, New York, NY, USA. Notes 31, 1, pg. 1-3. DOI= http://doi.acm.org/10.1145/1108768.1108771.

(Goulao, 2002) Goulao, M., Abreu, F. B., 2002. The Quest for Software Components Quality. IEEE Proceedings, $26^{\text {th }}$ Annual International Computer Software and Applications Conference (COMPSAC), Agosto, pp. 313-318.

(Heineman, 2001) Heineman, G. T., Council, W. T., 2001. Component-Based Software Engineering: Putting the Pieces Together, AddisonWesley.

(Holanda et al., Holanda, C. B. S., de Souza, C. A. A., Melo, W. L., 2001. Pro2001) Reuso: Um repositório de Componentes para Web Dirigido por um Processo de Reuso. Anais do XV Simpósio Brasileiro de Engenharia de Software, Rio de Janeiro-RJ, Brasil, Outubro, pp. 208-223. 
(Hopkins, 2000) Hopkins, J., 2000. Component Primer. Comunications of the ACM, Volume 43 (10): 27-30, October.

(IEEE, 2001)

IEEE 1063, 2001. Standard for Software User Documentation. Published by the Institute of Electrical and Electronics Engineers, Inc. ISBN 0-7381-3099-0, December.

(ISO, 1994)

ISO/IEC 12119, 1994. Information Technology - Software packages - Quality requirements and testing. Geneve, 16 p., Outubro.

(ISO, 1994a)

ISO/IEC 8402, 1994. Quality management and quality assurance vocabulary. Norma ISO/IEC, Geneve.

(ISO, 2001)

ISO/IEC 9126-1, 2001. Software Engineering - Product quality - Part 1: Quality model. Ed. 1.

(ISO, 2001a)

NBR ISO/IEC 14598-1, 2001. Tecnologia da Informação Avaliação de Produto de software - Parte 1: Visão Geral. ABNT, 16 p., Março.

(ISO, 2003)

ISO/IEC TR 9126-2, 2003. Software engineering - Product quality - Part 2: External metrics. Ed. 1.

(ISO, 2003a)

ISO/IEC TR 9126-3, 2003. Software engineering - Product quality - Part 3: Internal metrics. Ed. 1

(ISO, 2004)

ISO/IEC TR 9126-4, 2004. Software engineering - Product quality - Part 4: Quality in use metrics. Ed. 1.

(Kallio, 2001) Kallio, P., Niemelä, E., 2001. Documented Quality of COTS and COM Components. Proceedings of the $4^{\text {th }}$ ICSE Workshop on Component-Based Software Engineering, Toronto, Canada, May. 
(Kallio, 2002) Kallio, P., Ihme, T., 2002. Evolution of the Use Risks of Commercial Software Components. Proceedings of the $28^{\text {th }}$ Euromicro Conference, Dortmund, Germany, September, pp. $55-61$.

(Larman, 2004) Larman, C., 2004. Utilizando UML e padrões: uma introdução à análise e ao projeto orientado a objetos e ao Processo Unificado. 2.ed., Porto Alegre, Bookman, ISBN 85-363-03581

(Lau, 2006) Lau, K., 2006. Software component models. In Proceeding of the 28th International Conference on Software Engineering. ICSE '06. ACM Press, New York, NY, 1081-1082. DOI=http://doi.acm.org/10.1145/1134285.1134516

(Lee, 2005)

Lee, K., Lee, S. J., 2005. A Quantitative Software Quality Evaluation Model for the Artifacts of Component Based Development. Sixth International Conference on Software Engineering, Artificial Intelligence, Networking and Parallel/Distributed Computing and First ACIS International Workshop on Self-Assembling Wireless Networks (SNPD/SAWN'05), pp. 20-25.

(Li et al., 2006) Li, J., Conradi, R., Slyngstad, O. N., Bunse, C., Torchiano, M., Morisio, M., 2006. An empirical study on decision making in off-the-shelf component-based development. In Proceeding of the 28th International Conference on Software Engineering. ICSE '06. ACM Press, New York, NY, 897-900. DOI=http://doi.acm.org/10.1145/1134285.1134446 
(Mäki-Asiala, 2006) Mäki-Asiala, P., Matinlassi, M., 2006. Quality Assurance of Open Source Components: Integrator Point of View. 30th Annual International Computer Software and Applications Conference (COMPSAC'06), pp.189-194.

(McCall, 1977) McCall, J. A., Richards, P. G., Walters, G. F., 1977. Factors in Software Quality, Vols. I, II, and III (NTIS AD/A-049/015/055), NTIS, Springfield, VA.

(Morris et al., 2001) Morris, J., Lee, G., Parker, K., Bundell, G. A., Lam, C. P., 2001. Software Component Certification. IEEE Computer, Vol. 34, No. 9, Setembro, pp. 30-36.

(Ommering, 2002) Ommering, R. V., 2002. Building Product Populations with Software Components, In 24th International Conference on Software Engineering (ICSE). Orlando, Florida.

(Peres, 2006) Peres, D. R., Sanches, R., 2006. Um modelo de Qualidade para Componentes de Software. IV Workshop de Teses e Dissertações em Qualidade de Software (WTDQS) em conjunto com V Simpósio Brasileiro de Qualidade de Software (SBQS), Vila Velha-ES, Brasil, Maio.

(Preiss et al., 2001) Preiss, O., Wegmann, A., Wong, J., 2001. On Quality Attribute Based Software Engineering. Proceedings of the $27^{\text {th }}$ Euromicro Conference, Warsaw, Poland, September, pp. 114120.

(Preiss, 2002) Preiss, O., Wegmann, A., 2002. A System Perspective on the Quality Description of Software Components. Proceedings of the $6^{\text {th }}$ World Multiconference on Systemics, Cybernetics and Informatics, Orlando, July, Vol. VII, pp. 250-255. 
(Pressman, 2002) Pressman, R. S., 2002. Engenharia de Software. 5.ed. Rio de Janeiro, Editora McGraw-Hill, $843 \mathrm{p}$.

(Rêgo, 1996)

Rêgo, C. M., et al., 1996. MEDE-PROS - Método de Avaliação de Qualidade de Produtos de Software, versão 1.0. Patente junto à Fundação Biblioteca Nacional sob número de registro 135.620 , livro 216 , folha 84 . Pedido de registro de marca junto ao INPI sob número 820166243. Rio de Janeiro, Brasil.

(Rocha et al., 2001)

Rocha, A. R. C.; Maldonado, J. C.; Weber, K. C., 2001. Qualidade de Software. São Paulo: Prentice Hall.

(Sametinger, 1997) Sametinger, J., 1997. Software Engineering with Reusable Components, Springer Verlag, ISBN 3-540-62695-6.

(Schmidt, 2003) Schmidt, H., 2003. Trustworthy components: compositionality and prediction. Journal of Systems and Software, Vol. 65, No. 3, Março, pp. 215-225.

(Simão, 2003) Simão, R.P.S., Belchior, A., 2003. Quality Characteristics for Software Components: Hierarchy and Quality Guides. Component-Based Software Quality: Methods and Techniques, Lecture Notes in Computer Science (LNCS) Springer-Verlag, Vol. 2693, pp. 188-211.

(Stallinger et al., Stallinger, F., Dorling, A., Rout, T., Henderson-Sellers, B., 2002)

Lefever, B., 2002. Software Process Improvement for Component-Based Software Engineering: An Introduction to the OOSPICE Project. Proceedings of the $28^{\text {th }}$ Euromicro Conference, Dortmund, Germany, September, pp. 318-323. 
(Szyperski et al., Szyperski, C., Gruntz, D., Murer, S., 2002. Component 2002) Software - Beyond Object-Oriented Programming. Addison Wesley Professional, 2ª edição, Novembro.

(Tsukumo et al., Tsukumo, A. N., Rêgo, C. M., Salviano, C. F., Azevedo, G. F., 1997) Meneghetti, L. K., Costa, M. C.C., Carvalho, M. B., Colombo, R. M. T., 1997. Qualidade de Software: Visões de Produto e Processo de Software. Publicado na "II Escola Regional de Informática da Sociedade Brasileira de Computação Regional de São Paulo - II ERI da SBC, Piracicaba, SP, Junho, págs: 173-189.

(Villela, 2000) Villela, R. M. B., 2000. Busca e Recuperação de Componentes em Ambientes de Reutilização de Software, Tese de Doutorado, UFRJ-COPPE, Rio de Janeiro - RJ, Brasil.

(Wallnau, 2003) Wallnau, K. C., 2003. Volume III: A Technology for Predictable Assembly from Certifiable Components. Software Engineering Institute (SEI), Technical Report, Vol. III, Abril.

(Werner, 2000) Werner, C., M., L., Braga, R., M., 2000. Desenvolvimento Baseado em Componentes. XIV Simpósio Brasileiro de Engenharia de Software, Minicursos e Tutoriais, João Pessoa-PB.

(Williams, 2000) Williams, J. D., 2000. "Raising Components", Application Development Trends, vol. 7. 


\section{Anexo A - Atributos e Métricas do Modelo para Qualidade Externa}

\section{Descrição do componente}

1.1 Existência

\begin{tabular}{|c|c|c|c|c|c|c|c|}
\hline & \multicolumn{4}{|c|}{ Métrica } & & & \\
\hline Atributo & $\begin{array}{c}\text { Propósito da Métrica } \\
\text { (Questão) }\end{array}$ & Método de aplicação & $\begin{array}{c}\text { Fórmula e/ou } \\
\text { elementos de dados } \\
\text { para medição }\end{array}$ & Escala de Medição & Entrada para medição & Referência & Público alvo \\
\hline $\begin{array}{l}\text { Disponibilidade da } \\
\text { Descrição do } \\
\text { Componente }\end{array}$ & $\begin{array}{l}\text { Existe um documento } \\
\text { (ou página) de } \\
\text { descrição do } \\
\text { componente que o } \\
\text { acompanha? }\end{array}$ & $\begin{array}{l}\text { O avaliador deve } \\
\text { verificar no repositório } \\
\text { a existência desse } \\
\text { documento de } \\
\text { descrição. }\end{array}$ & $\begin{array}{l}\text { - Sim; } \\
\text { - Não; }\end{array}$ & $\begin{array}{l}0-100 \% \\
\text { Sim }=100 \% \\
\text { Não }=0 \%\end{array}$ & $\begin{array}{l}\text { Repositório do } \\
\text { componente em } \\
\text { avaliação. }\end{array}$ & MEDE-PROS & $\begin{array}{l}\text { Avaliador } \\
\text { Usuário } \\
\text { (Desenvolvedor, } \\
\text { integrador, arquiteto) }\end{array}$ \\
\hline
\end{tabular}




\subsection{Conteúdo}

\subsubsection{Conteúdo - Inteligibilidade}

\begin{tabular}{|c|c|c|c|c|c|c|c|}
\hline & \multicolumn{4}{|c|}{ Métrica } & \multirow[b]{2}{*}{ Entrada para medição } & \multirow[b]{2}{*}{ Referência } & \multirow[b]{2}{*}{ Público alvo } \\
\hline Atributo & $\begin{array}{c}\text { Propósito da Métrica } \\
\text { (Questão) }\end{array}$ & Método de aplicação & $\begin{array}{c}\text { Fórmula e/ou } \\
\text { elementos de dados } \\
\text { para medição }\end{array}$ & Escala de Medição & & & \\
\hline \multirow[b]{2}{*}{ Organização } & 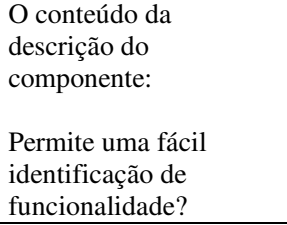 & $\begin{array}{l}\text { O avaliador deve } \\
\text { verificar o conteúdo da } \\
\text { descrição do } \\
\text { componente }\end{array}$ & $\begin{array}{l}\text { - Sim; } \\
\text { - Não; }\end{array}$ & $\begin{array}{l}0-100 \% \\
\text { Sim }=100 \% \\
\text { Não }=0 \%\end{array}$ & $\begin{array}{l}\text { Documento de } \\
\text { Descrição do } \\
\text { Componente }\end{array}$ & ISO 12119 & $\begin{array}{l}\text { Avaliador } \\
\text { Usuário } \\
\text { (Desenvolvedor, } \\
\text { integrador, arquiteto) }\end{array}$ \\
\hline & $\begin{array}{l}\text { Destaca informações } \\
\text { relevantes. Ex.: através } \\
\text { do uso de negrito, } \\
\text { itálico, palavras em } \\
\text { letra maiúscula, } \\
\text { numeração, } \\
\text { sombreamento de } \\
\text { texto? }\end{array}$ & $\begin{array}{l}\text { O avaliador deve } \\
\text { verificar o conteúdo da } \\
\text { descrição do } \\
\text { componente. }\end{array}$ & $\begin{array}{l}\text { - Sim; } \\
\text { - Não; }\end{array}$ & $\begin{array}{l}0-100 \% \\
\text { Sim }=100 \% \\
\text { Não }=0 \%\end{array}$ & $\begin{array}{l}\text { Documento de } \\
\text { Descrição do } \\
\text { Componente }\end{array}$ & ISO 12119 & $\begin{array}{l}\text { Avaliador } \\
\text { Usuário } \\
\text { (Desenvolvedor, } \\
\text { integrador, arquiteto) }\end{array}$ \\
\hline \multirow{2}{*}{ Clareza } & $\begin{array}{l}\text { O texto da descrição do } \\
\text { componente: } \\
\text { dá margem a } \\
\text { interpretações } \\
\text { ambíguas? }\end{array}$ & $\begin{array}{l}\text { O avaliador deve } \\
\text { verificar o conteúdo da } \\
\text { descrição do } \\
\text { componente. }\end{array}$ & $\begin{array}{l}\text { - Sim; } \\
\text { - Não; }\end{array}$ & $\begin{array}{l}0-100 \% \\
\text { Sim }=0 \% \\
\text { Não }=100 \%\end{array}$ & $\begin{array}{l}\text { Documento de } \\
\text { Descrição do } \\
\text { Componente }\end{array}$ & ISO 12119 & $\begin{array}{l}\text { Avaliador } \\
\text { Usuário } \\
\text { (Desenvolvedor, } \\
\text { integrador, arquiteto) }\end{array}$ \\
\hline & $\begin{array}{l}\text { apresenta erros } \\
\text { gramaticais e/ou } \\
\text { ortográficos? }\end{array}$ & $\begin{array}{l}\text { O avaliador deve } \\
\text { verificar o conteúdo da } \\
\text { descrição do } \\
\text { componente. }\end{array}$ & $\begin{array}{l}- \text { Muitos = 0; } \\
- \text { Poucos = 50; } \\
- \text { Nenhum = 100; }\end{array}$ & $\begin{array}{l}0-100 \% \\
\text { Muitos }=0 \% \\
\text { Poucos }=50 \% \\
\text { Nenhum }=100 \%\end{array}$ & $\begin{array}{l}\text { Documento de } \\
\text { Descrição do } \\
\text { Componente }\end{array}$ & ISO 12119 & $\begin{array}{l}\text { Avaliador } \\
\text { Usuário } \\
\text { (Desenvolvedor, } \\
\text { integrador, arquiteto) }\end{array}$ \\
\hline
\end{tabular}

\subsection{Identificação e Indicação}

\begin{tabular}{|c|c|c|c|c|c|c|c|}
\hline & \multicolumn{4}{|c|}{ Métrica } & & & \\
\hline Atributo & $\begin{array}{c}\text { Propósito da Métrica } \\
\text { (Questão) }\end{array}$ & Método de aplicação & $\begin{array}{c}\text { Fórmula e/ou } \\
\text { elementos de dados } \\
\text { para medição }\end{array}$ & Escala de Medição & Entrada para medição & Referência & Público alvo \\
\hline
\end{tabular}




\begin{tabular}{|c|c|c|c|c|c|c|c|}
\hline $\begin{array}{l}\text { Identificação da } \\
\text { Descrição do } \\
\text { Componente }\end{array}$ & $\begin{array}{l}\text { A descrição do } \\
\text { componente possui um } \\
\text { título que o identifica? } \\
\text { Ex.: "Descrição do } \\
\text { Componente", } \\
\text { "Informações do } \\
\text { Componente", } \\
\text { "Descrição Funcional } \\
\text { do Componente" ou } \\
\text { outro similar? }\end{array}$ & $\begin{array}{l}\text { O avaliador deve } \\
\text { verificar o conteúdo da } \\
\text { descrição do } \\
\text { componente. }\end{array}$ & $\begin{array}{l}\text { - Sim; } \\
\text { - Não; }\end{array}$ & $\begin{array}{l}0-100 \% \\
\text { Sim }=100 \% \\
\text { Não }=0 \%\end{array}$ & $\begin{array}{l}\text { Documento de } \\
\text { Descrição do } \\
\text { Componente }\end{array}$ & ISO 12119 & $\begin{array}{l}\text { Avaliador } \\
\text { Usuário } \\
\text { (Desenvolvedor, } \\
\text { integrador, arquiteto) }\end{array}$ \\
\hline \multirow{2}{*}{$\begin{array}{l}\text { Identificação do } \\
\text { Componente }\end{array}$} & $\begin{array}{l}\text { A Descrição do } \\
\text { Componente: } \\
\text { identifica o nome do } \\
\text { componente? }\end{array}$ & $\begin{array}{l}\text { O avaliador deve } \\
\text { verificar o conteúdo da } \\
\text { descrição do } \\
\text { componente. }\end{array}$ & $\begin{array}{l}\text { - Sim; } \\
\text { - Não; }\end{array}$ & $\begin{array}{l}0-100 \% \\
\text { Sim }=100 \% \\
\text { Não }=0 \%\end{array}$ & $\begin{array}{l}\text { Documento de } \\
\text { Descrição do } \\
\text { Componente }\end{array}$ & ISO 12119 & $\begin{array}{l}\text { Avaliador } \\
\text { Usuário } \\
\text { (Desenvolvedor, } \\
\text { integrador, arquiteto) }\end{array}$ \\
\hline & $\begin{array}{l}\text { identifica a versão ou a } \\
\text { data de criação do } \\
\text { componente? }\end{array}$ & $\begin{array}{l}\text { O avaliador deve } \\
\text { verificar o conteúdo da } \\
\text { descrição do } \\
\text { componente. }\end{array}$ & $\begin{array}{l}\text { - Sim; } \\
\text { - Não; }\end{array}$ & $\begin{array}{l}0-100 \% \\
\text { Sim }=100 \% \\
\text { Não }=0 \%\end{array}$ & $\begin{array}{l}\text { Documento de } \\
\text { Descrição do } \\
\text { Componente }\end{array}$ & ISO 12119 & $\begin{array}{l}\text { Avaliador } \\
\text { Usuário } \\
\text { (Desenvolvedor, } \\
\text { integrador, arquiteto) }\end{array}$ \\
\hline \multirow{2}{*}{$\begin{array}{l}\text { Identificação do } \\
\text { Produtor }\end{array}$} & $\begin{array}{l}\text { A Descrição do } \\
\text { Componente: } \\
\text { identifica o nome do } \\
\text { produtor/fornecedor do } \\
\text { componente? }\end{array}$ & $\begin{array}{l}\text { O avaliador deve } \\
\text { verificar o conteúdo da } \\
\text { descrição do } \\
\text { componente. }\end{array}$ & $\begin{array}{l}\text { - Sim; } \\
\text { - Não; }\end{array}$ & $\begin{array}{l}0-100 \% \\
\text { Sim }=100 \% \\
\text { Não }=0 \%\end{array}$ & $\begin{array}{l}\text { Documento de } \\
\text { Descrição do } \\
\text { Componente }\end{array}$ & ISO 12119 & $\begin{array}{l}\text { Avaliador } \\
\text { Usuário } \\
\text { (Desenvolvedor, } \\
\text { integrador, arquiteto) }\end{array}$ \\
\hline & $\begin{array}{l}\text { identifica uma forma de } \\
\text { contato? }\end{array}$ & $\begin{array}{l}\text { O avaliador deve } \\
\text { verificar o conteúdo da } \\
\text { descrição do } \\
\text { componente. }\end{array}$ & $\begin{array}{l}\text { - Sim; } \\
\text { - Não; }\end{array}$ & $\begin{array}{l}0-100 \% \\
\text { Sim }=100 \% \\
\text { Não }=0 \%\end{array}$ & $\begin{array}{l}\text { Documento de } \\
\text { Descrição do } \\
\text { Componente }\end{array}$ & ISO 12119 & $\begin{array}{l}\text { Avaliador } \\
\text { Usuário } \\
\text { (Desenvolvedor, } \\
\text { integrador, arquiteto) }\end{array}$ \\
\hline \multirow{3}{*}{$\begin{array}{l}\text { Identificação do } \\
\text { modelo de } \\
\text { componentes adotado }\end{array}$} & $\begin{array}{l}\text { A descrição do } \\
\text { componente identifica: } \\
\text { o modelo de } \\
\text { componentes cuja as } \\
\text { interfaces estão em } \\
\text { conformidade? (Ex.: } \\
\text { Java Beans, J2EE, } \\
\text { COM, CORBA, entre } \\
\text { outros.) }\end{array}$ & $\begin{array}{l}\text { O avaliador deve } \\
\text { verificar o conteúdo da } \\
\text { descrição do } \\
\text { componente. }\end{array}$ & $\begin{array}{l}\text { - Sim; } \\
\text { - Não; }\end{array}$ & $\begin{array}{l}0-100 \% \\
\text { Sim }=100 \% \\
\text { Não }=0 \%\end{array}$ & $\begin{array}{l}\text { Documento de } \\
\text { Descrição do } \\
\text { Componente }\end{array}$ & $\begin{array}{l}\text { ISO } 12119 \\
\text { Sametinger }\end{array}$ & $\begin{array}{l}\text { Avaliador } \\
\text { Usuário } \\
\text { (Desenvolvedor, } \\
\text { integrador, arquiteto) }\end{array}$ \\
\hline & $\begin{array}{l}\text { a linguagem de } \\
\text { programação dos } \\
\text { fontes? }\end{array}$ & $\begin{array}{l}\text { O avaliador deve } \\
\text { verificar o conteúdo da } \\
\text { descrição do } \\
\text { componente. }\end{array}$ & $\begin{array}{l}\text { - Sim; } \\
\text { - Não; }\end{array}$ & $\begin{array}{l}0-100 \% \\
\text { Sim }=100 \% \\
\text { Não }=0 \%\end{array}$ & $\begin{array}{l}\text { Documento de } \\
\text { Descrição do } \\
\text { Componente }\end{array}$ & $\begin{array}{l}\text { ISO } 12119 \\
\text { Sametinger }\end{array}$ & $\begin{array}{l}\text { Avaliador } \\
\text { Usuário } \\
\text { (Desenvolvedor, } \\
\text { integrador, arquiteto) }\end{array}$ \\
\hline & o sistema operacional? & $\begin{array}{l}\text { O avaliador deve } \\
\text { verificar o conteúdo da } \\
\text { descrição do } \\
\text { componente. }\end{array}$ & $\begin{array}{l}\text { - Sim; } \\
\text { - Não; }\end{array}$ & $\begin{array}{l}0-100 \% \\
\text { Sim }=100 \% \\
\text { Não }=0 \%\end{array}$ & $\begin{array}{l}\text { Documento de } \\
\text { Descrição do } \\
\text { Componente }\end{array}$ & $\begin{array}{l}\text { ISO } 12119 \\
\text { Sametinger }\end{array}$ & $\begin{array}{l}\text { Avaliador } \\
\text { Usuário } \\
\text { (Desenvolvedor, } \\
\text { integrador, arquiteto) }\end{array}$ \\
\hline
\end{tabular}




\begin{tabular}{|c|c|c|c|c|c|c|c|}
\hline \multirow[t]{2}{*}{$\begin{array}{l}\text { Identificação de } \\
\text { Requisitos de } \\
\text { Hardware e Software }\end{array}$} & $\begin{array}{l}\text { A Descrição do } \\
\text { Componente identifica: } \\
\text { os requisitos de } \\
\text { software requerido pelo } \\
\text { componente? (Ex.: } \\
\text { necessidade de } \\
\text { bibliotecas, APIs, etc.) }\end{array}$ & $\begin{array}{l}\text { O avaliador deve } \\
\text { verificar o conteúdo da } \\
\text { descrição do } \\
\text { componente. }\end{array}$ & $\begin{array}{l}\text { - Sim; } \\
\text { - Não; }\end{array}$ & $\begin{array}{l}0-100 \% \\
\text { Sim }=100 \% \\
\text { Não }=0 \%\end{array}$ & $\begin{array}{l}\text { Documento de } \\
\text { Descrição do } \\
\text { Componente }\end{array}$ & ISO 12119 & $\begin{array}{l}\text { Avaliador } \\
\text { Usuário } \\
\text { (Desenvolvedor, } \\
\text { integrador, arquiteto) }\end{array}$ \\
\hline & $\begin{array}{l}\text { os requisitos de } \\
\text { hardware requeridos } \\
\text { pelo componente? (Ex.: } \\
\text { equipamento, SO, etc.) }\end{array}$ & $\begin{array}{l}\text { O avaliador deve } \\
\text { verificar o conteúdo da } \\
\text { descrição do } \\
\text { componente. }\end{array}$ & $\begin{array}{l}\text { - Sim; } \\
\text { - Não; }\end{array}$ & $\begin{array}{l}0-100 \% \\
\text { Sim }=100 \% \\
\text { Não }=0 \%\end{array}$ & $\begin{array}{l}\text { Documento de } \\
\text { Descrição do } \\
\text { Componente }\end{array}$ & ISO 12119 & $\begin{array}{l}\text { Avaliador } \\
\text { Usuário } \\
\text { (Desenvolvedor, } \\
\text { integrador, arquiteto) }\end{array}$ \\
\hline $\begin{array}{l}\text { Indicação de Serviços } \\
\text { de Suporte }\end{array}$ & $\begin{array}{l}\text { A descrição do } \\
\text { componente contém: } \\
\text { declaração sobre } \\
\text { suporte? }\end{array}$ & $\begin{array}{l}\text { O avaliador deve } \\
\text { verificar o conteúdo da } \\
\text { descrição do } \\
\text { componente. }\end{array}$ & $\begin{array}{l}\text { - Sim; } \\
\text { - Não; }\end{array}$ & $\begin{array}{l}0-100 \% \\
\text { Sim }=100 \% \\
\text { Não }=0 \%\end{array}$ & $\begin{array}{l}\text { Documento de } \\
\text { Descrição do } \\
\text { Componente }\end{array}$ & ISO 12119 & $\begin{array}{l}\text { Avaliador } \\
\text { Usuário } \\
\text { (Desenvolvedor, } \\
\text { integrador, arquiteto) }\end{array}$ \\
\hline $\begin{array}{l}\text { Identificação do tipo } \\
\text { de licença do } \\
\text { componente }\end{array}$ & $\begin{array}{l}\text { A descrição do } \\
\text { componente contém } \\
\text { uma identificação do } \\
\text { tipo de licença do } \\
\text { componente? }\end{array}$ & $\begin{array}{l}\text { O avaliador deve } \\
\text { verificar o conteúdo da } \\
\text { descrição do } \\
\text { componente. }\end{array}$ & $\begin{array}{l}\text { - Sim; } \\
\text { - Não; }\end{array}$ & $\begin{array}{l}0-100 \% \\
\text { Sim }=100 \% \\
\text { Não }=0 \%\end{array}$ & $\begin{array}{l}\text { Documento de } \\
\text { Descrição do } \\
\text { Componente }\end{array}$ & $\begin{array}{l}\text { ISO } 12119 \\
\text { Sametinger }\end{array}$ & $\begin{array}{l}\text { Avaliador } \\
\text { Usuário } \\
\text { (Desenvolvedor, } \\
\text { integrador, arquiteto) }\end{array}$ \\
\hline
\end{tabular}

\subsection{Declaração}

\begin{tabular}{|c|c|c|c|c|c|c|c|}
\hline & \multicolumn{4}{|c|}{ Métrica } & & & \\
\hline Atributo & $\begin{array}{c}\text { Propósito da Métrica } \\
\text { (Questão) }\end{array}$ & Método de aplicação & $\begin{array}{c}\text { Fórmula e/ou } \\
\text { elementos de dados } \\
\text { para medição }\end{array}$ & Escala de Medição & Entrada para medição & Referência & Público alvo \\
\hline
\end{tabular}




\begin{tabular}{|c|c|c|c|c|c|c|c|}
\hline \multirow{4}{*}{$\begin{array}{l}\text { Declaração sobre } \\
\text { funcionalidade }\end{array}$} & $\begin{array}{l}\text { A Descrição do } \\
\text { componente contém: } \\
\text { declaração sobre a } \\
\text { funcionalidade única do } \\
\text { componente, ou seja, o } \\
\text { que o componente se } \\
\text { propõe a fazer? }\end{array}$ & $\begin{array}{l}\text { O avaliador deve } \\
\text { verificar o conteúdo da } \\
\text { descrição do } \\
\text { componente. }\end{array}$ & $\begin{array}{l}\text { - Sim; } \\
\text { - Não; }\end{array}$ & $\begin{array}{l}0-100 \% \\
\text { Sim }=100 \% \\
\text { Não }=0 \%\end{array}$ & $\begin{array}{l}\text { Descrição do } \\
\text { componente }\end{array}$ & ISO 12119 & $\begin{array}{l}\text { Avaliador } \\
\text { Usuário } \\
\text { (Desenvolvedor, } \\
\text { integrador, arquiteto) }\end{array}$ \\
\hline & $\begin{array}{l}\text { declaração sobre as } \\
\text { interfaces providas e } \\
\text { requeridas do } \\
\text { componente? }\end{array}$ & $\begin{array}{l}\text { O avaliador deve } \\
\text { verificar o conteúdo da } \\
\text { descrição do } \\
\text { componente. }\end{array}$ & $\begin{array}{l}\text { - Sim; } \\
\text { - Não; }\end{array}$ & $\begin{array}{l}0-100 \% \\
\text { Sim }=100 \% \\
\text { Não }=0 \%\end{array}$ & $\begin{array}{l}\text { Descrição do } \\
\text { componente }\end{array}$ & ISO 12119 & $\begin{array}{l}\text { Avaliador } \\
\text { Usuário } \\
\text { (Desenvolvedor, } \\
\text { integrador, arquiteto) }\end{array}$ \\
\hline & $\begin{array}{l}\text { declaração de valores- } \\
\text { limite (Caso o uso do } \\
\text { componente seja } \\
\text { limitado por eles)? }\end{array}$ & $\begin{array}{l}\text { O avaliador deve } \\
\text { verificar o conteúdo da } \\
\text { descrição do } \\
\text { componente. }\end{array}$ & $\begin{array}{l}\text { - Sim; } \\
\text { - Não; }\end{array}$ & $\begin{array}{l}0-100 \% \\
\text { Sim }=100 \% \\
\text { Não }=0 \%\end{array}$ & $\begin{array}{l}\text { Descrição do } \\
\text { componente }\end{array}$ & ISO 12119 & $\begin{array}{l}\text { Avaliador } \\
\text { Usuário } \\
\text { (Desenvolvedor, } \\
\text { integrador, arquiteto) }\end{array}$ \\
\hline & $\begin{array}{l}\text { Caso o componente } \\
\text { apresente recursos de } \\
\text { segurança de acesso, a } \\
\text { descrição do } \\
\text { componente descreve } \\
\text { os recursos para evitar } \\
\text { o acesso não autorizado } \\
\text { (acidental ou } \\
\text { intencional) aos seus } \\
\text { serviços e dados? }\end{array}$ & $\begin{array}{l}\text { O avaliador deve } \\
\text { verificar o conteúdo da } \\
\text { descrição do } \\
\text { componente. }\end{array}$ & $\begin{array}{l}\text { - Sim; } \\
\text { - Não; }\end{array}$ & $\begin{array}{l}0-100 \% \\
\text { Sim }=100 \% \\
\text { Não }=0 \%\end{array}$ & $\begin{array}{l}\text { Descrição do } \\
\text { componente }\end{array}$ & ISO 12119 & $\begin{array}{l}\text { Avaliador } \\
\text { Usuário } \\
\text { (Desenvolvedor, } \\
\text { integrador, arquiteto) }\end{array}$ \\
\hline $\begin{array}{l}\text { Declaração sobre } \\
\text { confiabilidade }\end{array}$ & $\begin{array}{l}\text { A descrição do } \\
\text { componente contém } \\
\text { declaração sobre } \\
\text { procedimentos de } \\
\text { preservação de dados? }\end{array}$ & $\begin{array}{l}\text { O avaliador deve } \\
\text { verificar o conteúdo da } \\
\text { descrição do } \\
\text { componente. }\end{array}$ & $\begin{array}{l}\text { - Sim; } \\
\text { - Não; }\end{array}$ & $\begin{array}{l}0-100 \% \\
\text { Sim }=100 \% \\
\text { Não }=0 \%\end{array}$ & $\begin{array}{l}\text { Descrição do } \\
\text { componente }\end{array}$ & ISO 12119 & $\begin{array}{l}\text { Avaliador } \\
\text { Usuário } \\
\text { (Desenvolvedor, } \\
\text { integrador, arquiteto) }\end{array}$ \\
\hline \multirow[t]{2}{*}{$\begin{array}{l}\text { Declaração sobre } \\
\text { Usabilidade }\end{array}$} & $\begin{array}{l}\text { A descrição do } \\
\text { componente contém: } \\
\text { declaração sobre os } \\
\text { conhecimentos } \\
\text { tecnológicos requeridos } \\
\text { pelo usuário do } \\
\text { componente? }\end{array}$ & $\begin{array}{l}\text { O avaliador deve } \\
\text { verificar o conteúdo da } \\
\text { descrição do } \\
\text { componente. }\end{array}$ & $\begin{array}{l}\text { - Sim; } \\
\text { - Não; }\end{array}$ & $\begin{array}{l}0-100 \% \\
\text { Sim }=100 \% \\
\text { Não }=0 \%\end{array}$ & $\begin{array}{l}\text { Descrição do } \\
\text { componente }\end{array}$ & ISO 12119 & $\begin{array}{l}\text { Avaliador } \\
\text { Usuário } \\
\text { (Desenvolvedor, } \\
\text { integrador, arquiteto) }\end{array}$ \\
\hline & $\begin{array}{l}\text { declaração sobre } \\
\text { direitos autorais? }\end{array}$ & $\begin{array}{l}\text { O avaliador deve } \\
\text { verificar o conteúdo da } \\
\text { descrição do } \\
\text { componente. }\end{array}$ & $\begin{array}{l}\text { - Sim; } \\
\text { - Não; }\end{array}$ & $\begin{array}{l}0-100 \% \\
\text { Sim }=100 \% \\
\text { Não }=0 \%\end{array}$ & $\begin{array}{l}\text { Descrição do } \\
\text { componente }\end{array}$ & ISO 12119 & $\begin{array}{l}\text { Avaliador } \\
\text { Usuário } \\
\text { (Desenvolvedor, } \\
\text { integrador, arquiteto) }\end{array}$ \\
\hline
\end{tabular}




\begin{tabular}{|c|c|c|c|c|c|c|c|}
\hline \multirow[t]{2}{*}{$\begin{array}{l}\text { Declaração sobre } \\
\text { Eficiência }\end{array}$} & $\begin{array}{l}\text { A Descrição do } \\
\text { Componente contém: } \\
\text { declaração sobre o } \\
\text { comportamento do } \\
\text { componente em relação } \\
\text { ao tempo? }\end{array}$ & $\begin{array}{l}\text { O avaliador deve } \\
\text { verificar o conteúdo da } \\
\text { descrição do } \\
\text { componente. }\end{array}$ & $\begin{array}{l}\text { - Sim; } \\
\text { - Não; }\end{array}$ & $\begin{array}{l}0-100 \% \\
\text { Sim }=100 \% \\
\text { Não }=0 \%\end{array}$ & $\begin{array}{l}\text { Descrição do } \\
\text { componente }\end{array}$ & ISO 12119 & $\begin{array}{l}\text { Avaliador } \\
\text { Usuário } \\
\text { (Desenvolvedor, } \\
\text { integrador, arquiteto) }\end{array}$ \\
\hline & $\begin{array}{l}\text { declaração sobre o } \\
\text { comportamento do } \\
\text { componente em relação } \\
\text { aos recursos? }\end{array}$ & $\begin{array}{l}\text { O avaliador deve } \\
\text { verificar o conteúdo da } \\
\text { descrição do } \\
\text { componente. }\end{array}$ & $\begin{array}{l}\text { - Sim; } \\
\text { - Não; }\end{array}$ & $\begin{array}{l}0-100 \% \\
\text { Sim }=100 \% \\
\text { Não }=0 \%\end{array}$ & $\begin{array}{l}\text { Descrição do } \\
\text { componente }\end{array}$ & ISO 12119 & $\begin{array}{l}\text { Avaliador } \\
\text { Usuário } \\
\text { (Desenvolvedor, } \\
\text { integrador, arquiteto) }\end{array}$ \\
\hline \multicolumn{8}{|c|}{ Pela ISO 12119, essa declaração não é obrigatória } \\
\hline $\begin{array}{l}\text { Declaração sobre } \\
\text { portabilidade }\end{array}$ & $\begin{array}{l}\text { A Descrição do } \\
\text { Componente contém } \\
\text { uma declaração sobre a } \\
\text { capacidade do } \\
\text { componente de ser } \\
\text { adaptado em diferentes } \\
\text { ambientes? }\end{array}$ & $\begin{array}{l}\text { O avaliador deve } \\
\text { verificar o conteúdo da } \\
\text { descrição do } \\
\text { componente. }\end{array}$ & $\begin{array}{l}\text { - Sim; } \\
\text { - Não; }\end{array}$ & $\begin{array}{l}0-100 \% \\
\text { Sim }=100 \% \\
\text { Não }=0 \%\end{array}$ & $\begin{array}{l}\text { Descrição do } \\
\text { componente }\end{array}$ & ISO 12119 & $\begin{array}{l}\text { Avaliador } \\
\text { Usuário } \\
\text { (Desenvolvedor, } \\
\text { integrador, arquiteto) }\end{array}$ \\
\hline
\end{tabular}




\section{Documentação do componente}

\subsection{Existência}

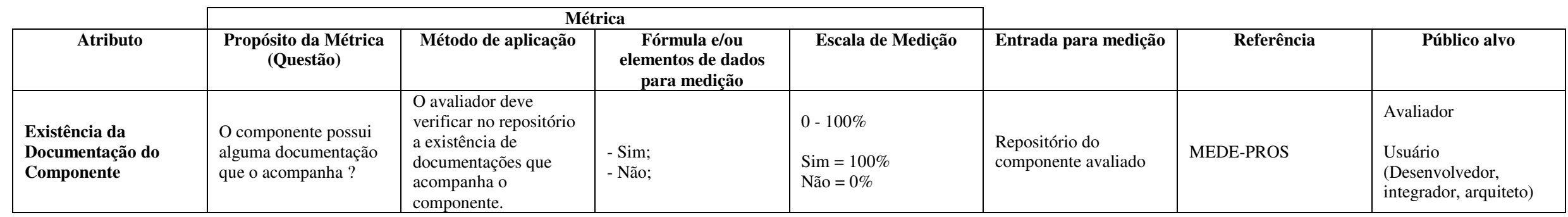

\subsection{Completitude}

2.2.1 Completitude - Identificação e Indicação

\begin{tabular}{|c|c|c|c|c|c|c|c|}
\hline & & & & & & & \\
\hline Atributo & $\begin{array}{c}\text { Propósito da Métrica } \\
\text { (Questão) }\end{array}$ & Método de aplicação & $\begin{array}{l}\text { Fórmula e/ou } \\
\text { elementos de dados } \\
\text { para medição }\end{array}$ & Escala de Medição & Entrada para medição & Referência & Público alvo \\
\hline
\end{tabular}




\begin{tabular}{|c|c|c|c|c|c|c|c|}
\hline \multirow{3}{*}{$\begin{array}{l}\text { Identificação do } \\
\text { Componente }\end{array}$} & $\begin{array}{l}\text { As documentações do } \\
\text { componente estão } \\
\text { identificadas em sua } \\
\text { página inicial com: } \\
\text { o nome do } \\
\text { componente? }\end{array}$ & $\begin{array}{l}\text { O avaliador deve } \\
\text { verificar o conteúdo da } \\
\text { documentação do } \\
\text { componente. }\end{array}$ & $\begin{array}{l}\text { - Todos; } \\
\text { - Quase todos; } \\
\text { - Alguns; } \\
\text { - Nenhum; }\end{array}$ & $\begin{array}{l}0-100 \% \\
\text { Todos }=100 \% \\
\text { Quase todos }=70 \% \\
\text { Alguns }=40 \% \\
\text { Nenhum }=0 \%\end{array}$ & $\begin{array}{l}\text { Documentação do } \\
\text { Componente }\end{array}$ & MEDE-PROS & $\begin{array}{l}\text { Avaliador } \\
\text { Usuário } \\
\text { (Desenvolvedor, } \\
\text { integrador, arquiteto) }\end{array}$ \\
\hline & $\begin{array}{l}\text { a versão ou data de } \\
\text { criação do } \\
\text { componente? }\end{array}$ & $\begin{array}{l}\text { O avaliador deve } \\
\text { verificar o conteúdo da } \\
\text { documentação do } \\
\text { componente. }\end{array}$ & $\begin{array}{l}\text { - Todos; } \\
\text { - Quase todos; } \\
\text { - Alguns; } \\
\text { - Nenhum; }\end{array}$ & $\begin{array}{l}0-100 \% \\
\text { Todos }=100 \% \\
\text { Quase todos }=70 \% \\
\text { Alguns }=40 \% \\
\text { Nenhum }=0 \% \\
\end{array}$ & $\begin{array}{l}\text { Documentação do } \\
\text { Componente }\end{array}$ & MEDE-PROS & $\begin{array}{l}\text { Avaliador } \\
\text { Usuário } \\
\text { (Desenvolvedor, } \\
\text { integrador, arquiteto) }\end{array}$ \\
\hline & $\begin{array}{l}\text { o tipo do documento? } \\
\text { (ex. manual do usuário, } \\
\text { manual de implantação, } \\
\text { etc.) }\end{array}$ & $\begin{array}{l}\text { O avaliador deve } \\
\text { verificar o conteúdo da } \\
\text { documentação do } \\
\text { componente. }\end{array}$ & $\begin{array}{l}\text { - Todos; } \\
\text { - Quase todos; } \\
\text { - Alguns; } \\
\text { - Nenhum; }\end{array}$ & $\begin{array}{l}0-100 \% \\
\text { Todos }=100 \% \\
\text { Quase todos }=70 \% \\
\text { Alguns }=40 \% \\
\text { Nenhum }=0 \% \\
\end{array}$ & $\begin{array}{l}\text { Documentação do } \\
\text { Componente }\end{array}$ & MEDE-PROS & $\begin{array}{l}\text { Avaliador } \\
\text { Usuário } \\
\text { (Desenvolvedor, } \\
\text { integrador, arquiteto) }\end{array}$ \\
\hline \multirow{3}{*}{$\begin{array}{l}\text { Identificação do } \\
\text { Produtor }\end{array}$} & $\begin{array}{l}\text { Nas documentações do } \\
\text { componente estão } \\
\text { indicadas: } \\
\text { o nome do } \\
\text { produtor/fornecedor? }\end{array}$ & $\begin{array}{l}\text { O avaliador deve } \\
\text { verificar o conteúdo da } \\
\text { documentação do } \\
\text { componente. }\end{array}$ & $\begin{array}{l}\text { - Todos; } \\
\text { - Quase todos; } \\
\text { - Alguns; } \\
\text { - Nenhum; }\end{array}$ & $\begin{array}{l}0-100 \% \\
\text { Todos }=100 \% \\
\text { Quase todos }=70 \% \\
\text { Alguns }=40 \% \\
\text { Nenhum }=0 \%\end{array}$ & $\begin{array}{l}\text { Documentação do } \\
\text { Componente }\end{array}$ & MEDE-PROS & $\begin{array}{l}\text { Avaliador } \\
\text { Usuário } \\
\text { (Desenvolvedor, } \\
\text { integrador, arquiteto) }\end{array}$ \\
\hline & $\begin{array}{l}\text { o endereço do } \\
\text { produtor/fornecedor? }\end{array}$ & $\begin{array}{l}\text { O avaliador deve } \\
\text { verificar o conteúdo da } \\
\text { documentação do } \\
\text { componente. }\end{array}$ & $\begin{array}{l}\text { - Todos; } \\
\text { - Quase todos; } \\
\text { - Alguns; } \\
\text { - Nenhum; }\end{array}$ & $\begin{array}{l}0-100 \% \\
\text { Todos }=100 \% \\
\text { Quase todos }=70 \% \\
\text { Alguns }=40 \% \\
\text { Nenhum }=0 \% \\
\end{array}$ & $\begin{array}{l}\text { Documentação do } \\
\text { Componente }\end{array}$ & MEDE-PROS & $\begin{array}{l}\text { Avaliador } \\
\text { Usuário } \\
\text { (Desenvolvedor, } \\
\text { integrador, arquiteto) }\end{array}$ \\
\hline & $\begin{array}{l}\text { o telefone, fax, e-mail, } \\
\text { site ou outra forma de } \\
\text { contato com o } \\
\text { produtor/fornecedor? }\end{array}$ & $\begin{array}{l}\text { O avaliador deve } \\
\text { verificar o conteúdo da } \\
\text { documentação do } \\
\text { componente. }\end{array}$ & $\begin{array}{l}\text { - Todos; } \\
\text { - Quase todos; } \\
\text { - Alguns; } \\
\text { - Nenhum; }\end{array}$ & $\begin{array}{l}0-100 \% \\
\text { Todos }=100 \% \\
\text { Quase todos }=70 \% \\
\text { Alguns }=40 \% \\
\text { Nenhum }=0 \%\end{array}$ & $\begin{array}{l}\text { Documentação do } \\
\text { Componente }\end{array}$ & MEDE-PROS & $\begin{array}{l}\text { Avaliador } \\
\text { Usuário } \\
\text { (Desenvolvedor, } \\
\text { integrador, arquiteto) }\end{array}$ \\
\hline $\begin{array}{l}\text { Identificação da } \\
\text { composição do } \\
\text { componente }\end{array}$ & $\begin{array}{l}\text { Na documentação do } \\
\text { componente, pelo } \\
\text { menos em um item do } \\
\text { conjunto de } \\
\text { documentos, está } \\
\text { identificado a } \\
\text { composição do } \\
\text { componente, caso ele } \\
\text { seja composto? }\end{array}$ & $\begin{array}{l}\text { O avaliador deve } \\
\text { verificar o conteúdo da } \\
\text { documentação do } \\
\text { componente. }\end{array}$ & $\begin{array}{l}\text { - Sim; } \\
\text { - Não; }\end{array}$ & $\begin{array}{l}0-100 \% \\
\text { Sim }=100 \% \\
\text { Não }=0 \%\end{array}$ & $\begin{array}{l}\text { Documentação do } \\
\text { Componente }\end{array}$ & MEDE-PROS & $\begin{array}{l}\text { Avaliador } \\
\text { Usuário } \\
\text { (Desenvolvedor, } \\
\text { integrador, arquiteto) }\end{array}$ \\
\hline
\end{tabular}




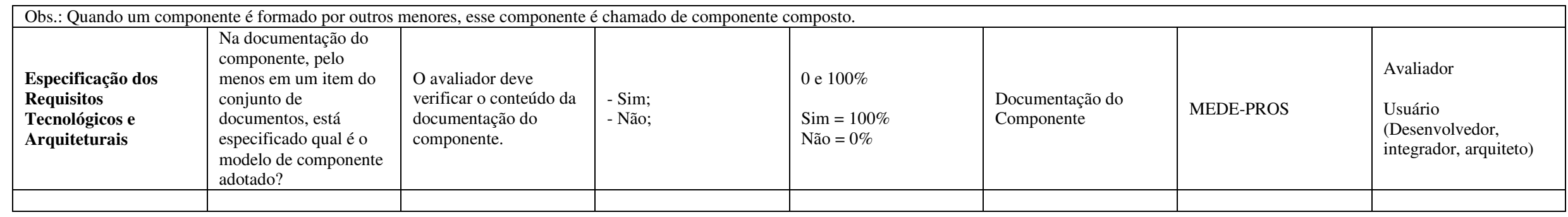

\subsubsection{Completitude - Descrição sobre funcionalidade}

\begin{tabular}{|c|c|c|c|c|c|c|c|}
\hline & \multicolumn{4}{|c|}{ Métrica } & & & \\
\hline Atributo & $\begin{array}{c}\text { Propósito da Métrica } \\
\text { (Questão) }\end{array}$ & Método de aplicação & $\begin{array}{c}\text { Fórmula e/ou } \\
\text { elementos de dados } \\
\text { para medição }\end{array}$ & Escala de Medição & Entrada para medição & Referência & Público alvo \\
\hline $\begin{array}{l}\text { Descrição sobre a } \\
\text { funcionalidade do } \\
\text { componente }\end{array}$ & $\begin{array}{l}\text { Na documentação do } \\
\text { componente, pelo } \\
\text { menos em um item do } \\
\text { conjunto de } \\
\text { documentos, possui } \\
\text { uma declaração sobre a } \\
\text { funcionalidade global } \\
\text { do componente? }\end{array}$ & $\begin{array}{l}\text { O avaliador deve } \\
\text { verificar o conteúdo da } \\
\text { documentação do } \\
\text { componente. }\end{array}$ & $\begin{array}{l}\text { - Sim; } \\
\text { - Não; }\end{array}$ & $\begin{array}{l}0-100 \% \\
\text { Sim }=100 \% \\
\text { Não }=0 \%\end{array}$ & $\begin{array}{l}\text { Documentação do } \\
\text { Componente }\end{array}$ & MEDE-PROS & $\begin{array}{l}\text { Avaliador } \\
\text { Usuário } \\
\text { (Desenvolvedor, } \\
\text { integrador, arquiteto) }\end{array}$ \\
\hline
\end{tabular}




\begin{tabular}{|c|c|c|c|c|c|c|c|}
\hline \multirow{3}{*}{$\begin{array}{l}\text { Descrição das } \\
\text { Interfaces do } \\
\text { Componente }\end{array}$} & $\begin{array}{l}\text { Na documentação do } \\
\text { componente, pelo } \\
\text { menos em um item do } \\
\text { conjunto de } \\
\text { documentos: } \\
\text { as interfaces fornecidas } \\
\text { pelo componente estão } \\
\text { especificadas? }\end{array}$ & $\begin{array}{l}\text { O avaliador deve } \\
\text { verificar o conteúdo da } \\
\text { documentação do } \\
\text { componente. }\end{array}$ & $\begin{array}{l}\text { - Sim; } \\
\text { - Não; }\end{array}$ & $\begin{array}{l}0-100 \% \\
\text { Sim }=100 \% \\
\text { Não }=0 \%\end{array}$ & $\begin{array}{l}\text { Documentação do } \\
\text { Componente }\end{array}$ & MEDE-PROS & $\begin{array}{l}\text { Avaliador } \\
\text { Usuário } \\
\text { (Desenvolvedor, } \\
\text { integrador, arquiteto) }\end{array}$ \\
\hline & $\begin{array}{l}\text { Os serviços das } \\
\text { interfaces fornecidas } \\
\text { são detalhados } \\
\text { (contratos, exemplos)? }\end{array}$ & $\begin{array}{l}\text { O avaliador deve } \\
\text { verificar o conteúdo da } \\
\text { documentação do } \\
\text { componente. }\end{array}$ & $\begin{array}{l}\text { - Sim; } \\
\text { - Não; }\end{array}$ & $\begin{array}{l}0-100 \% \\
\text { Sim }=100 \% \\
\text { Não }=0 \%\end{array}$ & $\begin{array}{l}\text { Documentação do } \\
\text { Componente }\end{array}$ & MEDE-PROS & $\begin{array}{l}\text { Avaliador } \\
\text { Usuário } \\
\text { (Desenvolvedor, } \\
\text { integrador, arquiteto) }\end{array}$ \\
\hline & $\begin{array}{l}\text { as interfaces requeridas } \\
\text { do componente estão } \\
\text { especificadas? }\end{array}$ & $\begin{array}{l}\text { O avaliador deve } \\
\text { verificar o conteúdo da } \\
\text { documentação do } \\
\text { componente. }\end{array}$ & $\begin{array}{l}\text { - Sim; } \\
\text { - Não; }\end{array}$ & $\begin{array}{l}0-100 \% \\
\text { Sim }=100 \% \\
\text { Não }=0 \%\end{array}$ & $\begin{array}{l}\text { Documentação do } \\
\text { Componente }\end{array}$ & MEDE-PROS & $\begin{array}{l}\text { Avaliador } \\
\text { Usuário } \\
\text { (Desenvolvedor, } \\
\text { integrador, arquiteto) }\end{array}$ \\
\hline Valores limites & $\begin{array}{l}\text { Na documentação do } \\
\text { componente são } \\
\text { descritos os valores } \\
\text { limite fornecidos no } \\
\text { documento de descrição } \\
\text { do componente? (Ex.: } \\
\text { valores máximos ou } \\
\text { mínimos.) }\end{array}$ & $\begin{array}{l}\text { O avaliador deve } \\
\text { verificar o conteúdo da } \\
\text { documentação do } \\
\text { componente. }\end{array}$ & $\begin{array}{l}\text { - Sim; } \\
\text { - Não; }\end{array}$ & $\begin{array}{l}0-100 \% \\
\text { Sim }=100 \% \\
\text { Não }=0 \%\end{array}$ & $\begin{array}{l}\text { Documentação do } \\
\text { Componente }\end{array}$ & MEDE-PROS & $\begin{array}{l}\text { Avaliador } \\
\text { Usuário } \\
\text { (Desenvolvedor, } \\
\text { integrador, arquiteto) }\end{array}$ \\
\hline $\begin{array}{l}\text { Indicação sobre } \\
\text { segurança de acesso }\end{array}$ & $\begin{array}{l}\text { Caso o componente } \\
\text { dependa de controle de } \\
\text { segurança, a } \\
\text { documentação do } \\
\text { componente contém } \\
\text { informações de como } \\
\text { evitar o acesso não } \\
\text { autorizado (acidental ou } \\
\text { intencional) a serviços } \\
\text { e/ou dados? (Ex.: senha } \\
\text { aos dados, criptografia, } \\
\text { etc.) }\end{array}$ & $\begin{array}{l}\text { O avaliador deve } \\
\text { verificar o conteúdo da } \\
\text { documentação do } \\
\text { componente. }\end{array}$ & $\begin{array}{l}\text { - Sim; } \\
\text { - Não; }\end{array}$ & $\begin{array}{l}0-100 \% \\
\text { Sim }=100 \% \\
\text { Não }=0 \%\end{array}$ & $\begin{array}{l}\text { Documentação do } \\
\text { Componente }\end{array}$ & MEDE-PROS & $\begin{array}{l}\text { Avaliador } \\
\text { Usuário } \\
\text { (Desenvolvedor, } \\
\text { integrador, arquiteto) }\end{array}$ \\
\hline
\end{tabular}




\subsubsection{Completitude - Descrição sobre usabilidade}

\begin{tabular}{|c|c|c|c|c|c|c|c|}
\hline & \multicolumn{4}{|c|}{ Métrica } & \multirow[b]{2}{*}{ Entrada para medição } & \multirow[b]{2}{*}{ Referência } & \multirow[b]{2}{*}{ Público alvo } \\
\hline Atributo & $\begin{array}{c}\text { Propósito da Métrica } \\
\text { (Questão) }\end{array}$ & Método de aplicação & $\begin{array}{c}\text { Fórmula e/ou } \\
\text { elementos de dados } \\
\text { para medição }\end{array}$ & Escala de Medição & & & \\
\hline $\begin{array}{l}\text { Adaptação as } \\
\text { necessidades do } \\
\text { usuário }\end{array}$ & $\begin{array}{l}\text { A documentação do } \\
\text { componente apresenta o } \\
\text { procedimento, } \\
\text { automatizado ou não, } \\
\text { para que o usuário } \\
\text { consiga configurar o } \\
\text { componente? }\end{array}$ & $\begin{array}{l}\text { O avaliador deve } \\
\text { verificar o conteúdo da } \\
\text { documentação do } \\
\text { componente. }\end{array}$ & $\begin{array}{l}\text { - Sim; } \\
\text { - Não; }\end{array}$ & $\begin{array}{l}0-100 \% \\
\text { Sim }=100 \% \\
\text { Não }=0 \%\end{array}$ & $\begin{array}{l}\text { Documentação do } \\
\text { Componente }\end{array}$ & MEDE-PROS & $\begin{array}{l}\text { Avaliador } \\
\text { Usuário } \\
\text { (Desenvolvedor, } \\
\text { integrador, arquiteto) }\end{array}$ \\
\hline $\begin{array}{l}\text { Descrição da proteção } \\
\text { contra infrações a } \\
\text { direitos autorais }\end{array}$ & $\begin{array}{l}\text { Na documentação do } \\
\text { componente a proteçãa } \\
\text { técnica contra infrações } \\
\text { a direitos autorais está } \\
\text { descrita, caso o } \\
\text { componente seja } \\
\text { protegido? }\end{array}$ & $\begin{array}{l}\text { O avaliador deve } \\
\text { verificar o conteúdo da } \\
\text { documentação do } \\
\text { componente. }\end{array}$ & $\begin{array}{l}\text { - Sim; } \\
\text { - Não; }\end{array}$ & $\begin{array}{l}0-100 \% \\
\text { Sim }=100 \% \\
\text { Não }=0 \%\end{array}$ & $\begin{array}{l}\text { Documentação do } \\
\text { Componente }\end{array}$ & MEDE-PROS & $\begin{array}{l}\text { Avaliador } \\
\text { Usuário } \\
\text { (Desenvolvedor, } \\
\text { integrador, arquiteto) }\end{array}$ \\
\hline $\begin{array}{l}\text { Descrição sobre } \\
\text { implantação }\end{array}$ & $\begin{array}{l}\text { A documentação do } \\
\text { componente contém } \\
\text { todas as informações } \\
\text { necessárias para a } \\
\text { implantação do } \\
\text { componente, } \\
\text { descrevendo todos os } \\
\text { passos para incorporar } \\
\text { o componente em um } \\
\text { sistema? (Ex.: } \\
\text { informações detalhadas } \\
\text { de interfaces, cenários } \\
\text { amostrais, } \\
\text { procedimentos de } \\
\text { diagnósticos) }\end{array}$ & $\begin{array}{l}\text { O avaliador deve } \\
\text { verificar o conteúdo da } \\
\text { documentação do } \\
\text { componente. }\end{array}$ & $\begin{array}{l}\text { - Todos; } \\
\text { - Quase todos; } \\
\text { - Alguns; } \\
\text { - Nenhum; }\end{array}$ & $\begin{array}{l}0-100 \% \\
\text { Todos }=100 \% \\
\text { Quase todos }=70 \% \\
\text { Alguns }=40 \% \\
\text { Nenhum }=0 \%\end{array}$ & $\begin{array}{l}\text { Documentação do } \\
\text { Componente }\end{array}$ & MEDE-PROS & $\begin{array}{l}\text { Avaliador } \\
\text { Usuário } \\
\text { (Desenvolvedor, } \\
\text { integrador, arquiteto) }\end{array}$ \\
\hline
\end{tabular}




\subsection{Usabilidade}

\begin{tabular}{|c|c|c|c|c|c|c|c|}
\hline & \multicolumn{4}{|c|}{ Métrica } & \multirow[b]{2}{*}{ Entrada para medição } & \multirow[b]{2}{*}{ Referência } & \multirow[b]{2}{*}{ Público alvo } \\
\hline Atributo & $\begin{array}{c}\text { Propósito da Métrica } \\
\text { (Questão) }\end{array}$ & Método de aplicação & $\begin{array}{c}\text { Fórmula e/ou } \\
\text { elementos de dados } \\
\text { para medição }\end{array}$ & Escala de Medição & & & \\
\hline Apreensibilidade & $\begin{array}{l}\text { A documentação do } \\
\text { componente possui } \\
\text { recursos que auxiliem } \\
\text { em sua compreensão } \\
\text { (através de, exemplos, } \\
\text { ilustrações, etc)? }\end{array}$ & $\begin{array}{l}\text { O avaliador deve } \\
\text { verificar o conteúdo da } \\
\text { documentação do } \\
\text { componente. }\end{array}$ & $\begin{array}{l}\text { - Sim; } \\
\text { - Não; }\end{array}$ & $\begin{array}{l}0-100 \% \\
\text { Sim }=100 \% \\
\text { Não }=0 \%\end{array}$ & $\begin{array}{l}\text { Documentação do } \\
\text { Componente }\end{array}$ & MEDE-PROS & $\begin{array}{l}\text { Avaliador } \\
\text { Usuário } \\
\text { (Desenvolvedor, } \\
\text { integrador, arquiteto) }\end{array}$ \\
\hline Operacionalidade & $\begin{array}{l}\text { A documentação do } \\
\text { componente possui } \\
\text { recursos que auxiliem } \\
\text { no seu manuseio? } \\
\text { (Índice Geral, } \\
\text { Remissivo, Referência } \\
\text { Cruzada) } \\
\end{array}$ & $\begin{array}{l}\text { O avaliador deve } \\
\text { verificar o conteúdo da } \\
\text { documentação do } \\
\text { componente. }\end{array}$ & $\begin{array}{l}\text { - Sim; } \\
\text { - Não; }\end{array}$ & $\begin{array}{l}0-100 \% \\
\text { Sim }=100 \% \\
\text { Não }=0 \%\end{array}$ & $\begin{array}{l}\text { Documentação do } \\
\text { Componente }\end{array}$ & MEDE-PROS & $\begin{array}{l}\text { Avaliador } \\
\text { Usuário } \\
\text { (Desenvolvedor, } \\
\text { integrador, arquiteto) }\end{array}$ \\
\hline $\begin{array}{l}\text { Inteligibilidade da } \\
\text { documentação do } \\
\text { componente }\end{array}$ & $\begin{array}{l}\text { Qual a proporçãa de } \\
\text { serviços da interface } \\
\text { (ou tipos de serviços) é } \\
\text { entendido depois de ler } \\
\text { a documentação do } \\
\text { componente? }\end{array}$ & $\begin{array}{l}\text { O avaliador deve } \\
\text { conduzir o teste de } \\
\text { usuário e entrevistar o } \\
\text { usuário com } \\
\text { questionários ou } \\
\text { observar o seu } \\
\text { comportamento. } \\
\text { Contar o número de } \\
\text { serviços que são } \\
\text { adequadamente } \\
\text { entendidos e comparar } \\
\text { com o número total de } \\
\text { serviços das interfaces } \\
\text { do componente. }\end{array}$ & $\begin{array}{l}\mathrm{X}=100 *(\mathrm{~A} / \mathrm{B}) \\
\text { A: Número de serviços } \\
\text { (ou tipos de serviços) } \\
\text { entendidos } \\
\text { B: Número total de } \\
\text { serviços (ou tipos de } \\
\text { serviços) }\end{array}$ & $\begin{array}{l}0<=\mathrm{X}<=100 \% \\
\text { Quanto mais próximo } \\
\text { de } 100 \%, \text { melhor. }\end{array}$ & $\begin{array}{l}\text { Especificação do } \\
\text { componente. } \\
\text { Entrevista com o } \\
\text { usuário }\end{array}$ & $9126-2$ & $\begin{array}{l}\text { Avaliador } \\
\text { Usuário } \\
\text { (Desenvolvedor, } \\
\text { integrador, arquiteto) }\end{array}$ \\
\hline
\end{tabular}




\section{Artefato: Componente}

\subsection{Funcionalidade}

\subsubsection{Funcionalidade - Adequação}

\begin{tabular}{|c|c|c|c|c|c|c|c|}
\hline & \multicolumn{4}{|c|}{ Métrica } & & & \\
\hline Atributo & $\begin{array}{c}\text { Propósito da Métrica } \\
\text { (Questão) }\end{array}$ & Método de aplicação & $\begin{array}{c}\text { Fórmula e/ou } \\
\text { elementos de dados } \\
\text { para medição }\end{array}$ & Escala de Medição & Entrada para medição & Referência & Público alvo \\
\hline Adequação Funcional & $\begin{array}{l}\text { Os serviços das } \\
\text { interfaces do } \\
\text { componente são } \\
\text { suficientemente } \\
\text { adequados para a } \\
\text { funcionalidade que o } \\
\text { mesmo se propõe a } \\
\text { realizar? }\end{array}$ & $\begin{array}{l}\text { O avaliador deve } \\
\text { verificar se os serviços } \\
\text { disponíveis nas } \\
\text { interfaces do } \\
\text { componente atendem a } \\
\text { necessidade específica } \\
\text { do componente. } \\
\text { Confrontar o número de } \\
\text { interfaces adequadas } \\
\text { pelo total de avaliadas. }\end{array}$ & $\begin{array}{l}\text { - Sim; } \\
\text { - Não; }\end{array}$ & $\begin{array}{l}0-100 \% \\
\operatorname{Sim}=100 \% \\
\text { Não }=0 \%\end{array}$ & $\begin{array}{l}\begin{array}{l}\text { Especificação do } \\
\text { componente }\end{array} \\
\text { Componente }\end{array}$ & ISO 9126-2 & $\begin{array}{l}\text { Avaliador } \\
\text { Usuário (Desenvolvedor, } \\
\text { integrador, arquiteto) }\end{array}$ \\
\hline $\begin{array}{l}\text { Cobertura da } \\
\text { Implementação } \\
\text { Funcional }\end{array}$ & $\begin{array}{l}\text { O componente } \\
\text { implementa todos os } \\
\text { serviços de suas } \\
\text { interfaces conforme } \\
\text { especificado em sua } \\
\text { documentação? }\end{array}$ & $\begin{array}{l}\text { O avaliador deve } \\
\text { verificar o número de } \\
\text { serviços implementados } \\
\text { no componente } \\
\text { comparado com o } \\
\text { número de serviços } \\
\text { especificados. }\end{array}$ & $\begin{array}{l}\mathrm{X}=100 *(\mathrm{~A} / \mathrm{B}) \\
\begin{array}{l}\text { A: Número de serviços } \\
\text { das interfaces } \\
\text { implementadas }\end{array} \\
\begin{array}{l}\text { B: Número total de } \\
\text { serviços das interfaces } \\
\text { descritas na } \\
\text { especificação }\end{array}\end{array}$ & $\begin{array}{l}0<=\mathrm{X}<=100 \% \\
\text { Quanto mais próximo de } \\
100 \%, \text { melhor }\end{array}$ & $\begin{array}{l}\text { Especificação do } \\
\text { componente }\end{array}$ & ISO 9126-2 & $\begin{array}{l}\text { Avaliador } \\
\text { Usuário (Desenvolvedor, } \\
\text { integrador, arquiteto) }\end{array}$ \\
\hline
\end{tabular}




\subsubsection{Funcionalidade - Acurácia}

\begin{tabular}{|c|c|c|c|c|c|c|c|}
\hline \multirow[b]{2}{*}{\begin{tabular}{|l|} 
Atributo \\
\end{tabular}} & \multicolumn{4}{|c|}{ Métrica } & \multirow[b]{2}{*}{ Entrada para medição } & \multirow[b]{2}{*}{ Referência } & \multirow[b]{2}{*}{ Público alvo } \\
\hline & $\begin{array}{c}\text { Propósito da Métrica } \\
\text { (Questão) }\end{array}$ & Método de aplicação & $\begin{array}{c}\text { Fórmula e/ou } \\
\text { elementos de dados } \\
\text { para medição }\end{array}$ & Escala de Medição & & & \\
\hline Precisão & $\begin{array}{l}\text { Os valores dos } \\
\text { resultados retornados } \\
\text { pelo componente são } \\
\text { corretos ou precisos? }\end{array}$ & $\begin{array}{l}\text { O avaliador deve testar o } \\
\text { componente e verificar o } \\
\text { número de resultados } \\
\text { corretos ou com precisão } \\
\text { esperados comparadas } \\
\text { com o número de } \\
\text { resultados obtidos em } \\
\text { uma dada série de } \\
\text { chamadas. }\end{array}$ & $\begin{array}{l}\mathrm{X}=100^{*}(\mathrm{~A} / \mathrm{B}) \\
\begin{array}{l}\text { A: Número de resultados } \\
\text { corretos ou com grau de } \\
\text { precisão esperado }\end{array} \\
\begin{array}{l}\text { B: Número de resultados } \\
\text { obtidos em uma dada } \\
\text { série de chamadas }\end{array}\end{array}$ & $\begin{array}{l}0<=X<=100 \% \\
\text { Quanto mais próximo de } \\
100 \% \text {, melhor. }\end{array}$ & $\begin{array}{l}\text { Especificação do } \\
\text { componente }\end{array}$ & 9126-2 & $\begin{array}{l}\text { Avaliador } \\
\text { Usuário (Desenvolvedor, } \\
\text { integrador, arquiteto) }\end{array}$ \\
\hline
\end{tabular}

\subsubsection{Funcionalidade - Interoperabilidade}

\begin{tabular}{|c|c|c|c|c|c|c|c|}
\hline & \multicolumn{4}{|c|}{ Métrica } & \multirow[b]{2}{*}{ Entrada para medição } & \multirow[b]{2}{*}{ Referência } & \multirow[b]{2}{*}{ Público alvo } \\
\hline Atributo & $\begin{array}{c}\text { Propósito da Métrica } \\
\text { (Questão) }\end{array}$ & Método de aplicação & $\begin{array}{c}\text { Fórmula e/ou } \\
\text { elementos de dados } \\
\text { para medição }\end{array}$ & Escala de Medição & & & \\
\hline $\begin{array}{l}\text { Compatibilidade dos } \\
\text { dados }\end{array}$ & $\begin{array}{l}\text { O componente utiliza } \\
\text { uma representação de } \\
\text { dados de entrada e saída } \\
\text { que esteja em } \\
\text { conformidade com } \\
\text { algum padrão ou } \\
\text { convenção } \\
\text { internacional? }\end{array}$ & $\begin{array}{l}\text { O avaliador deve } \\
\text { verificar os dados de } \\
\text { entrada e saída se existe } \\
\text { a presença de um padrão } \\
\text { de conformidade e, se } \\
\text { sim, qual o formato } \\
\text { utilizado. (ASN1, XML, } \\
\text { etc.) }\end{array}$ & $\begin{array}{l}\text { - Sim; } \\
\text { - Não; }\end{array}$ & $\begin{array}{l}0-100 \% \\
\text { Sim }=100 \% \\
\text { Não }=0 \%\end{array}$ & $\begin{array}{l}\text { Componente; } \\
\text { Documentação do } \\
\text { componente; }\end{array}$ & $\begin{array}{l}\text { ISO 9126-2; } \\
\text { Bertoa; }\end{array}$ & $\begin{array}{l}\text { Avaliador } \\
\text { Usuário (Desenvolvedor, } \\
\text { integrador, arquiteto) }\end{array}$ \\
\hline $\begin{array}{l}\text { Conformidade das } \\
\text { interfaces }\end{array}$ & $\begin{array}{l}\text { As interfaces do } \\
\text { componente estão em } \\
\text { conformidade com o } \\
\text { modelo de componente } \\
\text { definido em sua } \\
\text { documentação? }\end{array}$ & $\begin{array}{l}\text { O avaliador deve } \\
\text { verificar se as interfaces } \\
\text { do componente estão } \\
\text { realmente de acordo com } \\
\text { o modelo de } \\
\text { componentes descrito em } \\
\text { sua documentação. }\end{array}$ & $\begin{array}{l}\text { - Sim; } \\
\text { - Não; }\end{array}$ & $\begin{array}{l}0-100 \% \\
\text { Sim }=100 \% \\
\text { Não }=0 \%\end{array}$ & $\begin{array}{l}\text { Componente; } \\
\text { Documentação do } \\
\text { componente }\end{array}$ & $\begin{array}{l}\text { ISO 9126-2; } \\
\text { Sametinger; }\end{array}$ & $\begin{array}{l}\text { Avaliador } \\
\text { Usuário (Desenvolvedor, } \\
\text { integrador, arquiteto) }\end{array}$ \\
\hline
\end{tabular}




\subsubsection{Funcionalidade - Segurança de Acesso}

\begin{tabular}{|c|c|c|c|c|c|c|c|}
\hline & \multicolumn{4}{|c|}{ Métrica } & & & \\
\hline Atributo & $\begin{array}{c}\text { Propósito da Métrica } \\
\text { (Questão) }\end{array}$ & Método de aplicação & $\begin{array}{c}\text { Fórmula e/ou } \\
\text { elementos de dados } \\
\text { para medição }\end{array}$ & Escala de Medição & Entrada para medição & Referência & Público alvo \\
\hline $\begin{array}{l}\text { Controlabilidade de } \\
\text { Acesso }\end{array}$ & $\begin{array}{l}\text { Caso o componente lide } \\
\text { com autenticação e } \\
\text { autorização de acesso, } \\
\text { ele oferece esse controle } \\
\text { a seus serviços e dados? }\end{array}$ & $\begin{array}{l}\text { O avaliador deve } \\
\text { verificar a existência de } \\
\text { controle de acesso, } \\
\text { através de testes no } \\
\text { componente, tentando } \\
\text { acessar seus serviços. }\end{array}$ & $\begin{array}{l}\text { - Sim; } \\
\text { - Não; }\end{array}$ & $\begin{array}{l}0-100 \% \\
\text { Sim }=100 \% \\
\text { Não }=0 \%\end{array}$ & $\begin{array}{l}\text { Componente e sua } \\
\text { especificação }\end{array}$ & $9126-2$ & $\begin{array}{l}\text { Avaliador } \\
\text { Usuário (Desenvolvedor, } \\
\text { integrador, arquiteto) }\end{array}$ \\
\hline Criptografia dos Dados & $\begin{array}{l}\text { Caso o componente lide } \\
\text { com dados sigilosos, o } \\
\text { mesmo utiliza-se de } \\
\text { criptografia para } \\
\text { proteger esses dados? }\end{array}$ & $\begin{array}{l}\text { O avaliador deve } \\
\text { verificar a presença de } \\
\text { criptografias em seus } \\
\text { dados manipulados } \\
\text { conforme descrito em } \\
\text { sua especificação. }\end{array}$ & $\begin{array}{l}\text { - Sim; } \\
\text { - Não; }\end{array}$ & $\begin{array}{l}0-100 \% \\
\text { Sim }=100 \% \\
\text { Não }=0 \%\end{array}$ & $\begin{array}{l}\text { Componente e sua } \\
\text { especificação }\end{array}$ & $9126-2$ & $\begin{array}{l}\text { Avaliador } \\
\text { Usuário (Desenvolvedor, } \\
\text { integrador, arquiteto) }\end{array}$ \\
\hline
\end{tabular}

\subsubsection{Funcionalidade - Conformidade relacionada à funcionalidade}

\begin{tabular}{|c|c|c|c|c|c|c|c|}
\hline & \multicolumn{4}{|c|}{ Métrica } & & & \\
\hline Atributo & $\begin{array}{c}\text { Propósito da Métrica } \\
\text { (Questão) }\end{array}$ & Método de aplicação & $\begin{array}{c}\text { Fórmula e/ou } \\
\text { elementos de dados } \\
\text { para medição }\end{array}$ & Escala de Medição & Entrada para medição & Referência & Público alvo \\
\hline $\begin{array}{l}\text { Conformidade } \\
\text { funcional }\end{array}$ & $\begin{array}{l}\text { A funcionalidade do } \\
\text { componente está em } \\
\text { conformidade com } \\
\text { regulamentações, } \\
\text { padrões e convenções } \\
\text { aplicáveis previstas em } \\
\text { lei? }\end{array}$ & $\begin{array}{l}\text { O avaliador deve contar } \\
\text { o número de itens } \\
\text { requeridos de } \\
\text { conformidade que foram } \\
\text { encontrados e comparar } \\
\text { com o número total de } \\
\text { itens requeridos de } \\
\text { conformidade na } \\
\text { especificação. }\end{array}$ & $\begin{array}{l}\text { - Sim; } \\
\text { - Não; }\end{array}$ & $\begin{array}{l}0-100 \% \\
\text { Sim }=100 \% \\
\text { Não }=0 \%\end{array}$ & $\begin{array}{l}\text { Especificação do } \\
\text { componente }\end{array}$ & ISO 9126-2 & $\begin{array}{l}\text { Avaliador } \\
\text { Usuário (Desenvolvedor, } \\
\text { integrador, arquiteto) }\end{array}$ \\
\hline
\end{tabular}




\subsection{Confiabilidade}

\subsubsection{Confiabilidade - Maturidade}

\begin{tabular}{|c|c|c|c|c|c|c|c|}
\hline & \multicolumn{4}{|c|}{ Métrica } & \multirow[b]{2}{*}{ Entrada para medição } & \multirow[b]{2}{*}{ Referência } & \multirow[b]{2}{*}{ Público alvo } \\
\hline Atributo & $\begin{array}{c}\text { Propósito da Métrica } \\
\text { (Questão) }\end{array}$ & Método de aplicação & $\begin{array}{c}\text { Fórmula e/ou } \\
\text { elementos de dados } \\
\text { para medição }\end{array}$ & Escala de Medição & & & \\
\hline $\begin{array}{l}\text { Evolução entre versões } \\
\text { (Remoção de falhas) }\end{array}$ & $\begin{array}{l}\text { Qual a média de } \\
\text { remoção de falhas entre } \\
\text { as versões lançadas do } \\
\text { componente? }\end{array}$ & $\begin{array}{l}\text { O avaliador deve } \\
\text { verificar no histórico de } \\
\text { versões do componente o } \\
\text { número absoluto de } \\
\text { versões com remoções } \\
\text { de falhas e calcular a } \\
\text { média em comparação } \\
\text { com a quantidade total } \\
\text { de versões. }\end{array}$ & $\begin{array}{l}X=100 *(A / B) \\
\text { A: Total de versões com } \\
\text { remoção de falhas } \\
\text { B: Total de versões do } \\
\text { componente }\end{array}$ & $\begin{array}{l}0<=X<=100 \% \\
\text { Quanto mais próximo de } \\
100 \% \text {, melhor. }\end{array}$ & Histórico de versões & ISO 9126-2 Bertoa & $\begin{array}{l}\text { Avaliador } \\
\text { Usuário (Desenvolvedor, } \\
\text { integrador, arquiteto) }\end{array}$ \\
\hline $\begin{array}{l}\text { Evolução entre versões } \\
\text { (Novas atualizações) }\end{array}$ & $\begin{array}{l}\text { Qual a média de novas } \\
\text { atualizações entre as } \\
\text { versões lançadas do } \\
\text { componente? }\end{array}$ & $\begin{array}{l}\text { O avaliador deve } \\
\text { verificar no histórico de } \\
\text { versões do componente o } \\
\text { número absoluto de } \\
\text { versões com atualizações } \\
\text { e calcular a média em } \\
\text { comparação com a } \\
\text { quantidade total de } \\
\text { versões. }\end{array}$ & $\begin{array}{l}\mathrm{X}=100^{*}(\mathrm{~A} / \mathrm{B}) \\
\text { A: Total de versões com } \\
\text { novas } \\
\text { atualizações(novos } \\
\text { serviços) } \\
\text { B: Total de versões do } \\
\text { componente }\end{array}$ & $\begin{array}{l}0<=X<=100 \% \\
\text { Quanto mais próximo de } \\
100 \% \text {, melhor. }\end{array}$ & Histórico de versões & ISO 9126-2 Bertoa & $\begin{array}{l}\text { Avaliador } \\
\text { Usuário (Desenvolvedor, } \\
\text { integrador, arquiteto) }\end{array}$ \\
\hline Cobertura de testes & $\begin{array}{l}\text { O componente possui } \\
\text { casos de testes } \\
\text { especificados para todos } \\
\text { os serviços de suas } \\
\text { interfaces? }\end{array}$ & $\begin{array}{l}\text { O avaliador deve } \\
\text { verificar se existem } \\
\text { casos de testes e se, os } \\
\text { mesmos cobrem todos os } \\
\text { serviços das interfaces } \\
\text { do componente. }\end{array}$ & $\begin{array}{l}\text { - Todos; } \\
\text { - Quase Todos; } \\
\text { - Alguns; } \\
\text { - Nenhum; }\end{array}$ & $\begin{array}{l}0-100 \% \\
\text { Todos }=100 \% \\
\text { Quase Todos }=70 \% \\
\text { Alguns }=40 \% \\
\text { Nenhum }=0 \%\end{array}$ & $\begin{array}{l}\text { Documento de Casos de } \\
\text { Testes }\end{array}$ & ISO 9126-2 & $\begin{array}{l}\text { Avaliador } \\
\text { Usuário (Desenvolvedor, } \\
\text { integrador, arquiteto) }\end{array}$ \\
\hline
\end{tabular}




\subsubsection{Confiabilidade - Tolerância à falhas}

\begin{tabular}{|c|c|c|c|c|c|c|c|}
\hline & \multicolumn{4}{|c|}{ Métrica } & \multirow[b]{2}{*}{ Entrada para medição } & \multirow[b]{2}{*}{ Referência } & \multirow[b]{2}{*}{ Público alvo } \\
\hline Atributo & $\begin{array}{c}\text { Propósito da Métrica } \\
\text { (Questão) }\end{array}$ & Método de aplicação & $\begin{array}{c}\text { Fórmula e/ou } \\
\text { elementos de dados } \\
\text { para medição }\end{array}$ & Escala de Medição & & & \\
\hline $\begin{array}{l}\text { Prevenção de operações } \\
\text { incorretas }\end{array}$ & $\begin{array}{l}\text { Os serviços das } \\
\text { interfaces do } \\
\text { componente são } \\
\text { implementados com a } \\
\text { capacidade de prevenir } \\
\text { operações incorretas? }\end{array}$ & $\begin{array}{l}\text { O avaliador deve } \\
\text { verificar, através de } \\
\text { testes com operações } \\
\text { incorretas, a capacidade } \\
\text { do componente de } \\
\text { prevenir ocorrência de } \\
\text { falhas. }\end{array}$ & $\begin{array}{l}\mathrm{X}=100^{*}(\mathrm{~A} / \mathrm{B}) \\
\text { A: Número de prevenção } \\
\text { de ocorrências de falhas } \\
\text { B: Número de casos de } \\
\text { testes executados de } \\
\text { padrões de operações } \\
\text { incorretas durante o teste }\end{array}$ & $\begin{array}{l}0<=\mathrm{X}<=100 \% \\
\text { Quanto mais próximo de } \\
100 \%, \text { melhor. }\end{array}$ & $\begin{array}{l}\begin{array}{l}\text { Especificação do } \\
\text { componente }\end{array} \\
\text { Casos de testes }\end{array}$ & ISO 9126-2 & $\begin{array}{l}\text { Avaliador } \\
\text { Usuário (Desenvolvedor, } \\
\text { integrador, arquiteto) }\end{array}$ \\
\hline \multicolumn{8}{|c|}{ Obs.: operações incorretas são: passagem de parâmetros incorretos, sequiência incorreta de entrada de dados, e seqüência incorreta de operações. } \\
\hline Tratamento de erros & $\begin{array}{l}\text { Os serviços do } \\
\text { componente foram } \\
\text { implementados com a } \\
\text { capacidade de tratar } \\
\text { situações de erro? }\end{array}$ & $\begin{array}{l}\text { O avaliador deve } \\
\text { verificar, através da } \\
\text { documentação ou do } \\
\text { próprio componente, se } \\
\text { ele possui a habilidade } \\
\text { de tratar situações de } \\
\text { erros para os dados } \\
\text { manipulados. }\end{array}$ & $\begin{array}{l}\text { - Manipulação; } \\
\text { - Detecção e Aviso; } \\
\text { - Sem tratamento; }\end{array}$ & $\begin{array}{l}0-100 \% \\
\text { Manipulação } \\
=100 \% \\
\text { Detecção e aviso = 50\% } \\
\text { Sem tratamento = 0\% }\end{array}$ & $\begin{array}{l}\text { Documentação do } \\
\text { componente }\end{array}$ & Bertoa & $\begin{array}{l}\text { Avaliador } \\
\text { Usuário (Desenvolvedor, } \\
\text { integrador, arquiteto) }\end{array}$ \\
\hline
\end{tabular}

\subsubsection{Confiabilidade - Recuperabilidade}

\begin{tabular}{|c|c|c|c|c|c|c|c|}
\hline & \multicolumn{4}{|c|}{ Métrica } & \multirow[b]{2}{*}{ Entrada para medição } & \multirow[b]{2}{*}{ Referência } & \multirow[b]{2}{*}{ Público alvo } \\
\hline Atributo & $\begin{array}{c}\text { Propósito da Métrica } \\
\text { (Questão) }\end{array}$ & Método de aplicação & $\begin{array}{c}\text { Fórmula e/ou } \\
\text { elementos de dados } \\
\text { para medição }\end{array}$ & Escala de Medição & & & \\
\hline Persistência & $\begin{array}{l}\text { O componente é capaz } \\
\text { de recuperar seu estado } \\
\text { quando necessário? }\end{array}$ & \begin{tabular}{|l} 
O avaliador deve \\
verificar, através da \\
documentação ou do \\
próprio componente, se \\
ele possui a habilidade \\
de armazenar seus dados \\
em uma base. \\
\end{tabular} & $\begin{array}{l}\text { - Sim; } \\
\text { - Não; }\end{array}$ & $\begin{array}{l}0-100 \% \\
\text { Sim }=100 \% \\
\text { Não }=0 \%\end{array}$ & $\begin{array}{l}\text { Documentação do } \\
\text { componente }\end{array}$ & Bertoa & $\begin{array}{l}\text { Avaliador } \\
\text { Usuário (Desenvolvedor, } \\
\text { integrador, arquiteto) }\end{array}$ \\
\hline & & & & & & & \\
\hline
\end{tabular}




\subsection{Usabilidade}

\subsubsection{Usabilidade - Inteligibilidade}

\begin{tabular}{|c|c|c|c|c|c|c|c|}
\hline & \multicolumn{4}{|c|}{ Métrica } & \multirow[b]{2}{*}{ Entrada para medição } & \multirow[b]{2}{*}{ Referência } & \multirow[b]{2}{*}{ Público alvo } \\
\hline Atributo & $\begin{array}{c}\text { Propósito da Métrica } \\
\text { (Questão) }\end{array}$ & Método de aplicação & \begin{tabular}{|c|c} 
Fórmula e/ou \\
elementos de dados \\
para medição
\end{tabular} & Escala de Medição & & & \\
\hline Treinamento & $\begin{array}{l}\text { O componente possui } \\
\text { algum tipo de } \\
\text { treinamento oferecido } \\
\text { por terceiros? }\end{array}$ & $\begin{array}{l}\text { O avaliador deve } \\
\text { verificar se o } \\
\text { componente possui } \\
\text { algum tipo de } \\
\text { treinamento que ajude a } \\
\text { compreender suas } \\
\text { funcionalidades e como } \\
\text { utilizá-lo. }\end{array}$ & $\begin{array}{l}\text { - Sim; } \\
\text { - Não; }\end{array}$ & $\begin{array}{l}0-100 \% \\
\text { Sim }=100 \% \\
\text { Não }=0 \%\end{array}$ & $\begin{array}{l}\text { Manual de operação do } \\
\text { componente. }\end{array}$ & Bertoa & $\begin{array}{l}\text { Avaliador } \\
\text { Usuário (Desenvolvedor, } \\
\text { integrador, arquiteto) }\end{array}$ \\
\hline $\begin{array}{l}\text { Cobertura de } \\
\text { demonstração }\end{array}$ & $\begin{array}{l}\text { As interfaces do } \\
\text { componente são } \\
\text { demonstradas através de } \\
\text { vídeos ou programas } \\
\text { exemplos? }\end{array}$ & $\begin{array}{l}\text { O avaliador deve } \\
\text { verificar se o } \\
\text { componente possui um } \\
\text { demo para demonstrar as } \\
\text { funcionalidades de suas } \\
\text { interfaces providas e } \\
\text { assim poder verificar se } \\
\text { o componente é } \\
\text { apropriado ou não. }\end{array}$ & $\begin{array}{l}\mathrm{X}=100 *(\mathrm{~A} / \mathrm{B}) \\
\begin{array}{l}\text { A: Interfaces descobertas } \\
\text { em demo }\end{array} \\
\begin{array}{l}\text { B: Interfaces do } \\
\text { componente }\end{array}\end{array}$ & $\begin{array}{l}0<=\mathrm{X}<=100 \% \\
\text { Quanto mais próximo de } \\
100 \%, \text { melhor. }\end{array}$ & $\begin{array}{l}\text { Manual de operação do } \\
\text { componente. } \\
\text { Demo do componente }\end{array}$ & Bertoa & $\begin{array}{l}\text { Avaliador } \\
\text { Usuário (Desenvolvedor, } \\
\text { integrador, arquiteto) }\end{array}$ \\
\hline $\begin{array}{l}\text { Interfaces com } \\
\text { entradas e saídas } \\
\text { compreensíveis }\end{array}$ & $\begin{array}{l}\text { É possível identificar } \\
\text { claramente os dados } \\
\text { requeridos como entrada } \\
\text { e saída dos serviços } \\
\text { disponibilizados nas } \\
\text { interfaces do } \\
\text { componente? }\end{array}$ & $\begin{array}{l}\text { Conduzir os testes e } \\
\text { entrevistar o usuário com } \\
\text { questionários ou } \\
\text { observar o seu } \\
\text { comportamento. } \\
\text { Contar o número de } \\
\text { serviços cujo o formato } \\
\text { dos dados de entrada e } \\
\text { saída é entendido pelo } \\
\text { usuário e comparar com } \\
\text { o número total de } \\
\text { serviços do componente. }\end{array}$ & $\begin{array}{l}\text { - Todos; } \\
\text { - Quase Todos; } \\
\text { - Alguns; } \\
\text { - Nenhum; }\end{array}$ & $\begin{array}{l}0-100 \% \\
\text { Todos }=100 \% \\
\text { Quase Todos }=70 \% \\
\text { Alguns }=40 \% \\
\text { Nenhum }=0 \%\end{array}$ & Entrevista com o usuário & $9126-2$ & $\begin{array}{l}\text { Avaliador } \\
\text { Usuário (Desenvolvedor, } \\
\text { integrador, arquiteto) }\end{array}$ \\
\hline
\end{tabular}




\subsubsection{Usabilidade - Apreensibilidade}

\begin{tabular}{|c|c|c|c|c|c|c|c|}
\hline & \multicolumn{4}{|c|}{ Métrica } & & & \\
\hline Atributo & $\begin{array}{c}\text { Propósito da Métrica } \\
\text { (Questão) }\end{array}$ & Método de aplicação & $\begin{array}{c}\text { Fórmula e/ou } \\
\text { elementos de dados } \\
\text { para medição }\end{array}$ & Escala de Medição & Entrada para medição & Referência & Público alvo \\
\hline $\begin{array}{l}\text { Facilidade de } \\
\text { aprendizagem }\end{array}$ & $\begin{array}{l}\text { O componente oferece } \\
\text { recursos (tópicos de } \\
\text { ajuda, tutoriais, etc.), que } \\
\text { facilite o aprendizado de } \\
\text { seu uso? }\end{array}$ & $\begin{array}{l}\text { O avaliador deve } \\
\text { verificar se existe algum } \\
\text { tipo de recurso como } \\
\text { ajuda on-line, tutorial, } \\
\text { entre outros que } \\
\text { exemplifiquem o uso do } \\
\text { componente. }\end{array}$ & $\begin{array}{l}\text { Sim; } \\
\text { Não; }\end{array}$ & $\begin{array}{l}0-100 \% \\
\text { Sim }=100 \% ; \\
\text { Não }=0 \%\end{array}$ & $\begin{array}{l}\text { Documentação do } \\
\text { componente; }\end{array}$ & $9126-2$ & $\begin{array}{l}\text { Avaliador } \\
\text { Usuário (Desenvolvedor, } \\
\text { integrador, arquiteto) }\end{array}$ \\
\hline
\end{tabular}

\subsubsection{Usabilidade - Operacionalidade}

\begin{tabular}{|c|c|c|c|c|c|c|c|}
\hline & \multicolumn{4}{|c|}{ Métrica } & \multirow[b]{2}{*}{ Entrada para medição } & \multirow[b]{2}{*}{ Referência } & \multirow[b]{2}{*}{ Público alvo } \\
\hline Atributo & $\begin{array}{l}\text { Propósito da Métrica } \\
\text { (Questão) }\end{array}$ & Método de aplicação & $\begin{array}{c}\text { Fórmula e/ou } \\
\text { elementos de dados } \\
\text { para medição }\end{array}$ & Escala de Medição & & & \\
\hline $\begin{array}{l}\text { Complexidade das } \\
\text { interfaces do } \\
\text { componente }\end{array}$ & $\begin{array}{l}\text { Qual o número médio de } \\
\text { serviços por interfaces } \\
\text { providas do } \\
\text { componente? }\end{array}$ & $\begin{array}{l}\text { O avaliador deve contar } \\
\text { o número de serviços em } \\
\text { todas as interfaces } \\
\text { providas do componente } \\
\text { e comparar com o total } \\
\text { de interfaces providas } \\
\text { obtendo uma taxa de } \\
\text { complexidade de } \\
\text { operação do componente }\end{array}$ & $\begin{array}{l}\mathrm{X}=\mathrm{A} / \mathrm{B} \\
\text { A: Operações em todas } \\
\text { as interfaces providas. } \\
\text { B: Interfaces providas }\end{array}$ & $\begin{array}{l}0-100 \% \\
X<=10 \\
=100 \% \\
10<X<=15 \\
=80 \% \\
15<X<=20 \\
=50 \% \\
20<X \\
=0 \%\end{array}$ & $\begin{array}{l}\begin{array}{l}\text { Especificação do } \\
\text { componente }\end{array} \\
\text { Componente }\end{array}$ & $9126-2$ & $\begin{array}{l}\text { Avaliador } \\
\text { Usuário (Desenvolvedor, } \\
\text { integrador, arquiteto) }\end{array}$ \\
\hline & & & & & & & \\
\hline
\end{tabular}




\subsection{Eficiência}

\subsubsection{Eficiência - Comportamento em relação ao tempo}

\begin{tabular}{|c|c|c|c|c|c|c|c|}
\hline & \multicolumn{4}{|c|}{ Métrica } & & & \\
\hline Atributo & $\begin{array}{c}\text { Propósito da Métrica } \\
\text { (Questão) }\end{array}$ & Método de aplicação & $\begin{array}{c}\text { Fórmula e/ou } \\
\text { elementos de dados } \\
\text { para medição }\end{array}$ & Escala de Medição & Entrada para medição & Referência & Público alvo \\
\hline Tempo de resposta & $\begin{array}{l}\text { O tempo gasto pelos } \\
\text { serviços do componente } \\
\text { para executar suas } \\
\text { tarefas atingiram a meta } \\
\text { especificada em sua } \\
\text { documentação? }\end{array}$ & $\begin{array}{l}\text { O avaliador deve } \\
\text { verificar o tempo de } \\
\text { resposta medindo o } \\
\text { tempo que leva para o } \\
\text { serviço completar sua } \\
\text { operação. Comparar esse } \\
\text { tempo com o } \\
\text { especificado na } \\
\text { documentação. }\end{array}$ & $\begin{array}{l}\text { - Todos os serviços; - - } \\
\text { Quase Todos; } \\
\text { - Alguns; } \\
\text { - Nenhum; }\end{array}$ & $\begin{array}{l}0-100 \% \\
\text { Todos os serviços = } \\
100 \% \\
\text { Quase todos }=70 \% \\
\text { Alguns }=40 \% \\
\text { Nenhum }=0 \%\end{array}$ & $\begin{array}{l}\text { Documento de Operação } \\
\text { Documento de teste }\end{array}$ & $9126-2$ & $\begin{array}{l}\text { Avaliador } \\
\text { Usuário (Desenvolvedor, } \\
\text { integrador, arquiteto) } \\
\text { Mantenedor }\end{array}$ \\
\hline
\end{tabular}

\subsubsection{Eficiência - Utilização de Recursos}

\begin{tabular}{|c|c|c|c|c|c|c|c|}
\hline & \multicolumn{4}{|c|}{ Métrica } & \multirow[b]{2}{*}{ Entrada para medição } & \multirow[b]{2}{*}{ Referência } & \multirow[b]{2}{*}{ Público alvo } \\
\hline Atributo & $\begin{array}{c}\text { Propósito da Métrica } \\
\text { (Questão) }\end{array}$ & Método de aplicação & $\begin{array}{c}\text { Fórmula e/ou } \\
\text { elementos de dados } \\
\text { para medição }\end{array}$ & Escala de Medição & & & \\
\hline Memória requerida & $\begin{array}{l}\text { Utilizando a memória } \\
\text { especificada em sua } \\
\text { documentação, o } \\
\text { componente opera } \\
\text { conforme o esperado? }\end{array}$ & $\begin{array}{l}\text { O avaliador deve } \\
\text { verificar na } \\
\text { documentação do } \\
\text { componente a } \\
\text { quantidade de memória } \\
\text { requerida. Executar } \\
\text { testes em um ambiente } \\
\text { com as condições de } \\
\text { memória requeridas e } \\
\text { monitorar os resultados. }\end{array}$ & $\begin{array}{l}\text { - Operou conforme o } \\
\text { esperado } \\
\text { - Eficiência prejudicada } \\
\text { - Não foi possível operar }\end{array}$ & $\begin{array}{l}0-100 \% \\
\text { Conforme Esperado } \\
=100 \% \\
\text { Eficiência prejudicada } \\
=50 \% \\
\text { Não foi possível operar = } \\
0 \%\end{array}$ & $\begin{array}{l}\text { Documento de Operação } \\
\text { Documento de Teste }\end{array}$ & $9126-2$ & $\begin{array}{l}\text { Avaliador } \\
\text { Usuário (Desenvolvedor, } \\
\text { integrador, arquiteto) } \\
\text { Mantenedor }\end{array}$ \\
\hline Utilização de disco & $\begin{array}{l}\text { O componente e suas } \\
\text { partes constituintes, caso } \\
\text { ele possua, utilizam o } \\
\text { espaço em disco } \\
\text { especificado em sua } \\
\text { documentação? }\end{array}$ & $\begin{array}{l}\text { O avaliador deve } \\
\text { verificar o tamanho do } \\
\text { componente e suas } \\
\text { partes constituintes, caso } \\
\text { ele tenha, para indicar a } \\
\text { utilização necessária de } \\
\text { disco ocupado. }\end{array}$ & $\begin{array}{l}\text { - Sim; } \\
\text { - Não; }\end{array}$ & $\begin{array}{l}0-100 \% \\
\operatorname{Sim}=100 \% \\
\text { Não }=0 \%\end{array}$ & $\begin{array}{l}\text { Componente e } \\
\text { Documentações }\end{array}$ & $\begin{array}{l}9126-2 \\
\text { Bertoa }\end{array}$ & $\begin{array}{l}\text { Avaliador } \\
\text { Usuário (Desenvolvedor, } \\
\text { integrador, arquiteto) }\end{array}$ \\
\hline
\end{tabular}




\subsection{Portabilidade}

\subsubsection{Portabilidade - Adaptabilidade}

\begin{tabular}{|c|c|c|c|c|c|c|c|}
\hline \multirow[b]{2}{*}{ Atributo } & \multicolumn{4}{|c|}{ Métrica } & \multirow[b]{2}{*}{ Entrada para medição } & \multirow[b]{2}{*}{ Referência } & \multirow[b]{2}{*}{ Público alvo } \\
\hline & $\begin{array}{c}\text { Propósito da Métrica } \\
\text { (Questão) }\end{array}$ & Método de aplicação & $\begin{array}{c}\text { Fórmula e/ou } \\
\text { elementos de dados } \\
\text { para medição }\end{array}$ & Escala de Medição & & & \\
\hline $\begin{array}{l}\text { Facilidade de } \\
\text { adaptação }\end{array}$ & $\begin{array}{l}\text { O componente se adapta } \\
\text { em diferentes ambientes } \\
\text { e plataformas da maneira } \\
\text { prevista em sua } \\
\text { documentação? }\end{array}$ & $\begin{array}{l}\text { O avaliador deve realizar } \\
\text { testes, nas plataformas } \\
\text { especificadas na } \\
\text { documentação do } \\
\text { componente, para } \\
\text { verificar se ele se adapta } \\
\text { facilmente nesses } \\
\text { ambientes. }\end{array}$ & $\begin{array}{l}\text { - Todos; } \\
\text { - Quase todos; } \\
\text { - Alguns; } \\
\text { - Nenhum; }\end{array}$ & $\begin{array}{l}0-100 \% \\
\text { Todos }=100 \% \\
\text { Quase todos }=70 \% \\
\text { Alguns }=40 \% \\
\text { Nenhum }=0 \%\end{array}$ & $\begin{array}{l}\text { Documento de operação } \\
\text { do componente }\end{array}$ & $9126-2$ & $\begin{array}{l}\text { Avaliador } \\
\text { Usuário (Desenvolvedor, } \\
\text { integrador, arquiteto) } \\
\text { Mantenedor }\end{array}$ \\
\hline
\end{tabular}

\subsubsection{Portabilidade - Capacidade para ser implantado}

\begin{tabular}{|c|c|c|c|c|c|c|c|}
\hline & \multicolumn{4}{|c|}{ Métrica } & & & \\
\hline Atributo & $\begin{array}{c}\text { Propósito da Métrica } \\
\text { (Questão) }\end{array}$ & Método de aplicação & $\begin{array}{c}\text { Fórmula e/ou } \\
\text { elementos de dados } \\
\text { para medição }\end{array}$ & Escala de Medição & Entrada para mediçãa & Referência & Público alvo \\
\hline $\begin{array}{l}\text { Facilidade de } \\
\text { implantação }\end{array}$ & $\begin{array}{l}\text { Qual o grau de facilidade } \\
\text { de implantação é } \\
\text { oferecido pelo } \\
\text { componente? }\end{array}$ & $\begin{array}{l}\text { O avaliador deve } \\
\text { verificar se os arquivos } \\
\text { necessários para a } \\
\text { implantação descritos na } \\
\text { documentação do } \\
\text { componente estão } \\
\text { disponíveis, ou mesmo } \\
\text { se existe algum arquivo } \\
\text { (programa) que faça } \\
\text { automaticamente sua } \\
\text { implantacão. }\end{array}$ & $\begin{array}{l}\text { - Implantação } \\
\text { automática; } \\
\text { - Arquivos necessários } \\
\text { presentes; } \\
\text { - Criação de arquivos } \\
\text { necessários; }\end{array}$ & $\begin{array}{l}\text { Implantação automática: } \\
=100 \% ; \\
\text { Arquivos necessários } \\
\text { presentes: } \\
=50 \% ; \\
\text { Criação de arquivos } \\
\text { necessários ou mudança } \\
\text { no componente: } \\
=0 \% ;\end{array}$ & $\begin{array}{l}\text { Manual de implantação } \\
\text { do componente }\end{array}$ & $9126-2$ & $\begin{array}{l}\text { Avaliador } \\
\text { Usuário (Desenvolvedor, } \\
\text { integrador, arquiteto) } \\
\text { Mantenedor }\end{array}$ \\
\hline
\end{tabular}




\subsubsection{Portabilidade - Coexistência}

\begin{tabular}{|c|c|c|c|c|c|c|c|}
\hline & \multicolumn{4}{|c|}{ Métrica } & & & \\
\hline Atributo & $\begin{array}{c}\text { Propósito da Métrica } \\
\text { (Questão) }\end{array}$ & Método de aplicação & $\begin{array}{c}\text { Fórmula e/ou } \\
\text { elementos de dados } \\
\text { para medição }\end{array}$ & Escala de Medição & Entrada para medição & Referência & Público alvo \\
\hline Coexistência disponível & $\begin{array}{l}\text { O componente oferece } \\
\text { alguma restrição quando } \\
\text { operado } \\
\text { simultaneamente com } \\
\text { algum outro tipo de } \\
\text { software que não } \\
\text { especificado em sua } \\
\text { documentação? }\end{array}$ & $\begin{array}{l}\text { O avaliador deve } \\
\text { verificar o uso do } \\
\text { componente } \\
\text { simultaneamente com os } \\
\text { software que serão } \\
\text { utilizados no mesmo } \\
\text { ambiente. }\end{array}$ & $\begin{array}{l}\text { - Sim; } \\
\text { - Não; }\end{array}$ & $\begin{array}{l}0-100 \% \\
\text { Sim }=0 \% \\
\text { Não }=100 \%\end{array}$ & $\begin{array}{l}\text { Documento de Operação } \\
\text { Componente }\end{array}$ & $9126-2$ & $\begin{array}{l}\text { Avaliador } \\
\text { Usuário (Desenvolvedor, } \\
\text { integrador, arquiteto) } \\
\text { Mantenedor }\end{array}$ \\
\hline
\end{tabular}

\subsubsection{Portabilidade - Capacidade para substituir}

\begin{tabular}{|c|c|c|c|c|c|c|c|}
\hline & \multicolumn{4}{|c|}{ Métrica } & & & \\
\hline Atributo & $\begin{array}{c}\text { Propósito da Métrica } \\
\text { (Questão) }\end{array}$ & Método de aplicação & $\begin{array}{c}\text { Fórmula e/ou } \\
\text { elementos de dados } \\
\text { para medição }\end{array}$ & Escala de Medição & Entrada para medição & Referência & Público alvo \\
\hline $\begin{array}{l}\text { Compatibilidade de } \\
\text { versões }\end{array}$ & $\begin{array}{l}\text { O Componente atual é } \\
\text { compatível com outras } \\
\text { versões que estão } \\
\text { indicadas em sua } \\
\text { especificação? }\end{array}$ & $\begin{array}{l}\text { O avaliador deve } \\
\text { verificar se as interfaces } \\
\text { do componente são } \\
\text { realmente compatíveis } \\
\text { com as interfaces das } \\
\text { outras versões conforme } \\
\text { está especificado na } \\
\text { documentação do } \\
\text { componente. }\end{array}$ & $\begin{array}{l}\text { Sim; } \\
\text { Não; }\end{array}$ & $\begin{array}{l}0-100 \% \\
\text { Sim }=100 \% \\
\text { Não }=0 \%\end{array}$ & $\begin{array}{l}\text { Documentação do } \\
\text { componente }\end{array}$ & $\begin{array}{l}\text { 9126-2; } \\
\text { Bertoa; }\end{array}$ & $\begin{array}{l}\text { Avaliador } \\
\text { Usuário (Desenvolvedor, } \\
\text { integrador, arquiteto) } \\
\text { Mantenedor }\end{array}$ \\
\hline
\end{tabular}




\subsubsection{Portabilidade - Reusabilidade}

\begin{tabular}{|c|c|c|c|c|c|c|c|}
\hline & \multicolumn{4}{|c|}{ Métrica } & \multirow[b]{2}{*}{$\begin{array}{c}\text { Entrada para } \\
\text { medição }\end{array}$} & \multirow[b]{2}{*}{ Referência } & \multirow[b]{2}{*}{ Público alvo } \\
\hline Atributo & $\begin{array}{c}\text { Propósito da } \\
\text { Métrica (Questão) }\end{array}$ & Método de aplicação & $\begin{array}{c}\text { Fórmula e/ou } \\
\text { elementos de dados } \\
\text { para medição }\end{array}$ & Escala de Medição & & & \\
\hline $\begin{array}{l}\text { Nível de } \\
\text { dependência }\end{array}$ & $\begin{array}{l}\text { O componente possui } \\
\text { alguma dependência } \\
\text { com outros } \\
\text { componentes ou } \\
\text { sistemas? }\end{array}$ & $\begin{array}{l}\text { O avaliador deve } \\
\text { observar se o } \\
\text { componente, através } \\
\text { de suas interfaces } \\
\text { requeridas, está } \\
\text { dependente de outros } \\
\text { componentes ou } \\
\text { sistemas, dificultando } \\
\text { a sua reutilização } \\
\end{array}$ & $\begin{array}{l}\text { - Sim; } \\
\text { - Não; }\end{array}$ & $\begin{array}{l}0-100 \% \\
\text { Sim }=0 \% \\
\text { Não }=100 \%\end{array}$ & $\begin{array}{l}\text { Componente e sua } \\
\text { documentação }\end{array}$ & Sametinger & $\begin{array}{l}\text { Avaliador } \\
\text { Usuário } \\
\text { (Desenvolvedor, } \\
\text { integrador, arquiteto) }\end{array}$ \\
\hline $\begin{array}{l}\text { Funcionalidade clara } \\
\text { e específica }\end{array}$ & $\begin{array}{l}\text { O componente possui } \\
\text { uma funcionalidade } \\
\text { clara e específica? }\end{array}$ & $\begin{array}{l}\text { O avaliador deve } \\
\text { verificar, através da } \\
\text { documentação ou de } \\
\text { suas próprias } \\
\text { interfaces, se o } \\
\text { componente apresenta } \\
\text { e realiza de forma } \\
\text { clara os seus objetivos } \\
\text { especificados, } \\
\text { encapsulando detalhes } \\
\text { não relevante para } \\
\text { reutilização. }\end{array}$ & $\begin{array}{l}\text { - Sim; } \\
\text { - Não; }\end{array}$ & $\begin{array}{l}0-100 \% \\
\text { Sim }=100 \% \\
\text { Não }=0 \%\end{array}$ & $\begin{array}{l}\text { Componente e sua } \\
\text { documentação }\end{array}$ & Sametinger & $\begin{array}{l}\text { Avaliador } \\
\text { Usuário } \\
\text { (Desenvolvedor, } \\
\text { integrador, arquiteto) }\end{array}$ \\
\hline $\begin{array}{l}\text { Clareza de } \\
\text { identificação }\end{array}$ & $\begin{array}{l}\text { O componente está } \\
\text { contido em um único } \\
\text { arquivo facilitando a } \\
\text { sua identificação e } \\
\text { utilização? }\end{array}$ & $\begin{array}{l}\text { O avaliador deve } \\
\text { verificar, através da } \\
\text { documentação ou no } \\
\text { repositório, se o } \\
\text { componente está } \\
\text { composto em um } \\
\text { único arquivo. (Por } \\
\text { exemplo, através de } \\
\text { empacotamento) }\end{array}$ & $\begin{array}{l}\text { - Sim; } \\
\text { - Não; }\end{array}$ & $\begin{array}{l}0-100 \% \\
\text { Sim }=100 \% \\
\text { Não }=0 \%\end{array}$ & $\begin{array}{l}\text { Componente e sua } \\
\text { documentação }\end{array}$ & Sametinger & $\begin{array}{l}\text { Avaliador } \\
\text { Usuário } \\
\text { (Desenvolvedor, } \\
\text { integrador, arquiteto) }\end{array}$ \\
\hline
\end{tabular}




\section{Atributos e Métricas de Qualidade em Uso}

\section{Eficácia}

\begin{tabular}{|c|c|c|c|c|c|c|c|}
\hline & \multicolumn{4}{|c|}{ Métrica } & \multirow[b]{2}{*}{$\begin{array}{l}\text { Entrada para } \\
\text { medição }\end{array}$} & \multirow[b]{2}{*}{ Referência } & \multirow[b]{2}{*}{ Público alvo } \\
\hline Atributo & $\begin{array}{c}\text { Propósito da Métrica } \\
\text { (Questão) }\end{array}$ & Método de aplicação & $\begin{array}{l}\text { Fórmula e/ou elementos } \\
\text { de dados para medição }\end{array}$ & Escala de Medição & & & \\
\hline Eficácia da tarefa & $\begin{array}{l}\text { Os objetivos das tarefas } \\
\text { do sistema, no qual o } \\
\text { componente participa } \\
\text { diretamente, são } \\
\text { alcançados corretamente? }\end{array}$ & \begin{tabular}{|l|} 
Teste de usuário \\
Verificar se os valores das \\
saídas da tarefa, na qual o \\
componente participa \\
diretamente, são \\
completos e precisos.
\end{tabular} & $\begin{array}{l}\text { - Sim; } \\
\text { - Não; } \\
\end{array}$ & $\begin{array}{l}0-100 \% \\
\text { Sim }=100 \% \\
\text { Não }=0 \%\end{array}$ & $\begin{array}{l}\text { Relatório de } \\
\text { Operação (Testes) } \\
\text { Registro de } \\
\text { monitoramento de } \\
\text { uso }\end{array}$ & ISO 9126-4 & $\begin{array}{l}\text { Avaliador } \\
\text { Usuário } \\
\text { (Desenvolvedor, } \\
\text { integrador, arquiteto) }\end{array}$ \\
\hline Conclusão da tarefa & $\begin{array}{l}\text { As tarefas do sistema, no } \\
\text { qual o componente } \\
\text { participa diretamente, são } \\
\text { completadas conforme } \\
\text { esperadas? }\end{array}$ & $\begin{array}{l}\text { Teste de usuário } \\
\text { Verificar se as tarefas do } \\
\text { sistema no qual o } \\
\text { componente tem } \\
\text { participação são } \\
\text { completadas conforme } \\
\text { esperadas }\end{array}$ & $\begin{array}{l}\text { - Sim; } \\
\text { - Não; }\end{array}$ & $\begin{array}{l}0-100 \% \\
\text { Sim }=100 \% \\
\text { Não }=0 \%\end{array}$ & \begin{tabular}{|l} 
Relatório de \\
Operação (Testes) \\
Registro de \\
monitoramento de \\
uso
\end{tabular} & ISO 9126-4 & \begin{tabular}{|l} 
Avaliador \\
Usuário \\
(Desenvolvedor, \\
integrador, arquiteto)
\end{tabular} \\
\hline
\end{tabular}




\section{Produtividade}

\begin{tabular}{|c|c|c|c|c|c|c|c|}
\hline & \multicolumn{4}{|c|}{ Métrica } & \multirow[b]{2}{*}{$\begin{array}{c}\text { Entrada para } \\
\text { medição }\end{array}$} & \multirow[b]{2}{*}{ Referência } & \multirow[b]{2}{*}{ Público alvo } \\
\hline Atributo & $\begin{array}{c}\text { Propósito da Métrica } \\
\text { (Questão) }\end{array}$ & Método de aplicação & $\begin{array}{c}\text { Fórmula e/ou elementos } \\
\text { de dados para medição }\end{array}$ & Escala de Medição & & & \\
\hline Tempo da tarefa & \begin{tabular}{|l|} 
O tempo gasto numa \\
tarefa do sistema, \\
no qual o componente \\
participa diretamente, foi \\
apropriado?
\end{tabular} & \begin{tabular}{|l|} 
Teste de usuário \\
Verificar se o tempo gasto \\
numa determinada tarefa \\
do sistema no qual o \\
componente participa, foi \\
apropriado
\end{tabular} & $\begin{array}{l}\text { - Sim; } \\
\text { - Não; }\end{array}$ & $\begin{array}{l}0-100 \% \\
\text { Sim }=100 \% \\
\text { Não }=0 \%\end{array}$ & $\begin{array}{l}\text { Relatório de } \\
\text { Operação (Testes) } \\
\text { Registro de } \\
\text { monitoramento de } \\
\text { uso }\end{array}$ & ISO 9126-4 & $\begin{array}{l}\text { Avaliador } \\
\text { Usuario } \\
\text { (Desenvolvedor, } \\
\text { integrador, arquiteto) }\end{array}$ \\
\hline $\begin{array}{l}\text { Eficiência do } \\
\text { componente }\end{array}$ & $\begin{array}{l}\text { O componente, mostrou- } \\
\text { se eficiente para executar } \\
\text { as tarefas especificadas } \\
\text { do sistema? }\end{array}$ & \begin{tabular}{|l|} 
Verificar através do \\
atributo eficácia da tarefa \\
e do atributo tempo da \\
tarefa, se o componente \\
foi eficiente.
\end{tabular} & $\begin{array}{l}\text { - Sim; } \\
\text { - Não; }\end{array}$ & $\begin{array}{l}0-100 \% \\
\text { Sim }=100 \% \\
\text { Não }=0 \%\end{array}$ & $\begin{array}{l}\text { Relatório de } \\
\text { Operação (Testes) } \\
\text { Registro de } \\
\text { monitoramento de } \\
\text { uso }\end{array}$ & ISO 9126-4 & $\begin{array}{l}\text { Avaliador } \\
\text { Usuario } \\
\text { (Desenvolvedor, } \\
\text { integrador, arquiteto) }\end{array}$ \\
\hline
\end{tabular}




\section{Segurança (Safety)}

\begin{tabular}{|c|c|c|c|c|c|c|c|}
\hline & \multicolumn{4}{|c|}{ Métrica } & \multirow[b]{2}{*}{$\begin{array}{c}\text { Entrada para } \\
\text { medição }\end{array}$} & \multirow[b]{2}{*}{ Referência } & \multirow[b]{2}{*}{ Público alvo } \\
\hline Atributo & $\begin{array}{c}\text { Propósito da Métrica } \\
\text { (Questão) }\end{array}$ & Método de aplicação & $\begin{array}{c}\text { Fórmula e/ou elementos } \\
\text { de dados para medição }\end{array}$ & Escala de Medição & & & \\
\hline Danos no software & $\begin{array}{l}\text { O componente causou } \\
\text { algum dano no sistema } \\
\text { devido alguma falha em } \\
\text { sua funcionalidade? }\end{array}$ & $\begin{array}{l}\text { Estatísticas de uso } \\
\text { Verificar através de } \\
\text { registros de } \\
\text { monitoramento de uso se } \\
\text { o componente causou } \\
\text { algum dano ao software } \\
\text { (por exemplo, corrupção } \\
\text { de dados) }\end{array}$ & $\begin{array}{l}\text { - Sim; } \\
\text { - Não; }\end{array}$ & $\begin{array}{l}0-100 \% \\
\text { Sim }=100 \% \\
\text { Não }=0 \%\end{array}$ & $\begin{array}{l}\text { Registro de } \\
\text { monitoramento de } \\
\text { uso }\end{array}$ & ISO 9126-4 & $\begin{array}{l}\text { Avaliador } \\
\text { Usuario } \\
\text { (Desenvolvedor, } \\
\text { integrador, arquiteto) }\end{array}$ \\
\hline
\end{tabular}




\section{Satisfação}

\begin{tabular}{|c|c|c|c|c|c|c|c|}
\hline & \multicolumn{4}{|c|}{ Métrica } & \multirow[b]{2}{*}{$\begin{array}{c}\text { Entrada para } \\
\text { medição }\end{array}$} & \multirow[b]{2}{*}{ Referência } & \multirow[b]{2}{*}{ Público alvo } \\
\hline Atributo & $\begin{array}{c}\text { Propósito da Métrica } \\
\text { (Questão) }\end{array}$ & Método de aplicação & $\begin{array}{l}\text { Fórmula e/ou elementos } \\
\text { de dados para medição }\end{array}$ & Escala de Medição & & & \\
\hline Satisfação do usuário & $\begin{array}{l}\text { Existe uma satisfação do } \\
\text { usuário referente ao uso } \\
\text { do componente no } \\
\text { sistema? }\end{array}$ & \begin{tabular}{|l|} 
Teste de usuário e \\
observação de uso \\
Verificar se o usuário do \\
sistema está satisfeito \\
com a funcionalidade que \\
o componente oferece ao \\
sistema.
\end{tabular} & $\begin{array}{l}\text { - Sim; } \\
\text { - Não; }\end{array}$ & $\begin{array}{l}0-100 \% \\
\text { Sim }=100 \% \\
\text { Não }=0 \%\end{array}$ & $\begin{array}{l}\text { Relatório de } \\
\text { Operação (testes) } \\
\text { Registro de } \\
\text { monitoramento de } \\
\text { uso }\end{array}$ & ISO 9126-4 & $\begin{array}{l}\text { Avaliador } \\
\text { Usuario } \\
\text { (Desenvolvedor, } \\
\text { integrador, arquiteto) }\end{array}$ \\
\hline
\end{tabular}




\section{Anexo B}

\section{Questionário para Verificação da Aplicabilidade e Utilidade do Modelo de Qualidade de Componentes de Software}

\section{Introdução}

Este questionário objetiva colher a opinião dos avaliadores e/ou especialistas em Desenvolvimento baseado em Componentes (DBC), envolvidos nas avaliações dos componentes de software realizadas neste trabalho, sobre a aplicabilidade e utilidade do modelo de qualidade de componentes desenvolvido.

\section{Caracterização do Avaliador/Especialista}

Instituição/Empresa:

Nome:

E-mail:

a) Marque sua experiência ou as atividades (cargos) que já exerceu ou exerce:

( ) Gerente de Garantia da Qualidade;

( ) Avaliador

( ) Desenvolvedor de Componentes

( ) Desenvolvedor de Aplicações (com componentes)

( ) Arquiteto de Software

( ) Gerente de projeto baseado em componentes

( ) Professor (universitário) de informática (disciplinas relacionadas ao $\mathrm{DBC})$

( ) Outras:

\section{Questões sobre a aplicabilidade do modelo de qualidade desenvolvido}

a) Durante a avaliação as características, subcaracterísticas e atributos de qualidade do modelo desenvolvido apresentaram-se adequadas ao contexto de componentes?

( ) Sim, bem adequadas ao contexto de componentes

( ) Pouco adequadas ao contexto de componentes Justifique:

( ) Não, sem adequação ao contexto de componentes Justifique:

b) O modo como as características, subcaracterísticas e atributos de qualidade foram estruturadas no modelo facilita a sua aplicação nas avaliações?

( ) Sim, facilita.

( )Não facilita.

Justifique: 
c) As questões do modelo apresentaram-se claras e intuitivas facilitando o entendimento e aplicação da avaliação?

( ) Sim, bem claras e intuitivas

( ) Não muito claras e pouco intuitivas Justifique:

( ) Não claras e pouco intuitivas Justifique:

d) O método de aplicação, ou seja, as explicações destinadas ao avaliador de como proceder para obter as respostas das questões, auxiliou o avaliador na obtenção das respostas?

( ) Sim, auxiliou de forma excelente.

( ) Auxiliou de forma satisfatória.

Justifique:

( ) Não auxiliou ou auxiliou de forma insatisfatória.

Justifique:

e) Os tipos de respostas mostraram-se adequadas de acordo com suas respectivas questões?

( ) Sim, bem adequadas

( ) Pouco adequadas

Justifique:

( ) Nada adequadas

Justifique:

f) Concluindo, você considera a execução do questionário do modelo de qualidade desenvolvido:

( ) Fácil e rápida

( ) Fácil, mas um pouco trabalhosa Justifique:

( ) Difícil aplicação Justifique:

Observações Finais: 


\section{Questionário para Verificação da Aplicabilidade e Utilidade da Ferramenta de Apoio à Avaliação}

\section{Introdução}

Este questionário objetiva colher a opinião dos avaliadores e/ou especialistas em Desenvolvimento baseado em Componentes (DBC), envolvidos nas avaliações dos componentes de software realizadas neste trabalho, sobre a aplicabilidade da ferramenta de apoio à avaliação de componentes de software.

\section{Caracterização do Avaliador/Especialista}

Instituição/Empresa:

Nome:

E-mail:

a) Marque sua experiência ou as atividades (cargos) que já exerceu ou exerce:

( ) Gerente de Garantia da Qualidade;

( ) Avaliador

( ) Desenvolvedor de Componentes

( ) Desenvolvedor de Aplicações (com componentes)

( ) Arquiteto de Software

( ) Gerente de projeto baseado em componentes

( ) Professor (universitário) de informática (disciplinas relacionadas ao $\mathrm{DBC})$

( ) Outras:

\section{Questões sobre a aplicabilidade da ferramenta de apoio}

a) A ferramenta apresenta uma interface padronizada e amigável?
( ) Padronizada e amigável
( ) Padronizada e não amigável
( ) Não padronizada e amigável
( ) Nem padronizada e nem amigável

b) A forma como o método é disponibilizado pela ferramenta, torna agradável a execução da avaliação?
( ) Sim
( ) Não
Justifique: 
c) A ferramenta torna fácil a navegação entre as questões apresentadas?

( ) Sim

( ) Não

Justifique:

d) A ferramenta apresenta os textos de forma legível?

( ) Sim

( ) Não

Justifique:

e) A ferramenta se mostrou eficiente em relação ao tempo de resposta?

( ) Sim

( ) Não Justifique:

f) Durante a execução da ferramenta, houve a ocorrência de alguma falha?

( ) Sim Justifique:
( ) Não

Observações Finais: 